University of Rhode Island

DigitalCommons@URI

Open Access Master's Theses

2017

\title{
Effects of 10 Weeks of Periodized Resistance Training on Sarcopenia Classification in Older Women
}

Samuel Slezak

University of Rhode Island, samslezak@gmail.com

Follow this and additional works at: https://digitalcommons.uri.edu/theses

\section{Recommended Citation}

Slezak, Samuel, "Effects of 10 Weeks of Periodized Resistance Training on Sarcopenia Classification in Older Women" (2017). Open Access Master's Theses. Paper 1012.

https://digitalcommons.uri.edu/theses/1012

This Thesis is brought to you for free and open access by DigitalCommons@URI. It has been accepted for inclusion in Open Access Master's Theses by an authorized administrator of DigitalCommons@URI. For more information, please contact digitalcommons-group@uri.edu. 
EFFECTS OF 10 WEEKS OF PERIODIZED RESISTANCE TRAINING ON SARCOPENIA CLASSIFICATION IN OLDER WOMEN

BY

SAMUEL SLEZAK

A THESIS SUBMITTED IN PARTIAL FULFILLMENT OF THE

REQUIREMENTS FOR THE DEGREE OF

MASTER OF SCIENCE

IN

KINESIOLOGY

UNIVERSITY OF RHODE ISLAND

2017 


\section{MASTER OF SCIENCE THESIS}

OF

SAMUEL SLEZAK

\section{APPROVED:}

Thesis Committee:

Major Professor: Matthew J. Delmonico

Disa Hatfield

Ingrid Lofgren

Nasser H. Zawia

DEAN OF THE GRADUATE SCHOOL

UNIVERSITY OF RHODE ISLAND

2017 


\begin{abstract}
Sarcopenia is defined as the progressive, age related loss of lean muscle mass, which in turn has been associated with osteoporosis, decreases in physical function, and loss of independence. Newly established sarcopenia classification criteria include measures of appendicular lean mass (ALM), grip strength, and gait speed. Periodized resistance training (PRT) has been investigated in older adults, however the impact of PRT, particularly daily undulating periodized resistance training (DUP) on current sarcopenia classification criteria is unknown. The aim of this randomized controlled trial was to investigate the effects of a 10-week DUP intervention on sarcopenia classification in older women. Inactive women $(n=25)$ aged $72.3 \pm 4.6$ years, who were sarcopenic or symptomatic, were randomized to a DUP group or an active control group $(\mathrm{CON})$ and trained three days per week for 10 weeks. Measures of ALM, grip strength, and gait speed were recorded at baseline and post-intervention and sarcopenia was classified using established criteria. Other measures included upper and lower body strength, and global physical functioning. A McNemar's test found no significant within- or between-group changes in sarcopenia classification. Mixed models analyses found both groups significantly improved gait speed (DUP: $p=0.001$, CON: $p<0.001$ ) but DUP significantly increased grip strength compared to CON $(p=0.036)$. There were no significant changes in ALM for either group. Both groups significantly improved upper and lower body strength $(\mathrm{p}<0.001)$ and global physical function (DUP: $p=0.039, \mathrm{CON}: \mathrm{p}=0.008$ ). Results indicate DUP increases strength and function, but does not significantly alter sarcopenia classification compared to
\end{abstract}


CON. However, results are limited by sample size and demonstrate the need for future research to investigate trials in larger samples with longer durations. 


\section{ACKNOWLEDGMENTS}

The generous funding for the URI Resistance Exercise Study to Reclaim Lean Mass and Strength (URI RESTORE ME) was provided by the College of Human Science and Services. The study was conducted by the Department of Kinesiology and the Department of Nutrition and Food Sciences. I would like to thank all of the primary investigators of the URI RESTORE ME study: Dr. Delmonico, Dr. Xu, Dr. Hatfield, and Dr. Lofgren. I was fortunate enough to receive valuable guidance from these professors during my time as a graduate student. I would also like to recognize Dr. Delmonico's efforts as my primary advisor for my thesis. His experience, guidance, feedback, and motivation made completing this thesis possible. Also making this thesis possible was the hard work and dedication of my fellow study coordinators, Emily Renna and Kayla Mahoney. I would also like to thank my parents

for their support and assistance throughout this process. Finally I would like to thank my girlfriend Geena for always supporting and motivating me over the past two years of graduate school. The combined efforts of all of the above-mentioned individuals made completing this thesis and advancing the field of sarcopenia and resistance training research possible. 


\section{PREFACE}

This thesis is written to comply with the University of Rhode Island graduate school manuscript format. The thesis document contains one manuscript: Effects of

10 Weeks of Periodized Resistance Training on Sarcopenia Classification in Older

Women. The manuscript has been written in a form formatted for publication in the Journal of Aging and Physical Activity. 


\section{TABLE OF CONTENTS}

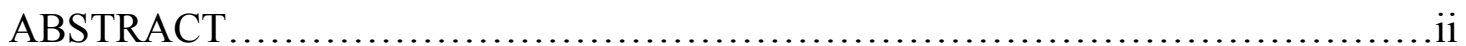

ACKNOWLEDGMENTS .....................................................

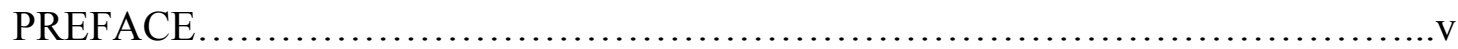

TABLE OF CONTENTS $\ldots \ldots \ldots \ldots \ldots \ldots \ldots \ldots \ldots \ldots \ldots \ldots \ldots \ldots \ldots \ldots \ldots \ldots \ldots \ldots$

LIST OF TABLES..................................................................vii

LIST OF FIGURES.............................................................

MANUSCRIPT: Effects of 10 Weeks of Periodized Resistance Training on

Sarcopenia Classification in Older Women......................................

ABSTRACT ............................................................

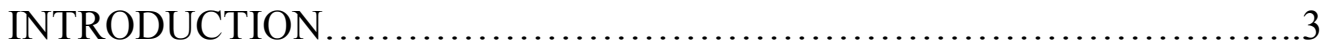

METHODS.....................................................................

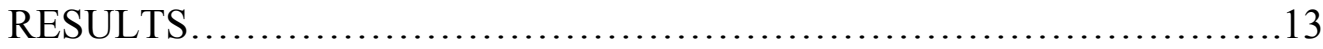

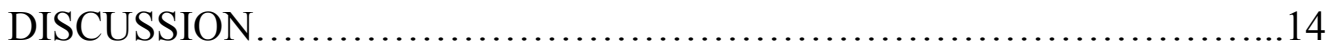

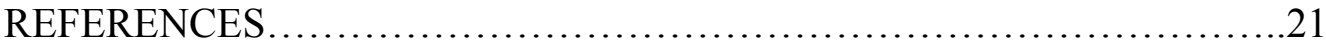

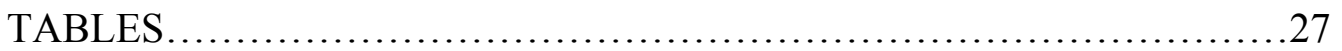

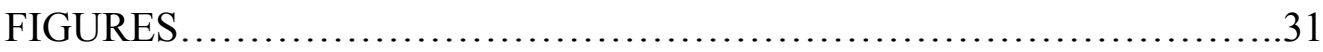

\section{APPENDICES}

APPENDIX A: Review of the Literature.....................................32

APPENDIX B: Phone Screen Assessment.................................78

APPENDIX C: Consent Form for Research............................... 82

APPENDIX D: Pre-participation Medical Clearance Form...................88

APPENDIX E: Medical History Questionnaire..............................89 
APPENDIX F: Baseline Data Collection Sheet.........................95

APPENDIX G: One Repetition Max Testing Sheet.........................101

APPENDIX H: Borg CR-10 Scale and Instructions...................... 102

APPENDIX I: Dietary Screening Tool....................................104

APPENDIX J: One-Week Training Program for Daily Undulating

Periodization Group..................................................108 


\section{LIST OF TABLES}

Table 1. Daily undulations of program variables

Table 2. Baseline characteristics of participants

Table 3. Baseline and post intervention changes in sarcopenia classification using different national and international sarcopenia classification criteria

Table 4. Mean changes in physical function, body composition, and strength measures compared to baseline values 


\section{LIST OF FIGURES}

Figure 1. Study Flow Chart 


\section{MANUSCRIPT}

\section{Effects of Periodized Resistance Training on Sarcopenia Classification in Older}

\section{Women}

Manuscript Type: Original Research

Authors: Samuel G. Slezak ${ }^{a}$, Emily N. Renna ${ }^{a}$, Kayla B. Mahoney ${ }^{\mathrm{a}}$, Ingrid E.

Lofgren $^{\mathrm{b}}$, Furong Xu $\mathrm{u}^{\mathrm{a}}$, Matthew J. Delmonico ${ }^{\mathrm{a}}$, Disa L. Hatfield ${ }^{\mathrm{a}}$

a Department of Kinesiology, University of Rhode Island, Kingston, Rhode Island, 02881, USA

${ }^{\mathrm{b}}$ Department of Nutrition and Food Sciences, University of Rhode Island, Kingston, Rhode Island, 02881, USA

Running head: Effects of Resistance Training on Sarcopenia

Number of Tables: 4

Number of Figures: 1

Abstract word count: 148

Manuscript word count: 4, 399

Corresponding Author:

Dr. Disa Hatfield

25 West Independence Way, Suite P

Kingston, RI, 02881

doch@uri.edu

401-874-5183

This manuscript was formatted and prepared for publication in: The Journal of Aging and Physical Activity 


\begin{abstract}
Sarcopenia is associated with negative health outcomes in older adults, but research on the effects of resistance training on sarcopenia is lacking. This study used a randomized trial to investigate the effects of daily undulating periodized resistance training (DUP) on sarcopenia classification. Inactive women $(n=25)$ aged $72.3 \pm 4.6$ years, who were sarcopenic or symptomatic, were randomized to a DUP group or an active control group $(\mathrm{CON})$ and trained three days per week for 10 weeks. No significant changes in sarcopenia classification were observed. Both groups significantly improved physical functioning (DUP: $p=0.039, \mathrm{CON}: \mathrm{p}=0.008$ ) and strength (DUP and CON; $<<0.001$ ), but DUP significantly increased grip strength compared to $\mathrm{CON}(\mathrm{p}=0.036)$. Results indicate DUP increases strength and function, but does not significantly alter sarcopenia classification compared to CON. However, results are limited by sample size and demonstrate the need for future research to investigate trials in larger samples with longer durations.
\end{abstract}

Keywords: post-menopausal, daily undulating periodization, strength training, EWGSOP, FNIHSP 


\section{INTRODUCTION}

The aging process contributes to multiple changes within the human body including muscle fiber atrophy, a loss of type 2 muscle fibers, and fatty infiltration of skeletal muscle (Alchin, 2014; Kostek \& Delmonico, 2011). Sarcopenia, known as the age-related loss of skeletal muscle mass, can negatively affect physical functioning and muscular strength. Indeed, following age 50 years, muscle mass decreases $\sim 1-2 \%$ per year and muscle strength decreases at rates 2 to 5 times faster than muscle mass. These decreases have been observed in both men and women of varying ethnicities (Batsis, Mackenzie, Barre, Lopez-Jimenez, \& Bartels, 2014; Cawthon et al., 2011; Delmonico et al., 2009; Visser et al., 2005). The atrophy of skeletal muscle fibers and subsequent loss of muscle mass that occur during the development of sarcopenia coupled with rapidly decreasing muscular strength places older individuals at risk for injury and/or disability (Yang, Ding, Luo, Hao, \& Dong, 2014).

Furthermore, the estimated healthcare costs directly associated with sarcopenia in 2000 were $\$ 18.5$ billion, with more than $\$ 7$ billion attributed to older women (Janssen, Shepard, Katzmarzyk, \& Roubenoff, 2004). A greater percentage of the older population is female, and they are at a greater risk of developing sarcopenia because women live longer, typically have lower amounts of lean mass and lower physical activity levels in old age when compared to men (Administration on Aging, 2014; Batsis et al., 2014; Borst, 2004; Chad et al., 2005; Douchi et al., 1998). Additionally, estimates indicate that there will be 80 million U.S. adults over the age of 65 by 2050, which is double the estimated 40 million adults in 2010 (US Department of Health \& Human Services, 2006). The already significant health care 
costs, increased risk for older women and estimated population increases indicate that sarcopenia is a serious public health issue, and intervention strategies are necessary to attenuate the loss of physical functioning, lean mass and muscular strength in older women.

Current sarcopenia classification criteria have been established by the European Working Group on Sarcopenia in Older People (EWGSOP) (Cruz-Jentoft et al., 2010), the International Working Group (IWG) (Fielding et al., 2011), and the Foundation for the National Institutes of Health Sarcopenia Project (FNIHSP) (Studenski et al., 2014). These criteria include diagnostic cut points for appendicular lean mass (ALM), gait speed (GS), and/or grip strength (GR), however cut-points do not agree between criteria. This lack of consensus between classification criteria may result in large variability in sarcopenia classification depending on the set of criteria used. That variation could result in inconsistent clinical classification of sarcopenia, the inability to compare research using different sets of classification criteria, and could lead to problems with identifying individuals for interventions.

Previously investigated treatment approaches for sarcopenia include diet and supplementation, hormonal therapies, and resistance training (RT) (Borst et al., 2014; Katsanos et al., 2008; Paddon-Jones \& Leidy, 2014; Rossouw et al., 2002). Resistance training has been previously documented as an effective method of increasing lean mass, strength, and physical functioning in post-menopausal women and appears to be the most promising treatment method for sarcopenia (Fiatarone et al., 1994; Peterson, Rhea, Sen, \& Gordon, 2010; Peterson, Sen, \& Gordon, 2011; Rhodes et al., 2000). Despite previous research, the effects of RT on sarcopenia 
classification remain widely uninvestigated. Periodized resistance training (PRT) programs use pre-planned variations of acute training program variables (exercise selection, order, intensity, volume, and rest) and has been shown to be superior to conventional RT (Fleck, 1999; Haff \& Triplett, 2015; Rhea \& Alderman, 2004). A further subset of PRT is daily undulating periodization (DUP), which modifies program variables on a daily basis and has been shown to be superior to other forms of PRT (Prestes et al., 2009; Rhea, Ball, Phillips, \& Burkett, 2002). To date, DUP has not been investigated in older women who are sarcopenic or symptomatic and it is unclear if a DUP intervention would provide necessary increases in ALM, GS, and GR measures to alter sarcopenia classification by current criteria. Therefore, the primary aim of this study was to investigate the effects of DUP on sarcopenia classification in older women with sarcopenia or symptoms of sarcopenia. The secondary aim of this study was to evaluate the effects of DUP on individual measures of strength and global physical function.

\section{METHODS}

\section{Design}

This study utilized a randomized controlled trial design among a cohort of 25 older, community dwelling women who met any component of sarcopenia classification criteria. The study evaluated the effects of a 10-week DUP intervention as a method of changing sarcopenia classification within the cohort. Secondary aims were to examine the effects of a 10-week DUP intervention on strength and physical functioning outcomes. Data were collected at four time points; baseline, mid-point, post intervention, and 6-months post intervention. 


\section{Participants and setting}

Participants were recruited from the local community surrounding the University of Rhode Island through a variety of methods including posters, newspaper advertisements, talks at senior centers and community centers, and word of mouth. All components of the study took place within the Kinesiology department at the University of Rhode Island, Kingston, Rhode Island, USA.

\section{Screening for eligibility and enrollment}

Initial screening was conducted via telephone interview to include women who were postmenopausal, aged 65-84 years, not involved in a regular exercise program, and met at least one component of either EWGSOP (Cruz-Jentoft et al., 2010), IWG (Fielding et al., 2011), or FNIHSP (Studenski et al., 2014) sarcopenia classification criteria (i.e. low grip strength, low gait speed, etc.) Reasons for study exclusion included failure to provide informed consent, inability to speak and read English, significant cognitive impairment, and the inability to safely engage in a mild to moderate intensity exercise. Participants with recent major joint, vascular, abdominal or thoracic surgery were excluded, as well as participants who had physician diagnosed cardiovascular or pulmonary disease or an implanted pacemaker or defibrillator. Uncontrolled diabetes, blood pressure, or anemia was reason for exclusion as were any medication changes within three weeks or changes to lipid lowering medication within six months.

Following the telephone interview, initially eligible participants visited the University of Rhode Island for an information session and a question and answer 
session with primary investigators. Participants then provided written informed consent and a teach-back process was also employed to ensure that participants understood the consent form. Participants then completed a four-meter gait speed test, a handgrip strength test, a single chair stand test and a body composition test using an InBody 570 multi-frequency bioelectrical impedance analysis (BIA) device (Biospace Co, Ltd, Korea). Participants' ALM, GS, and GR data were then evaluated using EWGSOP, IWG, and FNISHP criteria to determine sarcopenia status. The primary investigators then reviewed participants based on inclusion and exclusion criteria and sarcopenia status and determined study eligibility. All participants selected to participate in the study obtained pre-participation medical clearance from their physician. This study was approved by the Institutional Review Board of the University of Rhode Island.

\section{Interventions}

\section{Periodized Daily Undulating Resistance Training Intervention}

Participants in the periodized daily undulating resistance training intervention (DUP) group followed a program designed to target the entire body and trained three non-consecutive days per week for 45 minutes per session. The training program incorporated exercises that progressed in complexity (e.g. leg press to deadlifts) and included the use of selectorized RT equipment and free weights. This program modified program variables on daily basis and incorporated periods of low intensity work in an attempt to maintain participant interest in the program and prevent overtraining. Higher intensity periods were also programmed to stimulate increases in 
muscular strength and hypertrophy. A depiction of the daily program variations is presented in Table 1. Participants began every training session with a dynamic warmup and finished every session with a stretching cool down session. National Strength and Conditioning Association Certified Strength and Conditioning Specialists instructed and supervised all training sessions.

\section{Active Control Group}

The active control group $(\mathrm{CON})$ underwent identical screening and testing processes as the DUP group; however, during the 10-week intervention this group met three times per week for 45 minutes per session and completed a program composed of exercises ranging from light to vigorous intensities (stretching, Tai Chi, aerobics, calisthenics). Through the combination of warm up, moderate and vigorous intensity activity, and cool down the program approached the 150 minutes per week of moderate intensity physical activity for adults recommended by the ACSM (American College of Sports Medicine, 2009). These activities, while beneficial to overall health, have not been shown to produce adaptations similar to those experienced in RT. This style of control group was implemented to potentially reduce attrition and to provide a benefit for the "control" group.

\section{Measures}

The primary outcome measure was sarcopenia classification. Secondary outcome measures were body composition, chest, leg and grip strength, and global physical functioning. Sarcopenia classification was conducted at baseline and postintervention. Secondary measures were assessed at four time points: baseline, 5- 
weeks, post intervention, and 6-months post intervention. All testing was conducted during the same time of day for all time points.

\section{Anthropometrics}

Height was measured to the nearest $0.1 \mathrm{~cm}$ without shoes using a Seca wall mounted stadiometer and body weight was measured to the nearest $0.1 \mathrm{~kg}$ using a Seca balance beam scale (Seca, Chino, CA). Both height and weight were measured in duplicate and the averages were used to calculate body mass index (BMI).

\section{Body Composition}

Overall body composition was estimated using dual-energy x-ray absorptiometry (DXA) using fan-beam technology on a GE Lunar iDXA machine (GE, Waukesha, WI). Participants reported to testing in a fasted state ( $\sim 12$ hours) and wore surgical scrubs during the test. Standardized positioning procedures were followed and a licensed radiology technician performed all tests (Delmonico et al., 2005). Appendicular lean mass, total body fat mass, and percent fat were measured. Appendicular lean mass was considered the sum of non-bone lean mass in both arms and legs. Total body lean mass was defined as lean soft tissue mass plus total body bone mineral content.

\section{Physical Functioning}

Physical functioning was measured using several low burden tests. The Established Populations for Epidemiologic Studies of the Elderly short physical performance battery (SPPB) includes a standing balance test, a four-meter gait usual 
speed test, and timed five-chair stand test, and was conducted to assess each participant's global physical functioning (Guralnik et al., 1994). The best gait speed score measured in the SPPB was used for sarcopenia classification.

To further evaluate physical functioning participants completed a 400-meter walk test, which is a valid and reproducible measure of physical functioning (Simonsick, Montgomery, Newman, Bauer, \& Harris, 2001). Participants also completed a timed up and go (TUG) test to measure physical functioning and mobility (Whitney, Lord, \& Close, 2005). The TUG test was conducted according to standardized protocol; participants were asked to rise from a 46-cm high chair, walk forward eight feet at their usual walking pace, turn $180^{\circ}$ around a cone, walk back to the chair and sit down. Measures were taken in duplicate, with the best score recorded.

\section{Grip Strength}

Grip strength is a simple, safe, and effective method of predicting total body strength and future disability (Laukkanen, Heikkinen, \& Kauppinen, 1995; Rantanen et al., 1999). Handgrip strength was measured in both hands with the participant in a seated position using a handgrip dynamometer and standardized protocols (Jamar Hydraulic Dynamometer, J.A. Preston, Corp., Jackson, MS) (Bellace, Healy, Besser, Byron, \& Hohman, 2000). Two trials per hand were completed and the highest score measured was used for sarcopenia classification. 


\section{Muscle Strength}

All participants completed a familiarization with leg press and chest press machines one week prior to strength testing. The familiarization included a dynamic warm-up, determination of proper seat and handle positions and instructions regarding proper exercise and breathing technique. Participants then completed a set of 3-5 repetitions on each machine using a load determined by the participant to be comfortable, then a second set of 3-5 repetitions at an increased intensity, followed by 1-3 sets of progressively increasing intensity until the participant reached $80-90 \%$ of their maximal effort as rated on the Borg CR-10 scale (Borg, 1998).

Maximal leg press and chest press strength were assessed using previously published methods on Cybex seated leg press and chest press machines (Cybex International Inc., Medway, MA) (Delmonico et al., 2005; LeBrasseur, Bhasin, Miciek, \& Storer, 2008). Participants completed a dynamic warm-up prior to strength testing. The leg press test required the participant to extend their knees from a starting position of $\sim 90$ degrees until the legs are fully extended, but not locked at the knees. The chest press test required the participant hold on to handles perpendicular to the chest, located at the height of the sternum and extended their elbows completely and return to the starting position in a controlled manner. Participants followed a standard strength testing protocol and were given three minute rest periods between attempts (Fleck \& Kraemer, 2014).

\section{Sarcopenia Classification}

Following baseline testing, anthropometric, gait speed, grip strength, and ALM 
data were used to determine sarcopenia classification by EWGSOP (Cruz-Jentoft et al., 2010), IWG (Fielding et al., 2011), and FNIHSP (Studenski et al., 2014) criteria published previously. Following post-intervention testing, participants were reevaluated by the same classification criteria to determine any within group or between group changes in sarcopenia status as a result of the intervention.

\section{Nutritional Risk}

The Dietary Screening Tool (DST) was used to assess the participants' nutritional risk. The DST is a valid and reliable measure of dietary quality among older community-dwelling adults (Bailey et al., 2009). Based on DST scores (0-100) participants were categorized based on nutritional risk levels: at risk $(<60)$, possible risk (60-75), and not at risk (>75).

\section{Sample Size}

Between-group changes for the primary outcome variable of sarcopenia classification were estimated to calculate sample size. Data from Mason et al. (2013) were adjusted to reflect the duration of our study. Those estimates indicated an expected between group difference in sarcopenia classification of $1.41 \pm 1 \%$ following a 10 -week intervention. Based on those estimations, a minimum of 10 participants per group was required to provide sufficient statistical power $(0.80)$ to measure between group changes in sarcopenia classification.

\section{Randomization}

Following the completion of baseline testing participants were randomized into a resistance training intervention group (RTI) or a control group $(\mathrm{CON})$ using a 
random number generator using Random Allocation Software (Isfahan University of Medical Sciences, Isfahan, Iran).

\section{Statistical Analysis}

Continuous variables for primary and secondary outcomes were assessed for normality using Shapiro-Wilk tests. Outliers were identified using box plots and Tukey's method. Any influential outliers were excluded from analyses. Baseline characteristics were reported using descriptive statistics presented as means \pm standard deviation. Due to the paired nature of the data, changes in sarcopenia classification between groups were measured using McNemar's tests. Within and between group changes for all continuous variables were measured using mixed models analyses. Attrition rate was reported using descriptive statistics. The alpha was set at $\mathrm{p}<0.05$ for all analyses. Analyses were performed using SAS version 9.3 (SAS Institute Inc, Cary, NC).

\section{RESULTS}

A total of 160 participants were initially screened for study inclusion, 61 participants signed informed consent and underwent secondary screening, and 25 Caucasian women aged $72.3 \pm 4.6$ years met all inclusion and exclusion criteria and were enrolled in the study (Figure 1). All data points determined to be outliers did not influence significance, and were included in analyses. The baseline physical characteristics of the participants are shown in Table 2. There were no changes in nutritional risk measured by the DST. As shown in Table 3, there were no significant within or between group changes in sarcopenia classification, by any set of criteria. Participants in DUP experienced reversals in sarcopenia classification by IWG $(n=1)$ 
and FNIHSP $(n=2)$ criteria. One participant in DUP also transitioned from sarcopenia to pre-sarcopenia by EWGSOP criteria. The two changes in FNIHSP and one change EWGSOP classification were due to improvements in grip strength by the participants. The one change by IWG criteria was due to an improvement in gait speed. Participants in CON experienced reversals in sarcopenia classification by EWGSOP $(n=1)$ and IWG $(n=2)$ criteria. The two participants who reversed their IWG classification did so by improvements in gait speed. Those same two participants were also considered sarcopenic by EWGSOP criteria at baseline, and maintained that classification post intervention. The one participant who reversed their EWGSOP sarcopenia classification did so by improvements in $\mathrm{ALM} / \mathrm{ht}^{2}$. No participants in CON met FNIHSP criteria at baseline or post-intervention.

As shown in Table 4, both DUP $(\mathrm{p}<0.001)$ and CON $(\mathrm{p}>0.001)$ showed significant improvements in gait speed, and chest and leg press strength. Post intervention both DUP $(\mathrm{p}=0.001)$ and CON $(\mathrm{p}=0.046)$ experienced significant improvements in 400-meter walk time. Post intervention DUP also showed a mean increase in grip strength of 2.45 kilograms, which was significantly greater than CON $(p=0.024)$

\section{DISCUSSION}

These results present, for the first time, the effects of a 10-week periodized daily undulating resistance training intervention on sarcopenia classification in postmenopausal women who presented with sarcopenia or symptoms of sarcopenia based on newly established classification criteria. Our results indicate that when compared to an active control group, 10-weeks of DUP does not elicit significant changes in 
sarcopenia classification within a sample of older, post-menopausal women.

However, these results support the use DUP as a method of increasing muscular strength and physical functioning. Moreover, when compared to an active control group, DUP will significantly increase grip strength in older sarcopenic women. Although our primary hypothesis was not supported, we present findings that indicate 10 weeks of DUP or general exercise can significantly increase upper and lower body strength and physical functioning in older women with sarcopenia or symptoms of sarcopenia.

Other research investigating interventions for sarcopenia includes that of Mason et al. (2013), who investigated the effects of 12-months of aerobic exercise in 76 post-menopausal women classified as sarcopenic using IWG lean mass cut points. That study found small $(0.4 \%)$ but significant $(\mathrm{p}=0.004)$ increase in $\mathrm{ALM} / \mathrm{ht}^{2}$. Although those results were significant, they are quite small, and indicate that regular aerobic training can attenuate further loss of lean mass, but not increase ALM over time. Additionally, the women in that study did not undergo physical function testing, therefore the assessment of sarcopenia was not by full IWG criteria. Nonetheless, our results agree with those of Mason et al. (2013) suggesting that regular physical activity could be beneficial for lean mass maintenance in those who are not sarcopenic. However, in older women with sarcopenia, treatments other than aerobic exercise are likely required to increase lean mass to the point of reversing sarcopenia classification. Additionally, a recent study by Hassan et al. (2016) investigated the effects of six months of RT on sarcopenia classification in 42 adults aged $85.9 \pm 7.5$ years, living in nursing homes. Sarcopenia was classified using EWGSOP criteria and post- 
intervention there were no changes in sarcopenia classification in the intervention group. That study also found significant increases in grip strength in their intervention group compared to the control group $(\mathrm{p}=0.002)$. Our results are similar to those of Hassan et al. (2016), as we did not find any significant changes in sarcopenia classification post-intervention. However, that study only had six participants considered sarcopenic at baseline compared to our five participants in the DUP group who met EWGSOP criteria at baseline. While our findings agree that RT is effective at slowing the progression of sarcopenia, we also present the findings that 10 -weeks of general exercise attenuates the loss of ALM. However, our results and those of Hassan et al. (2016) demonstrate the need for future research to investigate intervention strategies in samples of older women with greater prevalence of sarcopenia at baseline.

Furthermore our findings indicate that increases in muscular strength, as measured by grip strength, were primarily responsible for changes in classification in the DUP group. While improvements in physical function, measured by gait speed, were responsible for the majority of changes in classification by the CON group. These results suggest that DUP or general exercise can improve sarcopenia classification, albeit through different channels. Our results also align with the recent findings of Santos et al. (2017) who found that a sample of 23 older women experienced significant increases in gait speed following eight weeks of RT. The novel finding of that study was that the improvements in gait speed were associated with increases in lower body muscular strength and not muscle mass. Our results corroborate those findings as both the DUP and CON group experienced significant 
increases in both leg press strength and gait speed, while maintaining baseline levels of lean mass. Our results present the new findings that DUP is a viable method of increasing gait speed and grip strength, independent of lean mass gains, and contributes to the body of literature regarding treatment methods for sarcopenia.

The unexpected strength increases of the CON group may be explained by Harber et al. (2009) who found that 12 weeks of aerobic training produced a significant $(\mathrm{p}<0.05) 55 \pm 7 \%$ increase in knee extensor power compared to baseline measures in a sample of seven older women aged $71 \pm 2$ years. A further study by Konopka et al. (2010) found that following 12 weeks of aerobic training a sample of nine older women maintained their overall body mass levels, and experienced small $(0.5 \mathrm{~kg})$ but significant increases in lean body mass. Furthermore, those researchers also found that following training participants had significantly lower levels of myostatin mRNA expression, which they hypothesized, was partially responsible for the increases in lean mass. While the mechanisms of myostatin expression in relation to aging are not completely understood, research has shown that inhibition of myostatin can lead to increases in lean mass in post-menopausal women (Attie et al., 2013; White \& LeBrasseur, 2014). While Konopka et al. (2010) had a relatively small sample size, the finding of decreased myostatin expression following aerobic exercise may partially explain the maintenance of lean mass in our CON group and present a possible avenue for future research investigating myostatin suppression and its effects on sarcopenia.

Furthermore, our results suggest that the FNIHSP criteria is more conservative with sarcopenia classification than the EWGSOP and IWG criteria. The EWGSOP 
and IWG criteria classified a combined 14 participants as sarcopenic at baseline, while the FNIHSP criteria only found two DUP participants to be weak with low lean mass at baseline. Interestingly, both participants that met FNIHSP criteria had BMIs $>30$, which is consistent with the results of Dam et al. (2014) who found individuals who met FNIHSP criteria to be heavier with larger BMIs compared to those who met EWGSOP or IWG criteria. Consequently, the FNIHSP criteria may be more appropriate for obese populations, while the EWGSOP and IWG criteria identify more individuals as sarcopenic and may be better suited for those with BMIs $<30$.

Considering the maintenance of ALM experienced by both groups, future research should investigate the potential effects of interdisciplinary interventions on sarcopenia classification, particularly the combined effects of DUP and a diet or supplementation intervention. A recent study by Bauer et al. (2015) found that after 13 weeks of whey protein and vitamin D supplementation, older, sarcopenic men and women experienced significant $(\mathrm{p}=0.045)$ increases in ALM when compared to a control group. Moreover, Cangussu et al. (2015) found that older, post-menopausal women who supplemented with vitamin D experienced significant $(\mathrm{p}<0.0001)$ improvements in chair stand tests compared to a control group. Based on those results, supplementation could provide older sarcopenic women with significant increases in ALM and physical function. Supplement induced increases in ALM combined with DUP induced increases in strength and physical function could present a strong method of altering sarcopenia classification in older women.

This pilot study has demonstrated the feasibility of delivering a 10-week DUP intervention to a group of older, post-menopausal women who had sarcopenia or 
symptoms of sarcopenia at baseline. Additionally this study had high external validity, as the RT equipment used is common among most fitness centers, and training three days per week is a feasible task for older adults. Attendance for the DUP group averaged $85.2 \pm 7.8 \%$, while the CON group averaged $82.6 \pm 7.2 \%$. Additionally, only three participants were lost to follow up (12\% attrition). This indicates that it is feasible and safe to deliver a three-day per week, DUP intervention to older sarcopenic women without any injury or undue attrition.

This study had several limitations including sample size and intervention duration. Having a sample size of 25 participants limited our ability to measure between group differences and gauge the success of the intervention. The cohort was also $100 \%$ Caucasian, which enhances the applicability of results to that population, but limits applicability of results to those of differing race. Furthermore, only seven participants in each group met sarcopenia classification criteria at baseline. The small exposure to cases of sarcopenia may have limited the ability to measure changes in sarcopenia classification, which was also a limitation of Hassan et al. (2016). Additionally, the use of an active control group may have influenced the results of CON. However in an invited commentary Booth \& Lees contend that interventions investigating exercise should include active control participants rather than traditional sedentary controls (Booth \& Lees, 2006). Moreover, the intervention duration of 10weeks may have impacted our ability to observe lean mass increases that would alter sarcopenia classification, as research indicates that muscle hypertrophy typically begins 6-8 weeks after onset of training, which limited the amount of time for measureable hypertrophy to occur (Deschenes \& Kraemer, 2002). However, previous 
studies have experienced significant increases in lean mass in 8 and 10 weeks, albeit in larger samples, indicating the potential for measurable hypertrophy in shorter duration interventions (Delmonico et al., 2005; Santos et al., 2017). Future research should seek to investigate longer duration DUP interventions in larger samples of older women with higher prevalence's of sarcopenia at baseline. Nonetheless, our results indicate that 10-weeks of DUP improved strength and physical function, and attenuated the age related loss of muscle mass in this sample.

\section{CONCLUSION}

In conclusion, this study presents novel new information regarding the use and feasibility of DUP as a potential treatment for sarcopenia in older, post-menopausal women. Our results indicate that through either general exercise or DUP, older women with sarcopenia or symptoms of sarcopenia can significantly increase their strength and physical functioning. Although, to garner maximum strength benefits older women should engage in DUP rather than general exercise. These results provide a new substrate from which future research can build upon to further investigate which forms of treatment provide the greatest change in sarcopenia classification in older women. 


\section{References}

Administration on Aging. (2014). Projected future growth of the older population. Retrieved from http://www.aoa.acl.gov/aging statistics/future growth/future growth.aspx\#age

Alchin, D. R. (2014). Sarcopenia: Describing rather than defining a condition. Journal of Cachexia, Sarcopenia and Muscle, 5(4), 265-268. doi:10.1007/s13539-0140156-8

American College of Sports Medicine, Chodzko-Zajko, W. J., Proctor, D. N., Fiatarone Singh, M. A., Minson, C. T., Nigg, C. R., Skinner, J. S. (2009). American college of sports medicine position stand. exercise and physical activity for older adults. Medicine and Science in Sports and Exercise, 41(7), 1510-1530. doi:10.1249/MSS.0b013e3181a0c95c

Attie, K. M., Borgstein, N. G., Yang, Y., Condon, C. H., Wilson, D. M., Pearsall, A. E., Sherman, M. L. (2013). A single ascending-dose study of muscle regulator ACE-031 in healthy volunteers. Muscle \& Nerve, 47(3), 416-423.

Bailey, R. L., Miller, P. E., Mitchell, D. C., Hartman, T. J., Lawrence, F. R., Sempos, C. T., \& Smiciklas-Wright, H. (2009). Dietary screening tool identifies nutritional risk in older adults. The American Journal of Clinical Nutrition, 90(1), 177-183. doi:10.3945/ajen.2008.27268

Batsis, J. A., Mackenzie, T. A., Barre, L. K., Lopez-Jimenez, F., \& Bartels, S. J. (2014). Sarcopenia, sarcopenic obesity and mortality in older adults: Results from the national health and nutrition examination survey III. European Journal of Clinical Nutrition, 68(9), 1001-1007. doi:10.1038/ejcn.2014.117

Bauer, J. M., Verlaan, S., Bautmans, I., Brandt, K., Donini, L. M., Maggio, M., Cederholm, T. (2015). Effects of a vitamin D and leucine-enriched whey protein nutritional supplement on measures of sarcopenia in older adults, the PROVIDE study: A randomized, double-blind, placebo-controlled trial. Journal of the American Medical Directors Association, 16(9), 740-747. doi:10.1016/j.jamda.2015.05.021

Bellace, J. V., Healy, D., Besser, M. P., Byron, T., \& Hohman, L. (2000). Validity of the dexter evaluation system's jamar dynamometer attachment for assessment of hand grip strength in a normal population. Journal of Hand Therapy, 13(1), 4651 .

Booth, F. W., \& Lees, S. J. (2006). Physically active subjects should be the control group. Medicine and Science in Sports and Exercise, 38(3), 405.

Borg, G. (1998). Borg's perceived exertion and pain scales. Human kinetics. 
Borst, S. E. (2004). Interventions for sarcopenia and muscle weakness in older people. Age and Ageing, 33(6), 548-555. doi:10.1093/ageing/afh201

Borst, S. E., Yarrow, J. F., Conover, C. F., Nseyo, U., Meuleman, J. R., Lipinska, J. A., Shuster, J. J. (2014). Musculoskeletal and prostate effects of combined testosterone and finasteride administration in older hypogonadal men: A randomized, controlled trial. American Journal of Physiology.Endocrinology and Metabolism, 306(4), E433-42. doi:10.1152/ajpendo.00592.2013

Cangussu, L. M., Nahas-Neto, J., Orsatti, C. L., Bueloni-Dias, F. N., \& Nahas, E. A. (2015). Effect of vitamin D supplementation alone on muscle function in postmenopausal women: A randomized, double-blind, placebo-controlled clinical trial. Osteoporosis International : A Journal Established as Result of Cooperation between the European Foundation for Osteoporosis and the National Osteoporosis Foundation of the USA, 26(10), 2413-2421. doi:10.1007/s00198015-3151-9

Cawthon, P. M., Fox, K. M., Gandra, S. R., Delmonico, M. J., Chiou, C. F., Anthony, M. S., Health, Aging and Body Composition Study. (2011). Clustering of strength, physical function, muscle, and adiposity characteristics and risk of disability in older adults. Journal of the American Geriatrics Society, 59(5), 781787. doi:10.1111/j.1532-5415.2011.03389

Chad, K. E., Reeder, B. A., Harrison, E. L., Ashworth, N. L., Sheppard, S. M., Schultz, S. L., Lawson, J. A. (2005). Profile of physical activity levels in community-dwelling older adults. Medicine and Science in Sports and Exercise, 37(10), 1774-1784. doi:00005768-200510000-00019

Cruz-Jentoft, A. J., Baeyens, J. P., Bauer, J. M., Boirie, Y., Cederholm, T., Landi, F., (2010). Sarcopenia: European consensus on definition and diagnosis: Report of the european working group on sarcopenia in older people. Age and Ageing, 39(4), 412-423. doi:10.1093/ageing/afq034

Dam, T. T., Peters, K. W., Fragala, M., Cawthon, P. M., Harris, T. B., McLean, R., Studenski, S. (2014). An evidence-based comparison of operational criteria for the presence of sarcopenia. The Journals of Gerontology.Series A, Biological Sciences and Medical Sciences, 69(5), 584-590. doi:10.1093/gerona/glu013

Delmonico, M. J., Ferrell, R. E., Meerasahib, A., Martel, G. F., Roth, S. M., Kostek, M. C., \& Hurley, B. F. (2005). Blood pressure response to strength training may be influenced by angiotensinogen A-20C and angiotensin II type I receptor A1166C genotypes in older men and women. Journal of the American Geriatrics Society, 53(2), 204-210. doi:JGS53104

Delmonico, M. J., Harris, T. B., Visser, M., Park, S. W., Conroy, M. B., VelasquezMieyer, P., Health, A., and Body. (2009). Longitudinal study of muscle strength, 
quality, and adipose tissue infiltration. The American Journal of Clinical Nutrition, 90(6), 1579-1585. doi:10.3945/ajcn.2009.28047

Delmonico, M. J., Kostek, M. C., Doldo, N. A., Hand, B. D., Bailey, J. A., RabonStith, K. M., Hurley, B. F. (2005). Effects of moderate-velocity strength training on peak muscle power and movement velocity: Do women respond differently than men? Journal of Applied Physiology (Bethesda, Md.: 1985), 99(5), 17121718. doi:01204.2004

Deschenes, M. R., \& Kraemer, W. J. (2002). Performance and physiologic adaptations to resistance training. American Journal of Physical Medicine \& Rehabilitation, 81(11 Suppl), S3-16. doi:10.1097/01.PHM.0000029722.06777.E9

Douchi, T., Yamamoto, S., Nakamura, S., Ijuin, T., Oki, T., Maruta, K., \& Nagata, Y. (1998). The effect of menopause on regional and total body lean mass. Maturitas, 29(3), 247-252. doi:S0378512298000358

Fiatarone, M. A., O'Neill, E. F., Ryan, N. D., Clements, K. M., Solares, G. R., Nelson, M. E., Evans, W. J. (1994). Exercise training and nutritional supplementation for physical frailty in very elderly people. The New England Journal of Medicine, 330(25), 1769-1775. doi:10.1056/NEJM199406233302501

Fielding, R. A., Vellas, B., Evans, W. J., Bhasin, S., Morley, J. E., Newman, A. B., Zamboni, M. (2011). Sarcopenia: An undiagnosed condition in older adults. current consensus definition: Prevalence, etiology, and consequences. international working group on sarcopenia. Journal of the American Medical Directors Association, 12(4), 249-256. doi:10.1016/j.jamda.2011.01.003

Fleck, S. J. (1999). Periodized strength training: A critical review. The Journal of Strength \& Conditioning Research, 13(1), 82-89.

Fleck, S. J., \& Kraemer, W. (2014). Designing resistance training programs, 4E. Human Kinetics.

Guralnik, J. M., Simonsick, E. M., Ferrucci, L., Glynn, R. J., Berkman, L. F., Blazer, D. G., Wallace, R. B. (1994). A short physical performance battery assessing lower extremity function: Association with self-reported disability and prediction of mortality and nursing home admission. Journal of Gerontology, 49(2), M8594.

Haff, G. G., \& Triplett, N. T. (2015). Essentials of strength training and conditioning, 4th Edition. Human Kinetics.

Harber, M. P., Konopka, A. R., Douglass, M. D., Minchev, K., Kaminsky, L. A., Trappe, T. A., \& Trappe, S. (2009). Aerobic exercise training improves whole muscle and single myofiber size and function in older women. American Journal 
of Physiology.Regulatory, Integrative and Comparative Physiology, 297(5), R1452-9. doi:10.1152/ajpregu.00354.2009

Hassan, B. H., Hewitt, J., Keogh, J. W., Bermeo, S., Duque, G., \& Henwood, T. R. (2016). Impact of resistance training on sarcopenia in nursing care facilities: A pilot study. Geriatric Nursing, 37(2), 116-121.

Janssen, I., Shepard, D. S., Katzmarzyk, P. T., \& Roubenoff, R. (2004). The healthcare costs of sarcopenia in the united states. Journal of the American Geriatrics Society, 52(1), 80-85. doi:52014

Katsanos, C. S., Chinkes, D. L., Paddon-Jones, D., Zhang, X. J., Aarsland, A., \& Wolfe, R. R. (2008). Whey protein ingestion in elderly persons results in greater muscle protein accrual than ingestion of its constituent essential amino acid content. Nutrition Research (New York, N.Y.), 28(10), 651-658. doi:10.1016/j.nutres.2008.06.007

Konopka, A. R., Douglass, M. D., Kaminsky, L. A., Jemiolo, B., Trappe, T. A., Trappe, S., \& Harber, M. P. (2010). Molecular adaptations to aerobic exercise training in skeletal muscle of older women. The Journals of Gerontology.Series A, Biological Sciences and Medical Sciences, 65(11), 1201-1207. doi:10.1093/gerona/glq109

Kostek, M. C., \& Delmonico, M. J. (2011). Age-related changes in adult muscle morphology. Current Aging Science, 4(3), 221-233. doi:BSP/CAS/E-Pub/000039

Laukkanen, P., Heikkinen, E., \& Kauppinen, M. (1995). Muscle strength and mobility as predictors of survival in 75-84-year-old people. Age and Ageing, 24(6), 468473.

LeBrasseur, N. K., Bhasin, S., Miciek, R., \& Storer, T. W. (2008). Tests of muscle strength and physical function: Reliability and discrimination of performance in younger and older men and older men with mobility limitations. Journal of the American Geriatrics Society, 56(11), 2118-2123. doi:10.1111/j.15325415.2008.01953.x [doi]

Mason, C., Xiao, L., Imayama, I., Duggan, C. R., Foster-Schubert, K. E., Kong, A., McTiernan, A. (2013). Influence of diet, exercise, and serum vitamin $d$ on sarcopenia in postmenopausal women. Medicine and Science in Sports and Exercise, 45(4), 607-614. doi:10.1249/MSS.0b013e31827aa3fa

McLean, R. R., Shardell, M. D., Alley, D. E., Cawthon, P. M., Fragala, M. S., Harris, T. B., Dam, T. T. (2014). Criteria for clinically relevant weakness and low lean mass and their longitudinal association with incident mobility impairment and mortality: The foundation for the national institutes of health (FNIH) sarcopenia 
project. The Journals of Gerontology.Series A, Biological Sciences and Medical Sciences, 69(5), 576-583. doi:10.1093/gerona/glu012

Paddon-Jones, D., \& Leidy, H. (2014). Dietary protein and muscle in older persons. Current Opinion in Clinical Nutrition and Metabolic Care, 17(1), 5-11. doi:10.1097/MCO.0000000000000011

Peterson, M. D., Rhea, M. R., Sen, A., \& Gordon, P. M. (2010). Resistance exercise for muscular strength in older adults: A meta-analysis. Ageing Research Reviews, 9(3), 226-237. doi:10.1016/j.arr.2010.03.004

Peterson, M. D., Sen, A., \& Gordon, P. M. (2011). Influence of resistance exercise on lean body mass in aging adults: A meta-analysis. Medicine and Science in Sports and Exercise, 43(2), 249-258. doi:10.1249/MSS.0b013e3181eb6265

Prestes, J., Frollini, A. B., de Lima, C., Donatto, F. F., Foschini, D., de Cassia Marqueti, R., Fleck, S. J. (2009). Comparison between linear and daily undulating periodized resistance training to increase strength. Journal of Strength and Conditioning Research, 23(9), 2437-2442. doi:10.1519/JSC.0b013e3181c03548

Rantanen, T., Guralnik, J. M., Foley, D., Masaki, K., Leveille, S., Curb, J. D., \& White, L. (1999). Midlife hand grip strength as a predictor of old age disability. Jama, 281(6), 558-560. doi:jbr80447

Rhea, M. R., \& Alderman, B. L. (2004). A meta-analysis of periodized versus nonperiodized strength and power training programs. Research Quarterly for Exercise and Sport, 75(4), 413-422.

Rhea, M. R., Ball, S. D., Phillips, W. T., \& Burkett, L. N. (2002). A comparison of linear and daily undulating periodized programs with equated volume and intensity for strength. Journal of Strength and Conditioning Research / National Strength \& Conditioning Association, 16(2), 250-255.

Rhodes, E. C., Martin, A. D., Taunton, J. E., Donnelly, M., Warren, J., \& Elliot, J. (2000). Effects of one year of resistance training on the relation between muscular strength and bone density in elderly women. British Journal of Sports Medicine, $34(1), 18-22$.

Rossouw, J. E., Anderson, G. L., Prentice, R. L., LaCroix, A. Z., Kooperberg, C., Stefanick, M. L., Writing Group for the Women's Health Initiative Investigators. (2002). Risks and benefits of estrogen plus progestin in healthy postmenopausal women: Principal results from the women's health initiative randomized controlled trial. Jama, 288(3), 321-333. doi:joc21036

Santos, L., Ribeiro, A. S., Schoenfeld, B. J., Nascimento, M. A., Tomeleri, C. M., Souza, M. F., Cyrino, E. S. (2017). The improvement in walking speed induced 
by resistance training is associated with increased muscular strength but not skeletal muscle mass in older women. European Journal of Sport Science, , 1-7. doi:10.1080/17461391.2016.1273394

Simonsick, E. M., Montgomery, P. S., Newman, A. B., Bauer, D. C., \& Harris, T. (2001). Measuring fitness in healthy older adults: The health $\mathrm{ABC}$ long distance corridor walk. Journal of the American Geriatrics Society, 49(11), 1544-1548. doi:4911247

Studenski, S., Perera, S., Patel, K., Rosano, C., Faulkner, K., Inzitari, M., Guralnik, J. (2011). Gait speed and survival in older adults. Jama, 305(1), 50-58. doi:10.1001/jama.2010.1923

Studenski, S. A., Peters, K. W., Alley, D. E., Cawthon, P. M., McLean, R. R., Harris, T. B., Vassileva, M. T. (2014). The FNIH sarcopenia project: Rationale, study description, conference recommendations, and final estimates. The Journals of Gerontology.Series A, Biological Sciences and Medical Sciences, 69(5), 547-558. doi:10.1093/gerona/glu010

Taekema, D. G., Gussekloo, J., Maier, A. B., Westendorp, R. G., \& de Craen, A. J. (2010). Handgrip strength as a predictor of functional, psychological and social health. A prospective population-based study among the oldest old. Age and Ageing, 39(3), 331-337. doi:10.1093/ageing/afq022

US Department of Health, \& Human Services. (2006). Health, united states, 2005: With chartbook on trends in the health of americans Claitor's Law Books and Publishing Division.

Visser, M., Goodpaster, B. H., Kritchevsky, S. B., Newman, A. B., Nevitt, M., Rubin, S. M., Harris, T. B. (2005). Muscle mass, muscle strength, and muscle fat infiltration as predictors of incident mobility limitations in well-functioning older persons. The Journals of Gerontology.Series A, Biological Sciences and Medical Sciences, 60(3), 324-333. doi:60/3/324

White, T. A., \& LeBrasseur, N. K. (2014). Myostatin and sarcopenia: Opportunities and challenges - a mini-review. Gerontology, 60(4), 289-293. doi:10.1159/000356740

Whitney, J. C., Lord, S. R., \& Close, J. C. (2005). Streamlining assessment and intervention in a falls clinic using the timed up and go test and physiological profile assessments. Age and Ageing, 34(6), 567-571. doi:34/6/567

Yang, M., Ding, X., Luo, L., Hao, Q., \& Dong, B. (2014). Disability associated with obesity, dynapenia and dynapenic-obesity in chinese older adults. Journal of the American Medical Directors Association, 15(2), 150.e11-150.e16. doi:10.1016/j.jamda.2013.10.009 


\section{TABLES}

Table 1. Daily undulations of program variables

\begin{tabular}{|l|c|c|c|}
\hline & Day 1 & Day 2 & Day 3 \\
\hline Week 1 & $\mathrm{L}$ & $\mathrm{M}$ & $\mathrm{H}$ \\
\hline Week 2 & $\mathrm{L}$ & $\mathrm{H}$ & $\mathrm{M}$ \\
\hline Week 3 & $\mathrm{L}$ & $\mathrm{M}$ & $\mathrm{H}$ \\
\hline Week 4 & $\mathrm{M}$ & $\mathrm{L}$ & $\mathrm{M}$ \\
\hline Week 5 & $\mathrm{H}$ & $\mathrm{M}$ & $\mathrm{L}$ \\
\hline Week 6 & $\mathrm{M}$ & $\mathrm{H}$ & $\mathrm{H}$ \\
\hline Week 7 & $\mathrm{L}$ & $\mathrm{H}$ & $\mathrm{H}$ \\
\hline Week 8 & $\mathrm{M}$ & $\mathrm{L}$ & $\mathrm{H}$ \\
\hline Week 9 & $\mathrm{M}$ & $\mathrm{H}$ & $\mathrm{M}$ \\
\hline Week 10 & $\mathrm{H}$ & $\mathrm{H}$ & $\mathrm{M}$ \\
\hline
\end{tabular}

$\mathrm{L}=$ Light day (12 repetitions, 60 seconds rest, $70 \% \mathrm{RM})$;

$\mathrm{M}=$ Medium day (8-10 repetitions, $90-120$ seconds rest, $75-80 \% \mathrm{RM}$ );

$\mathrm{H}=$ Heavy day (3-6 repetitions, $120-180$ seconds rest, $\geq 85 \% \mathrm{RM}$ ). 
Table 2. Baseline characteristics of participants

\begin{tabular}{|l|c|c|c|c|}
\hline & Total (n=25) & DUP (n=13) & CON (n=12) & p-value \\
\hline Age (years) & $72.3 \pm 4.6$ & $71.8 \pm 4.8$ & $72.9 \pm 4.6$ & 0.547 \\
\hline Attendance (\%) & $84.0 \pm 7.5$ & $85.2 \pm 7.8$ & $82.6 \pm 7.2$ & 0.270 \\
\hline Body mass (kg) & $65.4 \pm 13.5$ & $68.7 \pm 15.5$ & $61.8 \pm 10.3$ & 0.205 \\
\hline Height (cm) & $159.8 \pm 5.2$ & $160.0 \pm 5.7$ & $159.6 \pm 4.8$ & 0.851 \\
\hline BMI & $25.7 \pm 5.9$ & $27.1 \pm 7.3$ & $24.2 \pm 3.5$ & 0.446 \\
\hline Body Fat (\%) & $42.5 \pm 6.3$ & $43.9 \pm 7.8$ & $41.0 \pm 3.9$ & 0.256 \\
\hline ALM/ht $\mathbf{~} \mathbf{~ k g / m}$ ) $^{\mathbf{2}}$ & $5.92 \pm 1.1$ & $6.13 \pm 1.3$ & $5.69 \pm 0.8$ & 0.330 \\
\hline ALM/BMI & $0.60 \pm 0.07$ & $0.59 \pm 0.09$ & $0.60 \pm 0.04$ & 0.751 \\
\hline Systolic BP (mmHg) & $122.8 \pm 14.7$ & $129.1 \pm 14.2$ & $116.0 \pm 12.4$ & $0.022 *$ \\
\hline Diastolic BP (mmHg) & $74.5 \pm 8.5$ & $77.9 \pm 7.5$ & $70.8 \pm 8.2$ & $0.034 *$ \\
\hline Chest press (kg) & $17.0 \pm 6.6$ & $17.8 \pm 8.4$ & $16.1 \pm 4.3$ & 0.624 \\
\hline Leg press (kg) & $46.3 \pm 16.1$ & $50.6 \pm 18.5$ & $41.7 \pm 12.2$ & 0.220 \\
\hline Grip strength (kg) & $16.6 \pm 3.7$ & $17.5 \pm 4.5$ & $15.8 \pm 2.6$ & 0.492 \\
\hline SPPB & $10.2 \pm 1.6$ & $10.7 \pm 1.6$ & $9.8 \pm 1.5$ & 0.359 \\
\hline Gait speed (m/s) & $1.05 \pm 0.14$ & $1.07 \pm 0.16$ & $1.02 \pm 0.12$ & 0.398 \\
\hline TUG (s) & $7.5 \pm 1.1$ & $7.1 \pm 0.9$ & $7.8 \pm 1.1$ & 0.101 \\
\hline 400 meter walk (s) & $313.2 \pm 42.8$ & $311.9 \pm 40.0$ & $314.7 \pm 47.4$ & 0.874 \\
\hline
\end{tabular}

Abbreviations: BMI, Body Mass index; ALM, appendicular lean mass measured via dual-energy X-ray absorptiometry; SPPB, Short Physical Performance Battery; TUG, Timed up and go.

Data presented as means \pm standard deviation.

P-values obtained using t-tests.

*Indicates p-value $<0.05$ 
Table 3. Baseline and post intervention changes in sarcopenia classification using different national and international sarcopenia classification criteria.

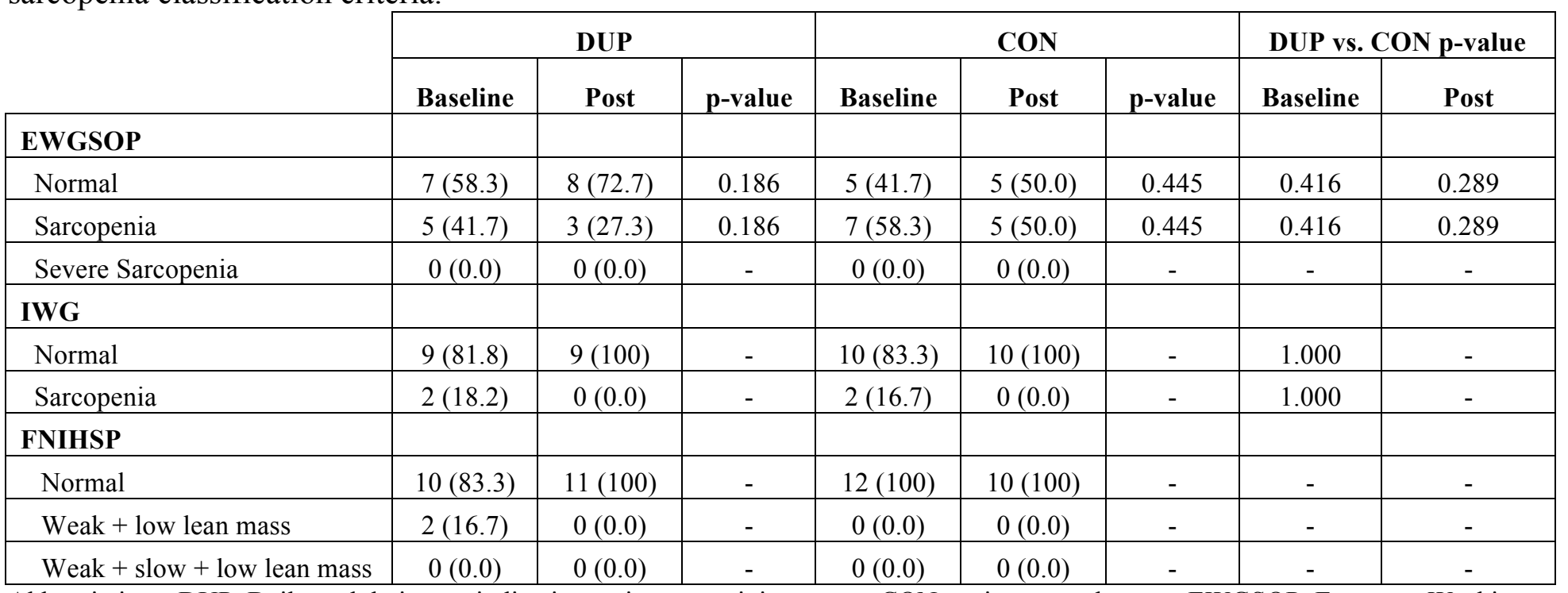

Abbreviations: DUP, Daily undulation periodization resistance training group; CON, active control group; EWGSOP, European Working

Group on Sarcopenia in Older People; IWG, International Working Group on Sarcopenia; FNIHSP, Foundation for the National Institutes of Health Sarcopenia Project.

Data are expressed as number of participants (\% of sample)

P-values were obtained using McNemar's Test or binomial exact test if discordant cell frequency was less than 4 
Table 4. Mean changes in physical function, body composition, and strength measures compared to baseline values.

\begin{tabular}{|c|c|c|c|c|c|}
\hline & \multicolumn{2}{|c|}{$\mathrm{CON}$} & \multicolumn{2}{|c|}{ DUP } & \multirow{2}{*}{$\begin{array}{c}\text { DUP vs. CON } \\
\text { p-value }\end{array}$} \\
\hline & Mean \pm SD & p-value & Mean \pm SD & p-value & \\
\hline \multicolumn{6}{|l|}{ GS (s) } \\
\hline Baseline & REF & & REF & & 0.383 \\
\hline Mid point & $1.45 \pm 2.79$ & $0.002 *$ & $1.08 \pm 3.56$ & $<0.001^{*}$ & 0.265 \\
\hline Post Testing & $-0.65 \pm 0.59$ & $<0.001^{*}$ & $-0.55 \pm 0.46$ & $0.001 *$ & 0.641 \\
\hline 6 month & $-0.40 \pm 0.37$ & $0.036 *$ & $-0.08 \pm 0.38$ & 0.793 & 0.472 \\
\hline \multicolumn{6}{|l|}{ DXA ALM (kg) } \\
\hline Baseline & REF & & REF & & 0.309 \\
\hline Post Testing & $0.15 \pm 0.53$ & 0.298 & $0.17 \pm 0.37$ & 0.216 & 0.304 \\
\hline \multicolumn{6}{|l|}{ ALM/ht ${ }^{2}$} \\
\hline Baseline & REF & & REF & & 0.326 \\
\hline Post Testing & $-0.05 \pm 0.16$ & 0.256 & $-0.04 \pm 0.23$ & 0.392 & 0.35 \\
\hline \multicolumn{6}{|l|}{ ALM/BMI } \\
\hline Baseline & REF & & REF & & 0.756 \\
\hline Post Testing & $0.61 \pm 0.05$ & 0.213 & $0.59 \pm 0.09$ & 0.92 & 0.587 \\
\hline \multicolumn{6}{|l|}{ GR (kg) } \\
\hline Baseline & REF & & REF & & 0.195 \\
\hline Midpoint & $1.45 \pm 2.79$ & 0.144 & $1.08 \pm 3.56$ & 0.203 & 0.303 \\
\hline Post Testing & $0.50 \pm 1.90$ & 0.644 & $1.67 \pm 4.48$ & 0.06 & $0.036 *$ \\
\hline 6 month & $-0.10 \pm 3.11$ & 0.861 & $0.25 \pm 3.45$ & 0.785 & 0.127 \\
\hline \multicolumn{6}{|l|}{ CP (kg) } \\
\hline Baseline & REF & & REF & & 0.567 \\
\hline Midpoint & $2.18 \pm 1.41$ & $<0.001^{*}$ & $3.56 \pm 1.70$ & $<0.001^{*}$ & 0.295 \\
\hline Post Testing & $2.68 \pm 1.76$ & $<0.001^{*}$ & $5.13 \pm 2.50$ & $<0.001^{*}$ & 0.149 \\
\hline 6 month & $1.94 \pm 1.99$ & $<0.001^{*}$ & $3.24 \pm 1.93$ & $<0.001^{*}$ & 0.299 \\
\hline \multicolumn{6}{|l|}{ LP (kg) } \\
\hline Baseline & REF & & REF & & 0.265 \\
\hline Midpoint & $10.95 \pm 4.57$ & $<0.001^{*}$ & $13.34 \pm 11.97$ & $<0.001^{*}$ & 0.171 \\
\hline Post Testing & $17.9 \pm 8.02$ & $<0.001 *$ & $20.8 \pm 14.2$ & $<0.001^{*}$ & 0.153 \\
\hline 6 month & $12.50 \pm 6.95$ & $<0.001 *$ & $15.08 \pm 10.90$ & $<0.001^{*}$ & 0.234 \\
\hline \multicolumn{6}{|l|}{ SPPB } \\
\hline Baseline & REF & & REF & & 0.062 \\
\hline Midpoint & $1.10 \pm 1.20$ & $0.041^{*}$ & $0.38 \pm 1.56$ & 0.372 & 0.511 \\
\hline Post Testing & $1.40 \pm 1.78$ & $0.008 *$ & $1.00 \pm 1.91$ & $0.039 *$ & 0.273 \\
\hline 6 month & $1.70 \pm 1.95$ & $0.001 *$ & $0.58 \pm 1.88$ & 0.25 & 0.802 \\
\hline \multicolumn{6}{|l|}{$400 \mathrm{~m}$ walk (s) } \\
\hline Baseline & REF & & REF & & 0.866 \\
\hline Midpoint & $-20.23 \pm 18.00$ & $0.012 *$ & $-14.29 \pm 29.95$ & $0.035 *$ & 0.894 \\
\hline Post Testing & $-20.89 \pm 23.99$ & $0.01 *$ & $-18.95 \pm 33.42$ & $0.007 *$ & 0.912 \\
\hline 6 month & $-23.68 \pm 23.77$ & $0.003 *$ & $-14.61 \pm 33.61$ & $0.035 *$ & 0.756 \\
\hline \multicolumn{6}{|l|}{ TUG (s) } \\
\hline Baseline & REF & & REF & & 0.101 \\
\hline Midpoint & $-0.94 \pm 0.59$ & $<0.001 *$ & $-0.38 \pm 0.88$ & 0.087 & 0.718 \\
\hline Post Testing & $-0.74 \pm 0.56$ & $0.005^{*}$ & $-0.48 \pm 1.04$ & 0.056 & 0.342 \\
\hline 6 month & $-0.13 \pm 0.69$ & 0.646 & $0.91 \pm 0.70$ & $<0.001 *$ & 0.404 \\
\hline
\end{tabular}

Abbreviations: DUP, Daily undulation periodization resistance training group; CON, active control group; GS, gait speed; DXA ALM, appendicular lean mass measured via dual-energy X-ray absorptiometry; ALM $/ \mathrm{ht}^{2}$, appendicular lean mass divided by height in meters squared; ALM/BMI, appendicular lean mass divided by body mass index; GR, grip strength; $\mathrm{CP}$, chest press strength; LP, leg press strength; SPPB, Short Physical Performance Battery; TUG, Timed up and go; 6 month, six months post intervention, REF, baseline values set as referent values.

Data are presented as means \pm standard deviation, with values for each time point representing change from baseline value Analyses were conducted using mixed models with baseline values set as referent value. 


\section{FIGURES}

Figure 1. Study Flow Chart.






\title{
APPENDICES
}

\section{Appendix A: Review of the Literature}

\begin{abstract}
The age related loss of muscle mass, known as sarcopenia can negatively affect physical functioning and muscular strength. Older women may be at a greater risk for sarcopenia and functional impairments due to gender specific differences in the aging process. Current classification criteria for sarcopenia developed by the European Working Group on Sarcopenia in Older People (EWGSOP), the International Working Group (IWG), and the Foundation for the National Institutes of Health Sarcopenia Project (FNIHSP) lack agreement, however most criteria incorporate measures of appendicular lean mass (ALM), muscular strength, and physical functioning. Resistance training (RT) is known to produce increases in muscle mass, strength, and improve physical function in older individuals. Periodized resistance training (PRT) is a form of RT program design, which modifies program variables in an attempt to maximize performance, and has been shown to be superior to conventional RT program design at eliciting gains in strength and physical functioning. To date no study has evaluated the effects of PRT on sarcopenia classification in older women.
\end{abstract}

\section{Introduction}

The term sarcopenia, originally coined in 1989 by Dr. Irwin Rosenberg, originates from the Greek language and translates to "poverty of the flesh" (Rosenberg, 1989). Sarcopenia has been reported as a global public health problem, and results in a gradual, age-accelerated loss of skeletal muscle mass, which can 
negatively affect physical functioning and muscular strength (Chen et al., 2014;

Cherin, Voronska, Fraoucene, \& de Jaeger, 2014; Cruz-Jentoft et al., 2014; Diz et al., 2016; W. Kemmler et al., 2015; Tichet et al., 2008). While sarcopenia is related to aging, several mechanisms are associated with this multifactorial process. Factors including decreased levels of physical activity, hormonal changes, altered nervous system activity, muscle fiber atrophy, loss of type 2 muscle fibers, and fatty infiltration of skeletal muscle all contribute to the accelerated loss of skeletal muscle (Alchin, 2014; Karakelides \& Nair, 2005; Kostek \& Delmonico, 2011). Following age 50 muscle mass decreases at a rate of $1-2 \%$ per year (Batsis, Mackenzie, Barre, Lopez-Jimenez, \& Bartels, 2014). Evidence suggests this progressive muscular atrophy contributes to rapid declines in muscle strength, power, and physical function; placing older individuals at risk for injury and/or disability (Batsis et al., 2014; Cawthon et al., 2011; Choi, 2013; Visser et al., 2005; Yang, Ding, Luo, Hao, \& Dong, 2014).

Furthermore, Jannssen et al. (2004) estimated that the healthcare costs directly associated with sarcopenia in 2000 were $\$ 18.5$ billion, with more than $\$ 7$ billion attributed to older women. Those estimates, coupled with the projected increase in the older population indicate that appropriate diagnostic and treatment strategies need to be developed in order to combat sarcopenia in older adults (Administration on Aging, 2014). Moreover, women typically live longer than men and therefore may have an increased risk of functional impairment as they age (Barford, Dorling, Davey Smith, \& Shaw, 2006; Borst, 2004). 
Currently there is no universally accepted definition or classification criteria for identifying sarcopenia in older individuals. However, several working groups have developed diagnostic criteria that include cut-points for low levels of ALM, low strength, and physical functioning markers. Although the current cut points and quantification variables do not agree, the European Working Group on Sarcopenia in Older People (EWGSOP), the International Working Group (IWG), and the Foundation for the National Institutes of Health Sarcopenia Project (FNIHSP) all concur that measures of ALM and/or grip strength or gait speed are necessary to classify an individual as sarcopenic (Cruz-Jentoft et al., 2010; Fielding et al., 2011; Studenski et al., 2014).

Treatment of sarcopenia centralizes around mechanisms that aim to maintain or increase levels of lean mass and physical functioning. Current approaches include hormone treatments, supplementation treatments, and physical activity or RT interventions (Anton et al., 2016; Evans, Boccardi, \& Paolisso, 2013; Kim et al., 2012; Solerte et al., 2008). All of these treatment modalities have strengths and weaknesses, however RT has been shown to be the most effective method of increasing muscle mass and physical function, with little to no accompanying side effects (Foster-Burns, 1999; Marcell, Hawkins, \& Wiswell, 2014; Paddon-Jones, Short, Campbell, Volpi, \& Wolfe, 2008; Sorensen, Rosenfalck, Hojgaard, \& Ottesen, 2001; Stewart, Saunders, \& Greig, 2014).

Periodized resistance training (PRT) is a form of RT program design that has elicited greater performance gains when compared to traditional RT programming (Kraemer et al., 2003; Monteiro et al., 2009; O'bryant, Byrd, \& Stone, 1988). While 
$\mathrm{RT}$ in older adults has been researched previously, no study has investigated if an intervention using a specific form of PRT: daily undulating periodized resistance training (DUP), would elicit changes in sarcopenia classification in older women considered sarcopenic by current criteria.

\section{Sarcopenia in Older Women}

Recent population estimates indicate a greater percentage of the older population is female, and they have a longer life expectancy and are at a greater risk of physical disability compared to men (Administration on Aging, 2014; Borst, 2004; Carrière et al., 2005). Additionally, compared to men, women typically have lower amounts of lean mass and lower levels of physical activity in old age, resulting in an increased risk of developing sarcopenia (Batsis et al., 2014; Chad et al., 2005). As shown in a study by Chad et al. (2005), $67 \%$ of women over the age of 50 are not active enough to achieve a reduction in chronic disease risk. Moreover, hormonal changes due to menopause result in decreases in lean mass accompanied by increases in fat mass, independent of age (Douchi et al., 1998; Orsatti et al., 2016). While men also experience decreases in testosterone that contribute to losses of muscle mass, women begin to experience changes in estrogen up to 10 years prior to the onset of menopause, contributing to pre-menopausal declines in muscle mass, bone mass, and strength (Brown, 2008; Burger, Hale, Robertson, \& Dennerstein, 2007; Delmonico \& Beck, 2015). Due to the increased risk of sarcopenia in older women detection and intervention strategies are critical to prevent and treat sarcopenia in this population. 
In a study assessing 18,913 older U.S. and English men and women, U.S. women experienced the steepest decline in measures of activities of daily living and physical function when compared to other study participants at eight years of follow up (Bendayan et al., 2016). Those researchers also determined that activities incorporating climbing stairs, kneeling down, or crouching were the first to decline among their cohort. That study indicates that as women in the U.S. age, they will likely experience declines in the ability to perform activities of daily living, therefore treatment strategies are necessary to regain physical function in older women.

Sarcopenia has also been associated with an increased risk of all-cause mortality. A recent meta-analysis by Chang \& Lin (2016) analyzed 10 longitudinal studies with 3,797 men and women with an average follow up of 4.17 years. Sarcopenia was classified using three different sets of criteria including EWGSOP criteria. With non-sarcopenic participants considered the referent group there was there was a significantly increased risk of all-cause mortality in those considered to have sarcopenia (HR:1.87, 95\% CI: 1.61-2.18). The finding that sarcopenia increased the risk of all-cause mortality underscores the impact of sarcopenia in older adults. Therefore, prevention and treatment of this condition is necessary in this population.

The body of evidence within the literature indicates that sarcopenia is a significant public health issue, especially in older women. As the population over 65 grows, it can be inferred that the prevalence of sarcopenia, the risk of all cause mortality, and healthcare expenses within this population will also increase. Therefore it is imperative that intervention strategies be developed to help attenuate the loss of physical functioning, lean mass and muscular strength in older women. 


\section{Dynapenia vs Sarcopenia}

Dynapenia, in contrast to sarcopenia, is defined as the age related loss of muscular strength that is not associated with any neurological or muscular disease (Clark \& Manini, 2012; Mitchell et al., 2015). Dynapenia is distinct from sarcopenia, however these two conditions are similar as research indicates that muscular strength and muscle mass are closely related (Clark \& Manini, 2008; Reed, Pearlmutter, Yochum, Meredith, \& Mooradian, 1991). Similar to sarcopenia, dynapenia is a multifactorial process influenced by changes to the nervous system and the muscular system. Clark \& Manini (2008) argue that decreased strength (dynapenia) may have a greater influence on physical functioning in older individuals than decreased muscle mass (sarcopenia). Those researchers contend that future research should focus on methods of preventing the loss of strength rather than muscle mass. However, the term sarcopenia is more widely recognized within the literature than dynapenia, and current sarcopenia classification criteria include measures of muscular strength. Furthermore, current criteria have been developed to be comprehensive clinical assessments, as individual diagnoses of low mass or low strength may be of limited clinical value (Cruz-Jentoft et al., 2010; Delmonico \& Beck, 2015).

Clark \& Manini (2008) clearly demonstrate that muscular strength is vital to maintaining physical function and completing activities of daily living. While there are various methods of assessing muscular strength in older individuals, few are as easy and portable to assess as grip strength. Isometric handgrip strength is related to lower body power and has also been shown to be a valid clinical marker of mobility (Lauretani et al., 2003). Additionally, research has shown a linear relationship 
between handgrip strength and future disability for activities of daily living (Al Snih, Markides, Ottenbacher, \& Raji, 2004). Due to the ease, affordability, and validity of this measure, handgrip strength is present in some sarcopenia classification criteria. However, this measure is not without limitations. Despite being a valid predictor of total body strength and future disability, grip strength may not be a valid measure for

older individuals with hand ailments such as arthritis (Erol, Ceceli, Uysal Ramadan, \& Borman, 2016; Rantanen et al., 1999).

\section{Importance of Gait Speed}

Ambulation is a vital component of activities of daily living and its importance in overall physical functioning cannot be understated. Indeed some researchers suggest that gait speed should be considered the "sixth vital sign" and assessed clinically along with breathing, temperature, heart rate, pain, and color (Fritz \& Lusardi, 2009). A study by Studenski et al. (2011) examining gait speed and survival in 34,485 older adults found that lower levels of gait speed were associated with increased risk of mortality. Additionally, those researchers determined an overall hazard ratio of 0.88 (95\% CI: 0.87-0.90) for each 0.1-meter per second $(\mathrm{m} / \mathrm{s})$ increase in gait speed. The results of that study suggest that older adults with poor gait speed and therefore reduced physical function are at a greater risk of all-cause mortality. Gait speed is also easy and inexpensive to measure, with the only requirements being a stopwatch and a pre-measured distance. Test distances for gait speed have varied from 2 to 40 meters in length, however for patient and clinician practicality and feasibility, it is recommended that tests not exceed 10 meters in distance (Middleton, 
Fritz, \& Lusardi, 2015). While protocols for specific tests may vary, gait speed tests are a validated method of assessing overall physical function in older adults.

Considering the immense importance of gait speed in relation to physical function and mortality including this measure in routine medical assessments would allow clinicians to monitor gait speed trajectory and determine if an individual's gait speed is improving or deteriorating.

Consequently, while the term sarcopenia by definition refers to the age related loss of muscle mass; some current sarcopenia classification criteria include measures of muscle mass, strength, and physical function. These criteria allow for a more comprehensive evaluation of individuals' overall health and physical function and may be beneficial for the detection of functional impairment in older individuals, regardless of the underlying mechanism or terminology.

\section{Sarcopenia Classification}

Researchers have faced difficulties designing and justifying interventions strategies for older adults with sarcopenia in part due to the lack of consensus definition/diagnostic criteria for sarcopenia and inability to compare results of different studies (Cruz-Jentoft et al., 2014). In addition, sarcopenia lacks significant clinical endpoints (e.g. fracture risk for osteoporosis), making it difficult to pinpoint the onset of the condition (Studenski et al., 2014). One of the earliest and most common methods of sarcopenia diagnosis is the skeletal muscle index (SMI) method (Baumgartner, Waters, Gallagher, Morley, \& Garry, 1999). The SMI method is calculated by dividing ALM in kilograms by height in meters squared $\left(\mathrm{kg} / \mathrm{m}^{2}\right)$, where 
ALM is measured via dual energy $\mathrm{x}$-ray absorptiometry (DXA), and considered the sum of non-bone lean mass in both arms and legs. Baumgartner et al. (1998) first used the SMI method in the New Mexico Aging Process study. That study classified sarcopenia in an older population using sex specific SMI cut points that were two standard deviations below the mean SMI of a healthy young adult population from the Rosetta Study (Baumgartner et al., 1998; Gallagher et al., 1997). The inclusion of height in the SMI is beneficial as taller individuals often have more ALM. Indeed, further data from the New Mexico Aging Process Study showed that 38\% of the variance in muscle mass measurements in older women was attributable to height differences, which demonstrates the need to account for skeletal size when assessing lean mass (Baumgartner et al., 1999).

Although the SMI method accounts for height and can be used with sex specific cut points, it is limited in that it doesn't account for fat mass and may fail to classify obese individuals as sarcopenic. This became evident when two separate studies analyzed data from the Health, Aging, and Body Composition (Health ABC) study. The first study by Newman et al. (2003) included data from 2,984 men and women aged 70-79 years. That study used two different methods of classifying sarcopenia in their cohort: the SMI method and a proposed new method of classifying sarcopenia using linear regression residuals. However in their use of the SMI method they did not compare participant data to that of a healthy reference population as Baumgartner et al. (1998) did, rather a participant was considered sarcopenic is their SMI value fell below the $20^{\text {th }}$ percentile of the sex-specific distribution of values within the Health $\mathrm{ABC}$ cohort. The residuals method also uses ALM in its sarcopenia 
classification however this method also accounts for fat mass. In order for those researchers to model the relationship between fat mass, height, and ALM, a linear regression was performed. The residuals of this regression were then used to determine sarcopenia classification. Any participant who fell below the $20^{\text {th }}$ percentile of the residuals of the Health $\mathrm{ABC}$ cohort was considered sarcopenic. This allowed for direct comparison with the SMI method using the $20^{\text {th }}$ percentile cut point.

The results of Newman et al.'s (2003) investigation indicated that when applying the SMI method to overweight and obese women $0.8 \%$ and $0 \%$, respectively, of the population was considered sarcopenic. Conversely, the residuals method reported $21.7 \%$ and $21 \%$ sarcopenia prevalence's in overweight and obese women respectively. Furthermore, when assessed using the residuals method, women had higher adjusted odds of lower extremity functional limitation (OR: 1.9, 95\% CI: 1.42.5), than when they were assessed with the SMI method (OR: 0.9, 95\% CI: 0.7-1.2).

The second study using Health ABC data by Delmonico et al. (2007) included a sample of 2,976 older men and women aged 70-79 at baseline. Participant data were assessed using the SMI method and the $20^{\text {th }}$ percentile of the Health $\mathrm{ABC}$ population cut point and the $20^{\text {th }}$ percentile of linear regression residuals cut point. Those researchers found that after five years of follow up the residuals method predicted increased risk of lower extremity limitation (HR: 1.34, 95\% CI: 1.11-1.61) while the SMI method initially predicted improvement in lower extremity (HR: $0.58,95 \% \mathrm{CI}$ : 0.48-0.72). However after adjustment for confounders including age, race, physical activity, and total body fat mass, the SMI results appeared to insignificantly predict future functional limitation (HR: 1.04, 95\% CI: 0.82-1.31). 
Those results demonstrate the limitations of using the SMI method to classify sarcopenia, especially in populations with a high prevalence of overweight and/or obese individuals. This also demonstrates the importance of including measures such as fat mass or percent body fat into classification criteria, and that the residuals method may offer better prediction of future incidence of functional limitations (Delmonico et al., 2007; Newman et al., 2003). Despite those findings some current sarcopenia classification criteria use the SMI method of quantifying lean mass and include measures of physical functioning and strength rather than fat mass, while other criteria have the ability to account for fat mass. To that end, based on the findings of Newman et al. and Delmonico et al., in order for sarcopenia classification criteria to be most applicable different populations a measure of fat mass should be included in ALM assessment.

Currently the most prominent sarcopenia classification criteria have been established by the European Working Group on Sarcopenia in Older People (EWGSOP), the International Working Group (IWG), and the Foundation for the National Institutes of Health Sarcopenia Project (FNIHSP) and are presented in Literature Review Table 1 (Cruz-Jentoft et al., 2010; Fielding et al., 2011; Studenski et al., 2014). All of these working groups included diagnostic cut points for lean mass, muscular strength (grip strength), and/or physical function (gait speed) for both men and women in their criteria. The cut points for women will be discussed in this review. The EWGSOP criteria includes measures of lean mass, physical function, and strength and incorporate established stages of sarcopenia: pre-sarcopenia, sarcopenia, and severe sarcopenia. In their consensus statement the EWGSOP lists various SMI 
cut points depending on the method used to measure ALM (DXA, bioelectrical impedance, MRI, etc.).

Literature Review Table 1: Current sarcopenia classification criteria for older women The European Working Group on Sarcopenia in $\quad$ The Foundation for the National Institutes Older People Sarcopenia (EWGSOP) and International Working Group on Sarcopenia (IWG) screening guidelines for sarcopenia and of Health Sarcopenia Project (FNIHSP) severe sarcopenia in older women recommended modalities and cut-points for identifying functional limitation, muscle weakness and low lean mass in older women.

\begin{tabular}{|c|c|c|c|c|}
\hline Sarcopenia & EWGSOP & $I W G$ & Weak with Low Lean Mass & Cut-Point \\
\hline Gait Speed & $<0.8 \mathrm{~m} / \mathrm{s}$ & $<1.0 \mathrm{~m} / \mathrm{s}$ & Gait Speed & - \\
\hline & $O R$ & & Weakness: Grip strength & $<16 \mathrm{~kg}$ \\
\hline Grip Strength & $<20 \mathrm{~kg}$ & $\mathrm{~N} / \mathrm{A}$ & Lean Mass: ALM/BMI & $<0.512$ \\
\hline & $A N D$ & & Weak and Slow with Low Lean & \\
\hline Lean Mass: $A L M / h t^{2}$ & $<5.67 \mathrm{~kg} / \mathrm{m}^{2}$ & $<5.67 \mathrm{~kg} / \mathrm{m}^{2}$ & Gait Speed & $<0.8 \mathrm{~m} / \mathrm{s}$ \\
\hline Severe Sarcopenia & & & Weakness: Grip strength & $<16 \mathrm{~kg}$ \\
\hline Gait Speed & $<0.8 \mathrm{~m} / \mathrm{s}$ & N/A & Lean Mass: $A L M / B M I$ & $<0.512$ \\
\hline & $A N D$ & & \multirow{4}{*}{\multicolumn{2}{|c|}{$\begin{array}{l}\text { Abbreviations: ALM, appendicular lean mass; } \\
\text { BMI, body mass index. } \\
\text { Lean mass cut points for all criteria are for use } \\
\text { with ALM measured via dual energy x-ray }\end{array}$}} \\
\hline Grip Strength & $<20 \mathrm{~kg}$ & $\mathrm{~N} / \mathrm{A}$ & & \\
\hline & $A N D$ & & & \\
\hline Lean Mass: $A L M / h t^{2}$ & $<5.67 \mathrm{~kg} / \mathrm{m}^{2}$ & $\mathrm{~N} / \mathrm{A}$ & & \\
\hline
\end{tabular}

They also include $20^{\text {th }}$ percentile cut points for the residuals method. To be considered pre-sarcopenic one must score below one of the established lean mass cut points presented in their criteria. In order to be considered sarcopenic one must score below the cut point for ALM and gait speed $(<0.8 \mathrm{~m} / \mathrm{s})$, or grip strength $(<20 \mathrm{~kg})$. A severe sarcopenia classification would require one to score below the cut points for gait speed, grip strength, and ALM. Although they state that they have reached a consensus agreement on proper sarcopenia classification criteria, the EWGSOP includes various different methodologies of evaluating and quantifying lean mass, strength, and physical functioning. This does not appear to be true consensus criteria, rather a list of multiple suggested methodologies and cut points that can used to screen for sarcopenia. Nonetheless, the EWGSOP criteria are widely featured among the 
current literature (Bahat et al., 2016; Beaudart et al., 2014; Masanés et al., 2016; Patel et al., 2015; Wen, An, Chen, Lv, \& Fu, 2015).

In contrast, the IWG criteria use a "yes" or "no" sarcopenia classification. To receive a "yes" classification one must score below a SMI cut point of $5.67 \mathrm{~kg} / \mathrm{m}^{2}$ and below a gait speed cut point of $1.0 \mathrm{~m} / \mathrm{s}$. The IWG also suggests the use of a single chair stand as an indicator of overall strength. While the chair stand is not included in the "yes" or "no" classification criteria it may be more indicative of overall strength and the ability to complete activities of daily living than grip strength alone (Delmonico \& Beck, 2015; Fielding et al., 2011). There appears to be less variation in how to use the IWG criteria, as for women there is only one cut point for ALM and one cut point for gait speed. Interestingly, the SMI cut point of $5.67 \mathrm{~kg} / \mathrm{m}^{2}$ is the same cut point developed by Delmonico (2007) and Newman (2003) that represents the SMI of the lowest $20 \%$ of the Health $\mathrm{ABC}$ cohort.

The FNISHP criteria use a somewhat different method of stratifying sarcopenia classification. Those criteria use "weak with low lean mass" and "weak and slow with low lean mass" to classify sarcopenia. Those criteria also utilize a different variable to quantify lean mass: ALM divided by body mass index (BMI). This measure was developed by Cawthon et al. (2014) who through classification and regression tree analysis of ALM data and grip strength data from 14 studies, developed lean mass cut points that were highly related to accompanying weakness in women (OR: 2.2, 95\% CI: 1.8-2.8). This departure from the SMI method of quantifying lean mass underscores the need to at least account for body mass, if not fat mass in cut point development. It remains to be seen if this method will aid in the 
detection of sarcopenic obesity by including a measure of overall body mass. A "weak with low lean mass" diagnosis requires a woman to score below cut points for both grip strength $(<16 \mathrm{~kg})$ and ALM/BMI $(<0.512)$, while a "weak and slow with low lean mass" diagnosis would also require meeting the aforementioned cut points and having a gait speed score of $<0.8 \mathrm{~m} / \mathrm{s}$. Of note, the FNIHSP criteria include a more conservative grip strength cut point $(<16 \mathrm{~kg})$ than the EWGSOP criteria $(<20 \mathrm{~kg})$, yet both sets of criteria agree on the $<0.8 \mathrm{~m} / \mathrm{s}$ gait speed cut point.

Through these three sets of criteria it is evident that the aforementioned working groups aimed to create comprehensive screening criteria to identify physical function limitations in older adults, rather than separate sarcopenia and dynapenia classifications. This has been argued to be beneficial for clinical assessment as ALM alone has not been validated as a clinical measure (Cruz-Jentoft et al., 2010). Due to the variation in cut-points and ALM quantification methods there is no clear consensus as to which criteria should be used among different clinical and research populations. Furthermore, some of the current criteria utilize ALM cut points that were developed using referent populations from the Rosetta study and the Health $\mathrm{ABC}$ study. While these cut-points are methodologically sound they may not be representative of all populations, indicating the need for future research to determine appropriate lean mass cut points for different populations. To that end, the use of any set of current criteria requires anthropometric, body composition, and physical functioning data at the very least. It is currently unclear which criteria are most appropriate for different populations. If clinical goals are early detection and prevention then the EWGSOP criteria may be ideal, as it includes a "pre-sarcopenia" 
stage, and that criteria has been shown to classify greater percentages of populations as sarcopenic than IWG or FNIHSP criteria (Dam et al., 2014). However the FNIHSP criteria has been shown to classify a greater percentage of obese participants as "weak with low lean mass" than other criteria, suggesting the adjustment of ALM by BMI may be an ideal method of classifying sarcopenia in overweight and obese populations (Dam et al., 2014). Without clear consensus, the classification criteria used may depend on the population being assessed. Researchers and clinicians seeking early detection of sarcopenia should use the EWGSOP criteria in populations with healthy BMIs, and apply FNIHSP criteria in overweight and/or obese populations. This variation in sarcopenia classification depending on the criteria used and the BMI of participants indicates the need for population specific classification criteria to effectively identify this condition.

\section{Treatment for Sarcopenia}

There are several treatment approaches available for sarcopenia. Treatments should focus around methods of maintaining or improving lean mass, physical functioning, and strength levels. The most common treatment methods include hormonal therapies, diet and supplementation approaches, physical activity, and RT.

\section{Hormonal Treatments}

Hormonal treatments for sarcopenia have been researched in males and females (Borst et al., 2014; Rossouw et al., 2002). The two most common therapies are testosterone and estrogen for males and females respectively. While some research indicates potential side effects, the market for testosterone replacement therapy is flourishing and it should be considered as a viable treatment option for older 
men with sarcopenia. The most common hormonal replacement therapy (HRT) for older women is estrogen and/or estradiol replacement therapy. While the research regarding HRT is encouraging, it remains inconclusive. Indeed some studies have reported negative side effects of HRT in women and that some women discontinued prescriptions due to side effects (Bjorn \& Backsrom, 1999; Manson et al., 2003). However, other studies have shown considerably beneficial effects of HRT in women including increases in lean body mass and reduction of risk for coronary heart disease (Grodstein, Manson, \& Stampfer, 2006; Sorensen et al., 2001). Overall, HRT in women presents a potentially viable treatment method for sarcopenia in women, but more research is needed to determine potential side effects and the impacts they may have on older women.

\section{Diet and Supplementation}

Currently there is encouraging evidence regarding dietary protein intake as well as supplementation for lean mass maintenance in older men and women (Katsanos et al., 2008; Paddon-Jones \& Leidy, 2014). Several studies have suggested that daily intakes of 1.0-1.6 grams of protein per kilogram of body mass is necessary for maintenance of muscle mass in older adults (Bauer et al., 2013; Lancha Jr, Zanella Jr, Tanabe, Andriamihaja, \& Blachier, 2016). However, some literature suggests that high dietary protein intake may lead to potential colon health issues and high protein diets may also be contraindicated in those with renal disease and Parkinson's disease (Fracasso, Morais, Gomez, Hilbig, \& Rabito, 2013; Russell et al., 2011; Zeller, Whittaker, Sullivan, Raskin, \& Jacobson, 1991). Supplementation research also 
presents a promising avenue for treatment of sarcopenia and is commonly paired with resistance training to assess the effects of supplements alone and combined with RT. Studies that have examined the effects of creatine supplementation and protein supplementation, with and without RT have shown that when combined, supplementation and RT provide significant increases in lean mass, strength, and physical function in samples of older women (Francis et al., 2016; Gualano et al., 2014). However, Francis et al. (2016) did not measure or control for dietary protein intake and it is unclear if higher dietary protein intake may have affected those results. Additionally, Gualano et al. (2014) conducted their study in older women with osteopenia and osteoporosis. While that was an older population, it is unclear if those benefits could be observed in women with sarcopenia. Therefore, dietary and supplementation approaches may treat sarcopenia and attenuate some of the decline in lean mass, more research is needed to assess potential side effects and ideal dosage strategies for older women with sarcopenia.

\section{Physical Activity}

Physical activity, often defined as aerobic exercise, has been shown to be excellent for overall health and wellbeing as well as preventing and treating other chronic diseases (Bonaiuti et al., 2002; Hirose, Hamajima, Takezaki, Miura, \& Tajima, 2003; Thompson et al., 2003). Physical activity has also been shown to have positive effects on balance and reduction of fall risk in older adults (Buchner et al., 1997; Gregg, Pereira, \& Caspersen, 2000). Despite those positive health benefits, evidence has shown that physical activity alone has little effect on muscular strength 
or mass. Some studies have found older adults to increase both strength and lean mass following aerobic exercise (Harber et al., 2009; Konopka et al., 2010). However those studies had very small sample sizes and the aerobic training groups were not compared to other methods of training. Additionally, those studies were not conducted in a sarcopenic population, and therefore have very limited applicability. Furthermore, in a longitudinal study with five years of follow up, Marcell et al. (2014) found that 35 active, older women who participated in regular endurance exercise experienced significant decreases in strength, while maintaining baseline levels of lean mass. Those results indicate that regular endurance exercise may help attenuate the loss of lean mass, yet do not prevent the age related loss of strength, which is included in sarcopenia classification criteria and associated with functional limitations.

Additionally, a study by Mason et al. (2013) examined the effects of diet, exercise, and diet and exercise combined on sarcopenia in 439 overweight and obese post-menopausal women over a 12-month study duration. The exercise group completed moderate to vigorous aerobic exercise five days per week for 45 minutes per session, and consisted of a combination of home and clinic based exercise. The diet intervention group set a weight loss goal of $10 \%$ of the baseline weight. Sarcopenia was classified using the SMI method developed by Baumgartner (1998) and cut points utilized by IWG criteria. However there was no measurement of gait speed, which is a component of IWG criteria. Post-intervention the exercise group experienced a small yet significant $0.4 \%$ increase in SMI $(\mathrm{p}=0.004)$ compared to the control group. In contrast, the diet group experienced a significant $(\mathrm{p}=0.01) 3.2 \%$ decrease in SMI, while the diet and exercise combined group did not significantly 
change their SMI. That study indicates that regular aerobic exercise can attenuate the loss of lean mass with or without a weight loss intervention. However those results are limited by the lack of physical function assessment, and thus the effects of that intervention are inconclusive, as incomplete data prevented pre and post intervention sarcopenia classification by current criteria. Therefore, while beneficial for overall health, and potential lean mass maintenance, physical activity (aerobic exercise) does not appear to be a viable method of increasing muscle mass or strength; and altering sarcopenia classification.

\section{Resistance Training}

Resistance training (RT) is structured, voluntary movements performed while under an external load or resistance (Cholewa et al., 2014). Resistance training can be conducted through a variety of modalities including free weights (Schick et al., 2010), selectorized equipment (Fleck \& Kraemer, 2014), pneumatic resistance (Frost, Bronson, Cronin, \& Newton, 2016), and elastic band resistance (Delshad, Ghanbarian, Mehrabi, Sarvghadi, \& Ebrahim, 2013; Kwak, Kim, \& Lee, 2016). The positive effects of RT on strength, lean mass, physical functioning, and gait speed have been documented in male and female populations of various ages (American College of Sports Medicine, 2009; Fiatarone et al., 1994; Kraemer et al., 2004; Newton et al., 2002). Therefore, due to its established benefits, RT merits further investigation as a potential treatment for sarcopenia.

Examining the effects of RT in older adults was a meta-analysis by Peterson et al. (2010). That analysis used 47 studies with a total of 1079 male and female subjects 
aged 50-92 years. The average study duration in that analysis was 17.6 weeks and subjects trained from one to three times per week. The intensity of training as well as volume (sets and repetitions) of exercises varied between studies, although most included measures of maximal leg press and/or chest press strength in their results. Those researchers found upper and lower body strength measured by chest and leg press to increase by $24 \%$ and $29 \%$ respectively. However, those results are from combined pool estimates of strength, and the studies included had large variation in training program design and participants. Nonetheless, those results indicate that both upper and lower body strength are responsive to RT in older adults.

A further meta-analysis by Peterson \& Gordon (2011) included 49 studies and 1,328 male and female participants with a mean age of 65.5 years. Study duration ranged from 10 to 52 weeks and resistance-training programs included communitybased programs, in home programs, and individual personal training programs. A weighted pooled estimate found a mean lean mass increase of $1.1 \mathrm{~kg}$ over a mean study duration of 20.5 weeks. Those results are encouraging and demonstrate the ability of older adults to experience muscular hypertrophy with RT. However, the variation in programming style and study duration may limit the applicability of these results and limit use in intervention design. Nonetheless, that study indicates that despite large variations in program design and training duration, older adults can experience increases in lean mass with RT. However information regarding ideal RT program design to increase lean mass in older adults is needed to apply these findings in a clinical setting. 
Although results from Peterson \& Gordon (2011) indicate significant increases in lean mass following 20.5 weeks of training, other research has found similar results in shorter durations. Delmonico et al. (2005) implemented a 10-week RT program in a cohort of 62 previously inactive older men and women. Participants trained three days per week and completed five sets of unilateral knee extensions on the dominant leg. This allowed for the non-dominant leg to act as a control. Those researchers found that following 10 weeks of RT significant increases in muscle volume were seen in men $\left(165 \mathrm{~cm}^{3}\right)$ and women $\left(93 \mathrm{~cm}^{3}\right)$ when compared to baseline measures $(p<0.001)$. Those data suggest that it is possible for older adults to experience significant increases in muscle volume following 10 weeks of regular RT. While those results are positive unilateral training of only one movement on one leg may limit the applicability of that study. Indeed structured RT programs typically include multiple exercises, often bilateral, to target the entire body (American College of Sports Medicine, 2009).

Gait speed is also responsive to resistance training. A study conducted by Fiatarone et al. (1994) included 90 older men and women aged $87 \pm 0.6$ years who were randomized into four groups: exercise, exercise and supplement, supplement placebo, and control. The exercise group completed movements that trained the hip and knee extensors three days per week for 10 weeks. The exercise group experienced a significant $8.6 \%(\mathrm{p}=0.009)$ increase in gait speed when compared to the inactive groups. Also of note, both the exercise and exercise plus supplement groups experienced significant increases in hip and knee strength $(\mathrm{p}<0.001)$. That study, while conducted in older adults, took place in 1994 prior to the development of current 
sarcopenia classification criteria. Therefore it is unclear if the participants were sarcopenic or had symptoms of sarcopenia (low gait speed, low strength, low ALM). However it is evident that RT can positively influence gait speed in older adults.

Also supporting the use of resistance training to improve gait speed was a recent study by Santos et al. (2017), who delivered an 8-week RT intervention to 23 healthy older women aged 69.6 \pm 6.4 years. Participants trained three days per week following a program designed to meet ACSM recommendations for muscle hypertrophy and strength. Following the training program participants' gait speed improved by $3.67 \%(\mathrm{p}=0.03)$. Those results indicate that $\mathrm{RT}$ can result in significant improvements in gait speed time in older women. However that study used a 10-meter fast walking speed test, which may not be indicative of normal gait speed in older adults. Additionally, although the women included in that study were older and inactive, they were not evaluated for sarcopenia and it is unknown if similar results can be observed in older sarcopenic women.

Recent research has also compared the effects of aerobic and resistance training on strength in 93 older men and women. Participants aged $65-75$ years, with sarcopenic obesity were randomized to four groups: aerobic training, resistance training, combined aerobic and resistance training, and a control group. Training groups trained two times per week for eight weeks and underwent post-intervention testing, and follow-up testing four weeks post intervention. Results indicated that the RT group experienced significant gains in grip strength $(3.5 \mathrm{~kg}, \mathrm{p}<0.05)$ that were maintained four weeks post intervention compared to all other groups (Chen, Chung, Chen, Ho, \& Wu, 2017). Those results indicate that one-day of RT per week will not 
produce significant gains in grip strength, and that greater frequencies of RT are needed to increase grip strength. Moreover, that study further demonstrated the shortcomings of aerobic exercise at treating symptoms of sarcopenia. Additionally, although the participants in that study were assessed for sarcopenia at baseline there was no discussion regarding change in sarcopenia status post intervention.

Nonetheless, grip strength is included in current sarcopenia classification criteria, and that study demonstrated that RT is the most effective method of increasing grip strength in that population compared to other exercise modalities.

Further demonstrating the efficacy of RT as a treatment for sarcopenia was a recent study by Stoever et al. (2015). Those researchers investigated the effects of RT on 18 obese, older men with sarcopenia and 15 obese, older men without sarcopenia. Sarcopenia was classified using the SMI method and participants completed a RT program two days per week for 16 weeks. Following the program the participants with sarcopenia had increased their grip strength by $12 \%$ and the non-sarcopenic participants maintained their baseline levels of strength. That study indicates that RT is effective at attenuating the age related loss of grip strength in non-sarcopenic men and improving grip strength in men with sarcopenia. Similar effects were seen in women in a study by Rhodes et al. (2000), who found 20 older women to increase grip strength by $8 \%$ following one year of RT. However, that study was conducted in women without sarcopenia and it is unclear if those results can be duplicated in older women with sarcopenia. 
While many RT studies vary in frequency, the most common frequency is three days per week. Farinatti et al. (2013) investigated the effects of different frequencies of RT on measures of strength and functional performance in 48 women over the age of 60. Participants were randomized to a control group or one of three training groups that trained one, two, or three days per week. Participants then completed a 16-week, single set RT program. Post intervention all three training groups experienced significant increases in strength compared to baseline measures and the control group. However, the training group that met three days per week experienced the greatest increase in overall gait speed, which was significantly greater than the other two training groups and the control group. The training group that met three days per week also experienced significant decreases in chair sit and stand time when compared to the group that trained 1 day per week. That study indicates that in older, untrained women lower frequency RT may provide enough of a stimulus to see initial increases in strength, but in order to see the greatest improvements in functional performance older women should train three days per week. Of particular interest is the vast improvements in the gait speed times for the three day per week training group (-11.6\%) compared to the two day per week training group (-5.1\%).

Considering that gait speed is a component of current sarcopenia classification criteria and an important functional measure, future RT interventions should seek to program training three days per week in order to realize the greatest improvements in gait speed. Furthermore, that study incorporated a single set RT program, which has been shown to be inferior to multiple set RT programs for strength improvements (W. K. Kemmler, Lauber, Engelke, \& Weineck, 2004). Therefore, in order for older 
women to experience maximum improvements in strength and functional performance they should partake in a multiple set RT program three days per week.

\section{Periodized Resistance Training}

The aforementioned studies demonstrate the efficacy of RT in treating symptoms of sarcopenia and utilized what is considered conventional RT. Conventional RT is commonly programmed using the progressive overload principle, which involves gradually increasing training workload (Hass, Feigenbaum, \& Franklin, 2001). Conventional RT programs, especially those in older individuals are typically structured using baseline strength measures, and progressively increase the intensity of the movements for the duration of intervention (Farinatti et al., 2013; Ferri

et al., 2003; Krist, Dimeo, \& Keil, 2013). In programs of that style, the number of sets and repetitions is often held constant (fixed volume), and the only variations in the training program are increases in intensity when appropriate (Pollock, Graves, Swart, \& Lowenthal, 1994). Other variations of conventional RT include programs where participants only complete one set of prescribed exercises per training session (single set) (Wolfe, LeMura, \& Cole, 2004). These types of design limit the ability of the participants to obtain maximum benefits from a RT program, as different intensities and repetition ranges can be used to target muscular strength, hypertrophy, endurance, and power (Haff \& Triplett, 2015).

A different method of designing RT programs is periodization. Periodized resistance training (PRT) programs use pre-planned variations of acute training program variables. The program variables that are modified are exercise selection, 
exercise order, intensity, volume, and rest periods (Bartolomei, Stout, Fukuda, Hoffman, \& Merni, 2015; Haff \& Triplett, 2015). There are many different methods of designing PRT programs and few studies incorporate identical training programs, which limits the comparison of results within the literature. While conventional RT can certainly be beneficial for many populations, multiple studies have demonstrated the benefits of PRT over conventional RT (Fleck, 1999; Rhea \& Alderman, 2004).

A meta-analysis by Rhea and Alderman (2004) compared the effects of conventional RT and PRT on strength and power outcomes. Those researchers conducted two separate analyses using the effect sizes of available research and found PRT to have a significantly greater effect size $(E S=0.84)$ for both strength and power outcomes when compared with conventional RT. Those researchers also found that when studies were equated for volume intensity that PRT still elicited greater training responses than conventional PRT.

Periodized resistance training can be broken down into linear and non-linear periodization. Linear PRT programs are oft characterized by progressive decreases in training volume (sets and repetitions) and increases in intensity (load or weight lifted) between cycles (Conlon et al., 2016). The most common form of linear periodization is block periodization, which was first introduced in the 1970s by Verkhoshansky, who designed programs for track and field athletes (Yessis, 1982). Block periodization is commonly programmed using four-week training segments, called mesocycles. Each mesocycle targets a single training outcome variable or adaptation (i.e., muscular hypertrophy, strength, or power). Athletes seeking peak performance 
for individual competitions or competitive seasons often use linear/block PRT programs (Turner, 2011).

In a study by Botero et al. (2013), 23 post-menopausal women followed a linear PRT program two days per week for 12 months. Participants were inactive prior to study inclusion and followed a traditional linear model of periodization: progressive increases in intensity, and decreases in volume. Following intervention participants displayed significant increases in bench press $(30.82 \%, \mathrm{p}<0.05)$ and leg press $(100.9 \%, \mathrm{p}<0.05)$. Participants also displayed significant increases in lean mass $(1.59 \%, \mathrm{p}=0.009)$. That study supports the use of PRT; especially linear PRT due to the significant increases in strength and lean mass experienced by the participants. However, that study did not include secondary test groups investigating other forms of $\mathrm{RT}$ in comparison to the PRT program or a control group. Additionally, due to the linear program design, participants had completed a strength cycle of training just prior to post-intervention testing, which may have influenced the final results. Furthermore, that study claimed that long-term PRT prevents sarcopenia, which is a bold claim, however there is no indication that these researchers assessed sarcopenia by any criteria. While that study produced positive results, it suggests further research is needed investigating forms of PRT in post-menopausal women who have been screened for sarcopenia. Additionally, linear PRT programs, while beneficial for individuals of all sexes and ages, may not be ideal for those who are not training for a specific event or season, but rather seeking to improve and maintain strength, lean mass, and physical functioning, like older adults (Kraemer et al., 2004; Miranda et al., 2011). 
Non-linear periodization still incorporates modifications of program variables similar to linear/block PRT programs, however non-linear PRT can be programmed so that participants train for separate outcomes (hypertrophy, strength, or endurance) on a daily or weekly basis, rather than a bi-weekly or monthly basis. This may be beneficial for those seeking a well-rounded training program that allows for continuous training of multiple outcomes. While there are not any set rules or guidelines one must follow to design non-linear PRT programs, a common method is weekly or daily undulations. The undulations signify modifications to program variables (exercise selection, order, intensity, volume, and rest periods). Individuals following weekly undulating PRT (WUP) programs will commonly train for a specific adaptation (i.e. strength) for one week, then train for a different adaptation (i.e. hypertrophy) the following week. Daily undulating PRT (DUP) programs simply incorporate modifications of training variables and targeted adaptation on a daily basis. These undulations are designed to provide periods of low intensity training, which allow adaptations to occur, decrease the risk of overtraining, and maintain interest in the program (Komi, 1986; Rhea \& Alderman, 2004).

Indeed, research shows that consistently high training intensities contribute to increased inflammatory markers and symptoms of delayed onset muscle soreness (Hasenoehrl et al., 2016; Nosaka, Newton, \& Sacco, 2002). Additionally, in a joint consensus statement, the European College of Sport Science and the American College of Sports Medicine suggested that adjusting daily training intensities and volumes and/or allowing rest days is vital to preventing overtraining (Meeusen et al., 2013). Those organizations also recommended avoiding monotonous training 
programs and that one of the best methods of preventing overtraining syndrome is appropriately periodizing training programs and allowing adequate time for rest and recovery (Meeusen et al., 2006). Therefore a DUP program would provide the variations required to prevent excessive soreness, overtraining, and boredom, all of which may promote adherence to a training program.

There is much debate within the literature regarding ideal RT program design for different populations, and researchers have compared linear PRT and non-linear PRT programs. A recent meta-analysis by Harries et al. (2015) compared the effects of linear and undulating PRT on strength measures. That analysis of 17 studies including 510 participants found no significant differences between linear or undulating programs on strength. However that study acknowledged that many of the studies in the meta-analysis included participants that were previously trained and that the short duration of the included studies may have confounded the results. Furthermore, no study included in that analysis included participants over the age 65 , with participants' ages ranging from 19-39 years. Due to the potential confounding variables and relatively young study populations, those results may not be applicable to older, untrained adults with functional limitations.

Conversely, a study by Bartolomei et al. (2015) randomized 17 trained women aged $24.7 \pm 4.2$ years to either a block periodization group or a WUP group. Both programs were equated for volume and both groups trained three days per week for 10 weeks. Post training, results indicated that both groups significantly increased strength, but the WUP group experienced significantly greater improvements in lower body strength $(\mathrm{p}=0.039)$ when compared to the block-periodized group. Furthermore, 
the WUP group experienced significant increases in thigh cross sectional area $(\mathrm{p}=0.001)$ when compared to the block-periodized group. Those results indicate that a WUP program may be superior to block periodization for improving strength and lean mass in women. However, that study included young, trained women and results may have limited applicability in older adults, especially those with sarcopenia.

Nonetheless, those results suggest that non-linear PRT is superior to linear PRT for strength and mass gains in women.

There have also been comparisons between linear PRT and non-linear DUP programs. One study compared those two program designs in 20 college-aged men over the course of 12 weeks. Both groups trained three days per week and both programs were equated for volume. Following training, both groups significantly increased their strength from baseline values. However the DUP group experienced a $28.8 \%$ increase in bench press strength, and a $55.8 \%$ increase in leg press strength from baseline values. Those increases were significantly greater than the linear PRT group, which experienced a $14.4 \%$ increase in bench press strength, and a $25.7 \%$ increase in leg press strength (Rhea, Ball, Phillips, \& Burkett, 2002).

Similar results were observed by Prestes et al. (2009), who compared 12 weeks of linear PRT and DUP in 40 trained, college-aged men. Participants trained four times per week, and following 12 weeks both groups significantly increased bench press and leg press strength, however the DUP group displayed significantly higher increases than the linear PRT group for both bench press $(\mathrm{p}=0.002)$ and leg press $(\mathrm{p}=0.001)$. However the studies by both Rhea et al. (2002) and Prestes et al. (2009) included college-aged men, and despite the potential benefits of DUP in older women, 
a search of the literature indicated that the effects of DUP have not been investigated in postmenopausal women with sarcopenia.

Although the available research regarding RT and PRT in women demonstrates the clear potential for increases in strength, mass, and physical function, no research is available regarding PRT, particularly DUP in women with sarcopenia. Due to the potential for greater increases in strength and other performance measures, as well as the potential for greater program adherence, DUP appears to have the potential to be an effective method of treating sarcopenia in older women, yet remains uninvestigated. Reasons for this lack of research are unclear and the feasibility of administering a DUP intervention to older women with sarcopenia remains to be seen. To date no study has investigated the effects of DUP on women with sarcopenia and it is unclear if this type of training would provide sufficient gains in lean mass, strength, and/or physical functioning to alter sarcopenia classification based on current criteria.

\section{Conclusion}

Based on the current literature, sarcopenia presents a growing public health issue with the potential to negatively affect the physical functioning and overall health levels of older adults, especially women. Due to lack of consensus among classification criteria, researchers may benefit from using the three most prominent sets of current criteria to classify sarcopenia as it would allow for greater overall assessment of sarcopenia and more direct comparison of results from other studies. Considering the lack of side effects and clearly established benefits on sarcopenia classification measures, RT appears to be the most valid method of treating sarcopenia 
in older adults. Furthermore, research suggests that DUP provides greater increases in performance when compared to conventional RT and has not been researched in older women with sarcopenia. It is unclear if a DUP intervention would provide necessary increases in performance measures to alter sarcopenia classification by current criteria. Therefore, future research should seek to investigate the effects of DUP on sarcopenia classification in older postmenopausal women with sarcopenia. 


\section{References}

Administration on Aging. (2014). Projected future growth of the older population. Retrieved from http://www.aoa.acl.gov/aging statistics/future growth/future growth.aspx\#age

Al Snih, S., Markides, K. S., Ottenbacher, K. J., \& Raji, M. A. (2004). Hand grip strength and incident ADL disability in elderly mexican americans over a sevenyear period. Aging Clin Exp Res, 16(6), 481-486.

Alchin, D. R. (2014). Sarcopenia: Describing rather than defining a condition. Journal of Cachexia, Sarcopenia and Muscle, 5(4), 265-268. doi:10.1007/s13539-0140156-8

American College of Sports Medicine. (2009). American college of sports medicine position stand. progression models in resistance training for healthy adults. Medicine and Science in Sports and Exercise, 41(3), 687-708. doi:10.1249/MSS.0b013e3181915670

American College of Sports Medicine, Chodzko-Zajko, W. J., Proctor, D. N., Fiatarone Singh, M. A., Minson, C. T., Nigg, C. R., Skinner, J. S. (2009). American college of sports medicine position stand. exercise and physical activity for older adults. Medicine and Science in Sports and Exercise, 41(7), 1510-1530. doi:10.1249/MSS.0b013e3181a0c95c

Anton, S. D., Hida, A., Mankowski, R., Layne, A., Solberg, L., Mainous, A. G., \& Buford, T. W. (2016). Nutrition and exercise in sarcopenia. Current Protein \& Peptide Science, doi:CPPS-EPUB-80609

Bahat, G., Tufan, A., Tufan, F., Kilic, C., Akpinar, T. S., Kose, M., Cruz-Jentoft, A. J. (2016). Cut-off points to identify sarcopenia according to european working group on sarcopenia in older people (EWGSOP) definition. Clinical Nutrition (Edinburgh, Scotland), doi:S0261-5614(16)00058-3

Barford, A., Dorling, D., Davey Smith, G., \& Shaw, M. (2006). Life expectancy: Women now on top everywhere. BMJ, 332

Bartolomei, S., Stout, J. R., Fukuda, D. H., Hoffman, J. R., \& Merni, F. (2015). Block vs. weekly undulating periodized resistance training programs in women. Journal of Strength and Conditioning Research / National Strength \& Conditioning Association, 29(10), 2679-2687. doi:10.1519/JSC.0000000000000948

Batsis, J. A., Mackenzie, T. A., Barre, L. K., Lopez-Jimenez, F., \& Bartels, S. J. (2014). Sarcopenia, sarcopenic obesity and mortality in older adults: Results from the national health and nutrition examination survey III. European Journal of Clinical Nutrition, 68(9), 1001-1007. doi:10.1038/ejcn.2014.117 
Bauer, J., Biolo, G., Cederholm, T., Cesari, M., Cruz-Jentoft, A. J., Morley, J. E., Teta, D. (2013). Evidence-based recommendations for optimal dietary protein intake in older people: A position paper from the PROT-AGE study group. Journal of the American Medical Directors Association, 14(8), 542-559.

Baumgartner, R. N., Koehler, K. M., Gallagher, D., Romero, L., Heymsfield, S. B., Ross, R. R., Lindeman, R. D. (1998). Epidemiology of sarcopenia among the elderly in new mexico. American Journal of Epidemiology, 147(8), 755-763.

Baumgartner, R. N., Waters, D. L., Gallagher, D., Morley, J. E., \& Garry, P. J. (1999). Predictors of skeletal muscle mass in elderly men and women. Mechanisms of Ageing and Development, 107(2), 123-136. doi:S0047-6374(98)00130-4

Beaudart, C., Reginster, J. Y., Slomian, J., Buckinx, F., Locquet, M., \& Bruyere, O. (2014). Prevalence of sarcopenia: The impact of different diagnostic cut-off limits. Journal of Musculoskeletal \& Neuronal Interactions, 14(4), 425-431.

Bendayan, R., Cooper, R., Wloch, E. G., Hofer, S. M., Piccinin, A. M., \& MunizTerrera, G. (2016). Hierarchy and speed of loss in physical functioning: A comparison across older U.S. and english men and women. The Journals of Gerontology.Series A, Biological Sciences and Medical Sciences, doi:glw209 [pii]

Bjorn, I., \& Backsrom, T. (1999). Drug related negative side-effects is a common reason for poor compliance in hormone replacement therapy. Maturitas, 32(2), 77-86. doi:S0378512299000183

Bonaiuti, D., Shea, B., Iovine, R., Negrini, S., Welch, V., Kemper, H. H., Cranney, A. (2002). Exercise for preventing and treating osteoporosis in postmenopausal women. The Cochrane Library,

Borst, S. E. (2004). Interventions for sarcopenia and muscle weakness in older people. Age and Ageing, 33(6), 548-555. doi:10.1093/ageing/afh201

Borst, S. E., Yarrow, J. F., Conover, C. F., Nseyo, U., Meuleman, J. R., Lipinska, J. A., Shuster, J. J. (2014). Musculoskeletal and prostate effects of combined testosterone and finasteride administration in older hypogonadal men: A randomized, controlled trial. American Journal of Physiology.Endocrinology and Metabolism, 306(4), E433-42. doi:10.1152/ajpendo.00592.2013

Botero, J. P., Shiguemoto, G. E., Prestes, J., Marin, C. T., Do Prado, W. L., Pontes, C. S., Perez, S. E. (2013). Effects of long-term periodized resistance training on body composition, leptin, resistin and muscle strength in elderly post-menopausal women. The Journal of Sports Medicine and Physical Fitness, 53(3), 289-294. doi:R40Y2013N03A0289 
Brown, M. (2008). Skeletal muscle and bone: Effect of sex steroids and aging. Advances in Physiology Education, 32(2), 120-126.

doi:10.1152/advan.90111.2008

Buchner, D. M., Cress, M. E., de Lateur, B. J., Esselman, P. C., Margherita, A. J., Price, R., \& Wagner, E. H. (1997). The effect of strength and endurance training on gait, balance, fall risk, and health services use in community-living older adults. The Journals of Gerontology.Series A, Biological Sciences and Medical Sciences, 52(4), M218-24.

Burger, H. G., Hale, G. E., Robertson, D. M., \& Dennerstein, L. (2007). A review of hormonal changes during the menopausal transition: Focus on findings from the melbourne women's midlife health project. Human Reproduction Update, 13(6), 559-565. doi:dmm020

Carrière, I., Colvez, A., Favier, F., Jeandel, C., Blain, H., \& EPIDOS study group. (2005). Hierarchical components of physical frailty predicted incidence of dependency in a cohort of elderly women. Journal of Clinical Epidemiology, 58(11), 1180-1187.

Cawthon, P. M., Fox, K. M., Gandra, S. R., Delmonico, M. J., Chiou, C. F., Anthony, M. S., Health, Aging and Body Composition Study. (2011). Clustering of strength, physical function, muscle, and adiposity characteristics and risk of disability in older adults. Journal of the American Geriatrics Society, 59(5), 781787. doi:10.1111/j.1532-5415.2011.03389

Cawthon, P. M., Peters, K. W., Shardell, M. D., McLean, R. R., Dam, T. T., Kenny, A. M., Alley, D. E. (2014). Cutpoints for low appendicular lean mass that identify older adults with clinically significant weakness. The Journals of Gerontology.Series A, Biological Sciences and Medical Sciences, 69(5), 567-575. doi:10.1093/gerona/glu023

Chad, K. E., Reeder, B. A., Harrison, E. L., Ashworth, N. L., Sheppard, S. M., Schultz, S. L., Lawson, J. A. (2005). Profile of physical activity levels in community-dwelling older adults. Medicine and Science in Sports and Exercise, 37(10), 1774-1784. doi:00005768-200510000-00019

Chang, S. F., \& Lin, P. L. (2016). Systematic literature review and meta-analysis of the association of sarcopenia with mortality. Worldviews on Evidence-Based Nursing / Sigma Theta Tau International, Honor Society of Nursing, doi:10.1111/wvn.12147

Chen, H., Chung, Y., Chen, Y., Ho, S., \& Wu, H. (2017). Effects of different types of exercise on body composition, muscle strength, and IGF-1 in the elderly with sarcopenic obesity. Journal of the American Geriatrics Society. 
Chen, L., Liu, L., Woo, J., Assantachai, P., Auyeung, T., Bahyah, K. S., Krairit, O. (2014). Sarcopenia in asia: Consensus report of the asian working group for sarcopenia. Journal of the American Medical Directors Association, 15(2), 95101.

Cherin, P., Voronska, E., Fraoucene, N., \& de Jaeger, C. (2014). Prevalence of sarcopenia among healthy ambulatory subjects: The sarcopenia begins from 45 years. Aging Clinical and Experimental Research, 26(2), 137-146. doi:10.1007/s40520-013-0132-8

Choi, K. M. (2013). Sarcopenia and sarcopenic obesity. Endocrinology and Metabolism (Seoul, Korea), 28(2), 86-89. doi:10.3803/EnM.2013.28.2.86

Cholewa, J., Guimaraes-Ferreira, L., da Silva Teixeira, T., Naimo, M. A., Zhi, X., de Sa, R. B., Zanchi, N. E. (2014). Basic models modeling resistance training: An update for basic scientists interested in study skeletal muscle hypertrophy. Journal of Cellular Physiology, 229(9), 1148-1156. doi:10.1002/jcp.24542

Clark, B. C., \& Manini, T. M. (2008). Sarcopenia =/= dynapenia. The Journals of Gerontology.Series A, Biological Sciences and Medical Sciences, 63(8), 829-834. doi:63/8/829

Clark, B. C., \& Manini, T. M. (2012). What is dynapenia? Nutrition (Burbank, Los Angeles County, Calif.), 28(5), 495-503. doi:10.1016/j.nut.2011.12.002

Conlon, J. A., Newton, R. U., Tufano, J. J., Banyard, H. G., Hopper, A. J., Ridge, A. J., \& Haff, G. G. (2016). Periodization strategies in older adults: Impact on physical function and health. Medicine and Science in Sports and Exercise, 48(12), 2426-2436. doi:10.1249/MSS.0000000000001053

Cruz-Jentoft, A. J., Baeyens, J. P., Bauer, J. M., Boirie, Y., Cederholm, T., Landi, F., European Working Group on Sarcopenia in Older People. (2010). Sarcopenia: European consensus on definition and diagnosis: Report of the european working group on sarcopenia in older people. Age and Ageing, 39(4), 412-423. doi:10.1093/ageing/afq034

Cruz-Jentoft, A. J., Landi, F., Schneider, S. M., Zuniga, C., Arai, H., Boirie, Y., Cederholm, T. (2014). Prevalence of and interventions for sarcopenia in ageing adults: A systematic review. report of the international sarcopenia initiative (EWGSOP and IWGS). Age and Ageing, 43(6), 748-759. doi:10.1093/ageing/afu115

Dam, T. T., Peters, K. W., Fragala, M., Cawthon, P. M., Harris, T. B., McLean, R., Studenski, S. (2014). An evidence-based comparison of operational criteria for the presence of sarcopenia. The Journals of Gerontology.Series A, Biological Sciences and Medical Sciences, 69(5), 584-590. doi:10.1093/gerona/glu013 
Delmonico, M. J., Harris, T. B., Lee, J., Visser, M., Nevitt, M., Kritchevsky, S. B., Newman, A. B. (2007). Alternative definitions of sarcopenia, lower extremity performance, and functional impairment with aging in older men and women. Journal of the American Geriatrics Society, 55(5), 769-774.

Delmonico, M. J., Kostek, M. C., Doldo, N. A., Hand, B. D., Bailey, J. A., RabonStith, K. M., Hurley, B. F. (2005). Effects of moderate-velocity strength training on peak muscle power and movement velocity: Do women respond differently than men? Journal of Applied Physiology (Bethesda, Md.: 1985), 99(5), 17121718. doi:01204.2004

Delmonico, M. J., \& Beck, D. T. (2015). The current understanding of sarcopenia: Emerging tools and interventional possibilities. American Journal of Lifestyle Medicine, doi:10.1177/1559827615594343

Delshad, M., Ghanbarian, A., Mehrabi, Y., Sarvghadi, F., \& Ebrahim, K. (2013). Effect of strength training and short-term detraining on muscle mass in women aged over 50 years old. International Journal of Preventive Medicine, 4(12), 1386-1394.

Diz, J. B., Leopoldino, A. A., Moreira, B. S., Henschke, N., Dias, R. C., Pereira, L. S., \& Oliveira, V. C. (2016). Prevalence of sarcopenia in older brazilians: A systematic review and meta-analysis. Geriatrics \& Gerontology International, doi:10.1111/ggi.12720

Douchi, T., Yamamoto, S., Nakamura, S., Ijuin, T., Oki, T., Maruta, K., \& Nagata, Y. (1998). The effect of menopause on regional and total body lean mass. Maturitas, 29(3), 247-252. doi:S0378512298000358

Erol, A. M., Ceceli, E., Uysal Ramadan, S., \& Borman, P. (2016). Effect of rheumatoid arthritis on strength, dexterity, coordination and functional status of the hand: The relationship with magnetic resonance imaging findings. [Effect of rheumatoid arthritis on strength, dexterity, coordination and functional status of the hand: the relationship with magnetic resonance imaging findings] Acta Reumatologica Portuguesa, doi:AO140260

Evans, W. J., Boccardi, V., \& Paolisso, G. (2013). Perspective: Dietary protein needs of elderly people: Protein supplementation as an effective strategy to counteract sarcopenia. Journal of the American Medical Directors Association, 14(1), 67-69. doi:10.1016/j.jamda.2012.09.025

Farinatti, P. T., Geraldes, A. A., Bottaro, M. F., Lima, M. V., Albuquerque, R. B., \& Fleck, S. J. (2013). Effects of different resistance training frequencies on the muscle strength and functional performance of active women older than 60 years. Journal of Strength and Conditioning Research / National Strength \& Conditioning Association, 27(8), 2225-2234. doi:10.1519/JSC.0b013e318278f0db 
Ferri, A., Scaglioni, G., Pousson, M., Capodaglio, P., Van Hoecke, J., \& Narici, M. (2003). Strength and power changes of the human plantar flexors and knee extensors in response to resistance training in old age. Acta Physiologica Scandinavica, 177(1), 69-78.

Fiatarone, M. A., O'Neill, E. F., Ryan, N. D., Clements, K. M., Solares, G. R., Nelson, M. E., Evans, W. J. (1994). Exercise training and nutritional supplementation for physical frailty in very elderly people. The New England Journal of Medicine, 330(25), 1769-1775. doi:10.1056/NEJM199406233302501

Fielding, R. A., Vellas, B., Evans, W. J., Bhasin, S., Morley, J. E., Newman, A. B., Zamboni, M. (2011). Sarcopenia: An undiagnosed condition in older adults. current consensus definition: Prevalence, etiology, and consequences. international working group on sarcopenia. Journal of the American Medical Directors Association, 12(4), 249-256. doi:10.1016/j.jamda.2011.01.003

Fleck, S. J. (1999). Periodized strength training: A critical review. The Journal of Strength \& Conditioning Research, 13(1), 82-89.

Fleck, S. J., \& Kraemer, W. (2014). Designing resistance training programs, 4E Human Kinetics.

Foster-Burns, S. B. (1999). Sarcopenia and decreased muscle strength in the elderly woman: Resistance training as a safe and effective intervention. Journal of Women \& Aging, 11(4), 75-85. doi:10.1300/J074v11n04_06

Fracasso, B. d. M., Morais, M. B., Gomez, R., Hilbig, A., \& Rabito, E. I. (2013). Protein intake and the use of levodopa in patients with parkinson's disease. Revista Chilena De Nutrición.Santiago, Chile.Vol.40, N.2 (Jun.2013), P.102-106,

Francis, P., Mc Cormack, W., Toomey, C., Norton, C., Saunders, J., Kerin, E., Jakeman, P. (2016). Twelve weeks' progressive resistance training combined with protein supplementation beyond habitual intakes increases upper leg lean tissue mass, muscle strength and extended gait speed in healthy older women.

Biogerontology, doi:10.1007/s10522-016-9671-7

Fritz, S., \& Lusardi, M. (2009). White paper: "Walking speed: The sixth vital sign". Journal of Geriatric Physical Therapy (2001), 32(2), 46-49.

Frost, D. M., Bronson, S., Cronin, J. B., \& Newton, R. U. (2016). Changes in maximal strength, velocity, and power after 8 weeks of training with pneumatic or free weight resistance. Journal of Strength and Conditioning Research, 30(4), 934944. doi:10.1519/JSC.0000000000001179

Gallagher, D., Visser, M., De Meersman, R. E., Sepulveda, D., Baumgartner, R. N., Pierson, R. N., Heymsfield, S. B. (1997). Appendicular skeletal muscle mass: 
Effects of age, gender, and ethnicity. Journal of Applied Physiology (Bethesda, Md.: 1985), 83(1), 229-239.

Gregg, E. W., Pereira, M. A., \& Caspersen, C. J. (2000). Physical activity, falls, and fractures among older adults: A review of the epidemiologic evidence. Journal of the American Geriatrics Society, 48(8), 883-893.

Grodstein, F., Manson, J. E., \& Stampfer, M. J. (2006). Hormone therapy and coronary heart disease: The role of time since menopause and age at hormone initiation. Journal of Women's Health (2002), 15(1), 35-44. doi:10.1089/jwh.2006.15.35

Gualano, B., Macedo, A. R., Alves, C. R. R., Roschel, H., Benatti, F. B., Takayama, L., Pereira, R. M. R. (2014). Creatine supplementation and resistance training in vulnerable older women: A randomized double-blind placebo-controlled clinical trial. Experimental Gerontology, 53, 7-15.

Haff, G. G., \& Triplett, N. T. (2015). Essentials of strength training and conditioning 4th edition Human Kinetics.

Harber, M. P., Konopka, A. R., Douglass, M. D., Minchev, K., Kaminsky, L. A., Trappe, T. A., \& Trappe, S. (2009). Aerobic exercise training improves whole muscle and single myofiber size and function in older women. American Journal of Physiology.Regulatory, Integrative and Comparative Physiology, 297(5), R1452-9. doi:10.1152/ajpregu.00354.2009

Harries, S. K., Lubans, D. R., \& Callister, R. (2015). Systematic review and metaanalysis of linear and undulating periodized resistance training programs on muscular strength. Journal of Strength and Conditioning Research, 29(4), 11131125. doi:10.1519/JSC.0000000000000712

Hasenoehrl, T., Wessner, B., Tschan, H., Vidotto, C., Crevenna, R., \& Csapo, R. (2016). Eccentric resistance training intensity may affect the severity of exercise induced muscle damage. The Journal of Sports Medicine and Physical Fitness, doi:R40Y9999N00A16051106

Hass, C. J., Feigenbaum, M. S., \& Franklin, B. A. (2001). Prescription of resistance training for healthy populations. Sports Medicine, 31(14), 953-964.

Hirose, K., Hamajima, N., Takezaki, T., Miura, S., \& Tajima, K. (2003). Physical exercise reduces risk of breast cancer in japanese women. Cancer Science, 94(2), 193-199.

Janssen, I., Shepard, D. S., Katzmarzyk, P. T., \& Roubenoff, R. (2004). The healthcare costs of sarcopenia in the united states. Journal of the American Geriatrics Society, 52(1), 80-85. doi:52014 
Karakelides, H., \& Nair, K. S. (2005). Sarcopenia of aging and its metabolic impact. Current Topics in Developmental Biology, 68, 123-148. doi:S00702153(05)68005-2

Katsanos, C. S., Chinkes, D. L., Paddon-Jones, D., Zhang, X. J., Aarsland, A., \& Wolfe, R. R. (2008). Whey protein ingestion in elderly persons results in greater muscle protein accrual than ingestion of its constituent essential amino acid content. Nutrition Research (New York, N.Y.), 28(10), 651-658. doi:10.1016/j.nutres.2008.06.007

Kemmler, W., Teschler, M., Goisser, S., Bebenek, M., von Stengel, S., Bollheimer, L. C., Freiberger, E. (2015). Prevalence of sarcopenia in germany and the corresponding effect of osteoarthritis in females 70 years and older living in the community: Results of the FORMoSA study. Clinical Interventions in Aging, 10, 1565-1573. doi:10.2147/CIA.S89585

Kemmler, W. K., Lauber, D., Engelke, K., \& Weineck, J. (2004). Effects of single- vs. multiple-set resistance training on maximum strength and body composition in trained postmenopausal women. Journal of Strength and Conditioning Research, 18(4), 689-694. doi:R-16164

Kim, H. K., Suzuki, T., Saito, K., Yoshida, H., Kobayashi, H., Kato, H., \& Katayama, M. (2012). Effects of exercise and amino acid supplementation on body composition and physical function in community-dwelling elderly japanese sarcopenic women: A randomized controlled trial. Journal of the American Geriatrics Society, 60(1), 16-23. doi:10.1111/j.1532-5415.2011.03776

Komi, P. (1986). Training of muscle strength and power: Interaction of neuromotoric, hypertrophic, and mechanical factors. International Journal of Sports Medicine, 7(S 1), S10-S15.

Konopka, A. R., Douglass, M. D., Kaminsky, L. A., Jemiolo, B., Trappe, T. A., Trappe, S., \& Harber, M. P. (2010). Molecular adaptations to aerobic exercise training in skeletal muscle of older women. The Journals of Gerontology.Series A, Biological Sciences and Medical Sciences, 65(11), 1201-1207. doi:10.1093/gerona/glq109 [doi]

Kostek, M. C., \& Delmonico, M. J. (2011). Age-related changes in adult muscle morphology. Current Aging Science, 4(3), 221-233. doi:BSP/CAS/E-Pub/000039 [pii]

Kraemer, W. J., Hakkinen, K., Triplett-McBride, N. T., Fry, A. C., Koziris, L. P., Ratamess, N. A., Newton, R. U. (2003). Physiological changes with periodized resistance training in women tennis players. Medicine and Science in Sports and Exercise, 35(1), 157-168. 
Kraemer, W. J., Nindl, B. C., Ratamess, N. A., Gotshalk, L. A., Volek, J. S., Fleck, S. J., Hakkinen, K. (2004). Changes in muscle hypertrophy in women with periodized resistance training. Medicine and Science in Sports and Exercise, 36(4), 697-708. doi:00005768-200404000-00019

Krist, L., Dimeo, F., \& Keil, T. (2013). Can progressive resistance training twice a week improve mobility, muscle strength, and quality of life in very elderly nursing-home residents with impaired mobility? A pilot study. Clin Interv Aging, $8,443-448$.

Kwak, C. J., Kim, Y. L., \& Lee, S. M. (2016). Effects of elastic-band resistance exercise on balance, mobility and gait function, flexibility and fall efficacy in elderly people. Journal of Physical Therapy Science, 28(11), 3189-3196. doi:10.1589/jpts.28.3189

Lancha Jr, A. H., Zanella Jr, R., Tanabe, S. G. O., Andriamihaja, M., \& Blachier, F. (2016). Dietary protein supplementation in the elderly for limiting muscle mass loss. Amino Acids, , 1-15.

Lauretani, F., Russo, C. R., Bandinelli, S., Bartali, B., Cavazzini, C., Di Iorio, A., Ferrucci, L. (2003). Age-associated changes in skeletal muscles and their effect on mobility: An operational diagnosis of sarcopenia. Journal of Applied Physiology (Bethesda, Md.: 1985), 95(5), 1851-1860.

doi:10.1152/japplphysiol.00246.2003

Manson, J. E., Hsia, J., Johnson, K. C., Rossouw, J. E., Assaf, A. R., Lasser, N. L., Women's Health Initiative Investigators. (2003). Estrogen plus progestin and the risk of coronary heart disease. The New England Journal of Medicine, 349(6), 523-534. doi:10.1056/NEJMoa030808

Marcell, T. J., Hawkins, S. A., \& Wiswell, R. A. (2014). Leg strength declines with advancing age despite habitual endurance exercise in active older adults. Journal of Strength and Conditioning Research / National Strength \& Conditioning Association, 28(2), 504-513. doi:10.1519/JSC.0b013e3182a952cc

Masanés, F., Rojano, i. L., Salvà, A., Serra-Rexach, J., Artaza, I., Formiga, F., CruzJentoft, A. (2016). Cut-off points for muscle mass — not grip strength or gait speed - determine variations in sarcopenia prevalence. The Journal of Nutrition, Health \& Aging, , 1-5. doi:10.1007/s12603-016-0844-5

Mason, C., Xiao, L., Imayama, I., Duggan, C. R., Foster-Schubert, K. E., Kong, A., McTiernan, A. (2013). Influence of diet, exercise, and serum vitamin d on sarcopenia in postmenopausal women. Medicine and Science in Sports and Exercise, 45(4), 607-614. doi:10.1249/MSS.0b013e31827aa3fa 
Meeusen, R., Duclos, M., Gleeson, M., Rietjens, G., Steinacker, J., \& Urhausen, A. (2006). Prevention, diagnosis and treatment of the overtraining syndrome: ECSS position statement 'task force'. European Journal of Sport Science, 6(01), 1-14.

Meeusen, R., Duclos, M., Foster, C., Fry, A., Gleeson, M., Nieman, D., American College of Sports Medicine. (2013). Prevention, diagnosis, and treatment of the overtraining syndrome: Joint consensus statement of the european college of sport science and the american college of sports medicine. Medicine and Science in Sports and Exercise, 45(1), 186-205. doi:10.1249/MSS.0b013e318279a10a

Middleton, A., Fritz, S. L., \& Lusardi, M. (2015). Walking speed: The functional vital sign. Journal of Aging and Physical Activity, 23(2), 314-322.

doi:10.1123/japa.2013-0236

Miranda, F., Simao, R., Rhea, M., Bunker, D., Prestes, J., Leite, R. D., Novaes, J. (2011). Effects of linear vs. daily undulatory periodized resistance training on maximal and submaximal strength gains. Journal of Strength and Conditioning Research, 25(7), 1824-1830. doi:10.1519/JSC.0b013e3181e 7ff75

Mitchell, W. K., Williams, J., Atherton, P., Larvin, M., Lund, J., \& Narici, M. (2015). Sarcopenia, dynapenia, and the impact of advancing age on human skeletal muscle size and strength; a quantitative review. Physiology and Pathophysiology of Musculoskeletal Aging, 3, 1-18.

Monteiro, A. G., Aoki, M. S., Evangelista, A. L., Alveno, D. A., Monteiro, G. A., Picarro Ida, C., \& Ugrinowitsch, C. (2009). Nonlinear periodization maximizes strength gains in split resistance training routines. Journal of Strength and Conditioning Research, 23(4), 1321-1326. doi:10.1519/JSC.0b013e3181a00f96

Newman, A. B., Kupelian, V., Visser, M., Simonsick, E., Goodpaster, B., Nevitt, M., Health ABC Study Investigators. (2003). Sarcopenia: Alternative definitions and associations with lower extremity function. Journal of the American Geriatrics Society, 51(11), 1602-1609. doi:51534

Newton, R. U., Hakkinen, K., Hakkinen, A., McCormick, M., Volek, J., \& Kraemer, W. J. (2002). Mixed-methods resistance training increases power and strength of young and older men. Medicine and Science in Sports and Exercise, 34(8), 13671375.

Nosaka, K., Newton, M., \& Sacco, P. (2002). Delayed-onset muscle soreness does not reflect the magnitude of eccentric exercise-induced muscle damage. Scandinavian Journal of Medicine \& Science in Sports, 12(6), 337-346.

O'bryant, H. S., Byrd, R., \& Stone, M. H. (1988). Cycle ergometer performance and maximum leg and hip strength adaptations to two different methods of weighttraining. The Journal of Strength \& Conditioning Research, 2(2), 27-30. 
Orsatti, F. L., Nunes, P. R., Souza, A. P., Martins, F. M., de Oliveira, A. A., Nomelini, R. S., Murta, E. F. (2016). Predicting functional capacity from measures of muscle mass in postmenopausal women. $P M \& R$ : The Journal of Injury, Function, and Rehabilitation, doi:S1934-1482(16)30988-1

Paddon-Jones, D., \& Leidy, H. (2014). Dietary protein and muscle in older persons. Current Opinion in Clinical Nutrition and Metabolic Care, 17(1), 5-11. doi:10.1097/MCO.0000000000000011

Paddon-Jones, D., Short, K. R., Campbell, W. W., Volpi, E., \& Wolfe, R. R. (2008). Role of dietary protein in the sarcopenia of aging. The American Journal of Clinical Nutrition, 87(5), 1562S-1566S. doi:87/5/1562S

Patel, H. P., White, M. C., Westbury, L., Syddall, H. E., Stephens, P. J., Clough, G. F., Sayer, A. A. (2015). Skeletal muscle morphology in sarcopenia defined using the EWGSOP criteria: Findings from the hertfordshire sarcopenia study (HSS). BMC Geriatrics, 15, 171-015-0171-4. doi:10.1186/s12877-015-0171-4

Peterson, M. D., \& Gordon, P. M. (2011). Resistance exercise for the aging adult: Clinical implications and prescription guidelines. The American Journal of Medicine, 124(3), 194-198. doi:10.1016/j.amjmed.2010.08.020

Peterson, M. D., Rhea, M. R., Sen, A., \& Gordon, P. M. (2010). Resistance exercise for muscular strength in older adults: A meta-analysis. Ageing Research Reviews, 9(3), 226-237. doi:10.1016/j.arr.2010.03.004

Pollock, M. L., Graves, J. E., Swart, D. L., \& Lowenthal, D. T. (1994). Exercise training and prescription for the elderly. Southern Medical Journal, 87(5), S8895.

Prestes, J., Frollini, A. B., de Lima, C., Donatto, F. F., Foschini, D., de Cassia Marqueti, R., Fleck, S. J. (2009). Comparison between linear and daily undulating periodized resistance training to increase strength. Journal of Strength and Conditioning Research, 23(9), 2437-2442. doi:10.1519/JSC.0b013e3181c03548

Rantanen, T., Guralnik, J. M., Foley, D., Masaki, K., Leveille, S., Curb, J. D., \& White, L. (1999). Midlife hand grip strength as a predictor of old age disability. $J A M A, 281(6)$, 558-560. doi:jbr80447

Reed, R. L., Pearlmutter, L., Yochum, K., Meredith, K. E., \& Mooradian, A. D. (1991). The relationship between muscle mass and muscle strength in the elderly. Journal of the American Geriatrics Society, 39(6), 555-561.

Rhea, M. R., \& Alderman, B. L. (2004). A meta-analysis of periodized versus nonperiodized strength and power training programs. Research Quarterly for Exercise and Sport, 75(4), 413-422. 
Rhea, M. R., Ball, S. D., Phillips, W. T., \& Burkett, L. N. (2002). A comparison of linear and daily undulating periodized programs with equated volume and intensity for strength. Journal of Strength and Conditioning Research / National Strength \& Conditioning Association, 16(2), 250-255.

Rhodes, E. C., Martin, A. D., Taunton, J. E., Donnelly, M., Warren, J., \& Elliot, J. (2000). Effects of one year of resistance training on the relation between muscular strength and bone density in elderly women. British Journal of Sports Medicine, $34(1), 18-22$.

Rosenberg, I. H. (1989). Summary comments. The American Journal of Clinical Nutrition, 50(5), 1231-1233.

Rossouw, J. E., Anderson, G. L., Prentice, R. L., LaCroix, A. Z., Kooperberg, C., Stefanick, M. L., Writing Group for the Women's Health Initiative Investigators. (2002). Risks and benefits of estrogen plus progestin in healthy postmenopausal women: Principal results from the women's health initiative randomized controlled trial. Jama, 288(3), 321-333. doi:joc21036

Russell, W. R., Gratz, S. W., Duncan, S. H., Holtrop, G., Ince, J., Scobbie, L., Flint, H. J. (2011). High-protein, reduced-carbohydrate weight-loss diets promote metabolite profiles likely to be detrimental to colonic health. The American Journal of Clinical Nutrition, 93(5), 1062-1072. doi:10.3945/ajcn.110.002188

Santos, L., Ribeiro, A. S., Schoenfeld, B. J., Nascimento, M. A., Tomeleri, C. M., Souza, M. F., Cyrino, E. S. (2017). The improvement in walking speed induced by resistance training is associated with increased muscular strength but not skeletal muscle mass in older women. European Journal of Sport Science, , 1-7. doi:10.1080/17461391.2016.1273394

Schick, E. E., Coburn, J. W., Brown, L. E., Judelson, D. A., Khamoui, A. V., Tran, T. T., \& Uribe, B. P. (2010). A comparison of muscle activation between a smith machine and free weight bench press. Journal of Strength and Conditioning Research, 24(3), 779-784. doi:10.1519/JSC.0b013e3181cc2237

Solerte, S. B., Gazzaruso, C., Bonacasa, R., Rondanelli, M., Zamboni, M., Basso, C., Fioravanti, M. (2008). Nutritional supplements with oral amino acid mixtures increases whole-body lean mass and insulin sensitivity in elderly subjects with sarcopenia. The American Journal of Cardiology, 101(11A), 69E-77E. doi:10.1016/j.amjcard.2008.03.004

Sorensen, M. B., Rosenfalck, A. M., Hojgaard, L., \& Ottesen, B. (2001). Obesity and sarcopenia after menopause are reversed by sex hormone replacement therapy. Obesity Research, 9(10), 622-626. doi:10.1038/oby.2001.81 
Stewart, V., Saunders, D., \& Greig, C. (2014). Responsiveness of muscle size and strength to physical training in very elderly people: A systematic review. Scandinavian Journal of Medicine \& Science in Sports, 24(1), e1-e10.

Stoever, K., Heber, A., Eichberg, S., Zijlstra, W., \& Brixius, K. (2015). Changes of body composition, muscular strength and physical performance due to resistance training in older persons with sarcopenic obesity. The Journal of Frailty \& Aging, 4(4), 216-222. doi:10.14283/jfa.2015.67

Studenski, S., Perera, S., Patel, K., Rosano, C., Faulkner, K., Inzitari, M., Guralnik, J. (2011). Gait speed and survival in older adults. Jama, 305(1), 50-58. doi:10.1001/jama.2010.1923

Studenski, S. A., Peters, K. W., Alley, D. E., Cawthon, P. M., McLean, R. R., Harris, T. B., Vassileva, M. T. (2014). The FNIH sarcopenia project: Rationale, study description, conference recommendations, and final estimates. The Journals of Gerontology.Series A, Biological Sciences and Medical Sciences, 69(5), 547-558. doi:10.1093/gerona/glu010

Thompson, P. D., Buchner, D., Piña, I. L., Balady, G. J., Williams, M. A., Marcus, B. H., Franklin, B. (2003). Exercise and physical activity in the prevention and treatment of atherosclerotic cardiovascular disease. Arteriosclerosis, Thrombosis, and Vascular Biology, 23(8), e42-e49.

Tichet, J., Vol, S., Goxe, D., Salle, A., Berrut, G., \& Ritz, P. (2008). Prevalence of sarcopenia in the french senior population. The Journal of Nutrition, Health \& Aging, 12(3), 202-206.

Turner, A. (2011). The science and practice of periodization: A brief review. Strength \& Conditioning Journal, 33(1), 34-46.

Visser, M., Goodpaster, B. H., Kritchevsky, S. B., Newman, A. B., Nevitt, M., Rubin, S. M., Harris, T. B. (2005). Muscle mass, muscle strength, and muscle fat infiltration as predictors of incident mobility limitations in well-functioning older persons. The Journals of Gerontology. Series A, Biological Sciences and Medical Sciences, 60(3), 324-333. doi:60/3/324

Wen, X., An, P., Chen, W. C., Lv, Y., \& Fu, Q. (2015). Comparisons of sarcopenia prevalence based on different diagnostic criteria in chinese older adults. The Journal of Nutrition, Health \& Aging, 19(3), 342-347. doi:10.1007/s12603-0140561

Wolfe, B. L., LeMura, L. M., \& Cole, P. J. (2004). Quantitative analysis of single- vs. multiple-set programs in resistance training. Journal of Strength and Conditioning Research, 18(1), 35-47. doi:R-12002 
Yang, M., Ding, X., Luo, L., Hao, Q., \& Dong, B. (2014). Disability associated with obesity, dynapenia and dynapenic-obesity in chinese older adults. Journal of the American Medical Directors Association, 15(2), 150.e11-150.e16. doi:10.1016/j.jamda.2013.10.009

Yessis, M. (1982). Trends in soviet strength and conditioning: The role of all-round, general physical preparation in the multiyear and yearly training programs. Strength \& Conditioning Journal, 4(5), 48-50.

Zeller, K., Whittaker, E., Sullivan, L., Raskin, P., \& Jacobson, H. R. (1991). Effect of restricting dietary protein on the progression of renal failure in patients with insulin-dependent diabetes mellitus. New England Journal of Medicine, 324(2), 78-84. 
Appendix B: Phone Screen Assessment

URI Resistance Exercise Study to Reclaim Lean Muscle and Strength (URI

RESTORE ME Project)

Data Sheet for Detailed Subject Telephone Interview

$\square$ Brief Explanation of Study

$\square$ Permission to Conduct Interview?

Yes No

Comment:

Name: Dr./Ms./Mrs.

Address:

Phone \#:

E-Mail:

Best Way and Time to Contact:

- Time Commitment - Available

Comment:

Yes __ No Wants to be contacted after

(Date)

- Proximity to URI

Length of commute:

Within reasonable commute miles or minutes commute

Too far to commute

- Age

Age: yrs

Date of Birth:

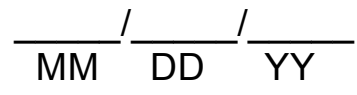

Approximate Height: Approximate Weight:

BMI:

- Race American Indian or Alaskan Native Asian or Pacific Islander Black, not of Hispanic origin Hispanic White, not of Hispanic origin Other/Unknown

- Highest level of education completed Less than high school High school or GED 
Some college

Two-year college degree (e.g. Associates)

Four-year college degree (e.g. B.S., B.A.)

Masters degree

Doctoral degree

Professional degree (e.g. M.D., J.D.)

Other (please specify)

- Have you attained menopause? Yes

No

If Yes, for how long?

- Smoking Smoker

Always Non-Smoker____ Non-Smoker for

- Physical Activity

Participates in regular (>1x/wk for past 3 months) exercise? No

If yes, describe in detail (e.g. frequency, intensity, duration, mode)

Describe other non-structured physical activity (e.g. leisure time, gardening, occupational, or other)

- Cardiovascular (heart, blood, or blood vessel) conditions?

No__ Yes (Record on Medical History/Treatment Form)

Comments:

- Respiratory Conditions?

No___ Yes (Record on Medical History/Treatment Form)

Comments:

$-$

$-$

- Osteoarthritis/Degenerative Arthritis

No _ Yes 
If yes, how long and what was the severity

- High Blood Pressure

No

Yes_ Controlled (Record High BP and Treatment on Medical

History/Treatment Form)

Yes__ Uncontrolled

Comments:

- Orthopedic conditions (knee, neck, or other back pain)

No

Yes

If yes, describe in detail including severity

- Diabetes

No

Yes - Type 2. If type 2, taking insulin now?

Yes - Type 1 (Insulin Dependent)

Comments:

$-$

- Any major surgeries as an adult?

No Yes

If yes, what type (e.g. surgeries of the joints, heart surgeries, angioplasty, bypass surgery, pacemakers, etc.) and date(s)

- Other Medical Conditions (especially those that would make exercise difficult or unsafe)

No

Yes (Record on Medical History/Treatment Form)

Comments: 
- Medication Info - See last page

No

Yes (Record on Medical History/Treatment Form)

Comments:

\section{- Personal Physician Info}

Name of Physician:

Specialty of Physician:

Phone

Number:

Fax Number:

Address (if phone and fax unknown):

\section{- Summary}

Interviewer Printed Name:

Interviewer Signature:

Questions/

Comments:

Reviewer Initials:

Appears to Qualify

Need

More Information

Needs Drs. Delmonico, Hatfield, Xu, or Lofgren to review

Not

Qualified

Questions/

Comments: 


\section{Appendix C: Consent Form for Research}

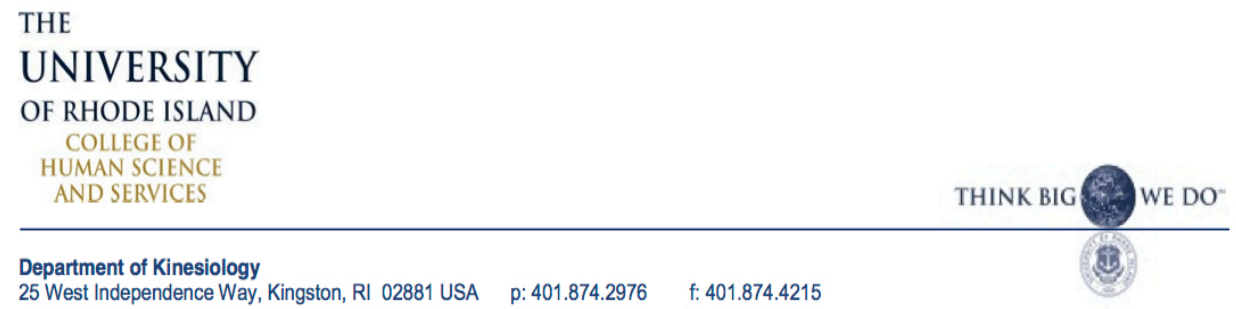

\section{CONSENT FORM FOR RESEARCH}

Title of Project: Effects of a Resistance Training Program in Older Women with Sarcopenia

You are invited to take part in a research project described below. The researchers will explain the project to you in detail. You should feel free to ask questions. If you have more questions later, Drs. Matthew Delmonico (Phone: 401-874-5440) and Ingrid Lofgren (401-8745706) from the Departments of Kinesiology and Nutrition and Food Sciences at the University of Rhode Island (URI), the persons mainly responsible for this study, will discuss them with you. The general eligibility criteria for inclusion to this study include having/being 1) a woman with low physical function and/or low lean mass, 2) age 65-84 years, 3) no recent medication changes, 4) post-menopausal, 5) the ability to speak and read English, 6) a body mass index of $18.5-45.0 \mathrm{~kg} / \mathrm{m}^{2}$ and 6 ) free of diseases or conditions that would prevent reasonably safe participation in an exercise program.

\section{Description of the project:}

You understand that the primary purpose of this study is to assess the role that a 12-week resistance exercise training program plays in improving muscle mass, physical functioning, and sarcopenia (the age-related loss of muscle mass) classification factors. Resistance training is has been shown to be effective for improving health outcomes in older women, including physical functioning but has not been tested in women who have been identified by new guidelines as having low muscle mass and physical functioning. Another purpose of the study will be to assess the influence resistance training on changes in bone density, blood pressure, muscle function, health indicators, blood lipids (fats) and sugar, fat and protein metabolism. Your participation time will vary depending on which group to which you are randomized and can range from 3-4 hours per week. All of the testing and intervention sessions will take place on the URI Kingston campus (Independence Square building, and you are responsible for your own transportation to all of the testing and intervention sessions).

What will be done:

You understand that if you choose to participate, the study potentially requires your involvement in five phases.

PHASE 1: During Phase 1, you will undergo a screening visit to determine if you meet the criteria for sarcopenia which include low muscle mass and either 1) slow normal walking speed or 2) low grip strength. The muscle mass test simply requires you to stand barefoot on a device with metal conducting pads while holding onto another set of conducting pads with

Initial Date Page 1 of 6
THE
IRB \# HU1415-168

RB Approval Date 06/24/2015

IRB Approval Expiration 06/17/2016 
your hands. This will tell us in less than one minute how much arm and leg muscle you have. This device uses a very low electrical current in order to estimate muscle and fat mass on your body. This test only takes about one minute to complete but is a valid and reliable measure of body composition with very few risks. The walking test simply requires you to walk four meters (about 15 feet) at your normal walking pace. The hand grip strength test only takes a couple of minutes and you will be asked to squeeze a device two times with both hands (separately) as hard as you can. Your height and weight will also be measured at this visit. If you meet the criteria that identify you as having sarcopenia, then you will be invited to take part in the project. If you do not meet these criteria, we will provide you with information about your muscle mass and physical functioning, along with information about how you can maintain or improve these health aspects on your own.

PHASE 2: If you are identified as having sarcopenia, then you will be invited to take part in the research trial. Preliminary testing (four visits of $\sim 1-1.5$ hours per visit) will be necessary. In addition to a repeat of some of the measures in Phase 1, your, waist and hip girths will be measured and you will be asked to complete some tasks to measure your ability to carry out normal daily activities at the Independence Square building. These tasks include a usual pace 400 meter $(\sim 1 / 4$ mile) walk, rising from a chair, standing balance tests, and short walks. Any risk of injury during the completion of these tasks will be minimized by having all sessions supervised by an exercise physiologist qualified to direct this type of testing. In addition, you will be asked to complete several health questionnaires. These include sleep quality, general health, food intake, a dietary screening tool, a balance survey, and physical activity habits.

You understand that your percent body fat and bone density will be performed using dual energy x-ray absorptiometry (DXA) located in room 129 of the Independence Square building. This will require you to lay on a table a wearing hospital scrubs for about 20 minutes for the entire procedure. A licensed radiology technician will perform the DXA scans. There is no cost to you or your insurance for these scans.

The flexibility of your leg muscles will be tested by using a simple test that requires you to attempt to touch your toes while seated. You also understand that strength assessments will be performed on machines or devices that measure how much force and how fast you can exert force through a typical range of leg, back, chest and knee extension motion. Leg strength testing will be performed by measuring the maximal amount of force that you can move through the full range of an exercise. You may experience some temporary muscle soreness as a result of the testing sessions. There is also a risk of muscle soreness or skeletal injury from strength and testing as well as from the exercise training. The investigators of this study will use procedures designed to minimize this risk.

A blood test will be done that will include two blood draws to analyze blood sugar, lipids (fats), and other blood proteins. You understand that there is a risk of bruising, pain, and in rare cases, infection or fainting as a result of blood sampling. However, these risks to you will be minimized by allowing only qualified people to draw your blood. Your blood pressure will also be assessed during this first phase.

Initial Date Page 2 of 6
THE

UNIVERSITY IRB \# HU1415-168

OF RHODE ISLAND IRB Approval Date 06/24/2015 DIVISION OF RESEARCH IRB Approval Expiration 06/17/2016 
At the end of the Phase 2 (testing), you will be randomly assigned (like a flip of a coin) to either a resistance training group or a general physical activity group for Phase 3 . You understand that you are not allowed to choose which group you will be assigned.

\section{PHASE 3: INTERVENTION}

\section{Resistance Training Sessions (Resistance Training Group)}

If you are randomized to the resistance training exercise group, you will also be asked to participate in three (3) supervised exercise sessions per week ( $\sim 5$ minutes per visit) for the 12 -week intervention in the Independence Square building, room 190. During each resistance training session you will be asked to exercise on machines or free weights that offer resistance against extending and flexing your arms, legs, and trunk region. All sessions will start with a resting blood pressure and a brief warm-up. The first several resistance training sessions will begin with lighter resistances to get you used to the resistance training program. The resistances will be gradually increased based on individual progress. The resistance will always be adjusted so that you are exercising at near maximal effort. You will be able to provide feedback using standardized pain and discomfort rating scales. Your overall progress will be monitored by an exercise specialist so that you are able to tolerate the exercise. Each session will end with a cool-down and a final blood pressure measurement. No special clothing is required, but you should dress in clothing that is comfortable and that allows you to move freely. You will also be instructed to stop exercising immediately if you experience chest pain, muscle injuries, or any other unexpected symptoms. Although you will always have supervision when doing exercise training during this study, if you ever experience chest pain while exercising at other times, you should immediately call 911 to seek emergency care and notify your primary care physician. If you have any problems or injuries, you should also notify a member of the study team. Study team members and their phone numbers are noted on the first page of this consent form.

\section{General Physical Activity Sessions (Active Control Group)}

If you are assigned to the active control group, you will also be asked to participate in three (3) supervised exercise sessions per week ( 45 minutes per visit) for the 12-week intervention in the Independence Square building, room 190. During each general physical activity session, you will engage in individual and group exercise sessions to increase your overall weekly physical activity. Activity sessions will vary but will include activities recommended by the American College of Sports Medicine for adults 65 years and older. Some of these activities may include walking, Tai Chi, light calisthenics, and stretching. All sessions will start with a resting blood pressure and a brief warm-up. The first several exercise sessions will begin with very light activities to get you used to the training program. The difficulty of the exercises will be gradually increased based on individual progress. You will be able to provide feedback using standardized pain and discomfort rating scales. Your overall progress will be monitored by an exercise specialist so that you are able to tolerate the exercise. Each session will end with a cool-down and a final blood pressure measurement. No special clothing is required, but you should dress in clothing that is comfortable and that allows you to move freely. You will also be instructed to stop exercising immediately if you experience chest pain, muscle injuries, or any other unexpected symptoms. Although you will always have supervision when doing

Initial Date Page 3 of 6 THE 
exercise training during this study, if you ever experience chest pain while exercising at other times, you should immediately call 911 to seek emergency care and notify your primary care physician. If you have any problems or injuries, you should also notify a member of the study team. Study team members and their phone numbers are noted on the first page of this consent form.

PHASE 4: Phase 4 will be a repeat of previously taken measures at the mid-point (week 6) and at the end (after week 12) of the 12-week exercise intervention.

PHASE 5: Phase 5 (the final phase) of the project will be six month follow-up testing session after Phase 4. You do not need to do any special activity or diet during this period.

\section{Risks or discomfort:}

You understand that it is possible that heart or blood vessel problems could arise during your participation in the testing or training involved in this study. Although highly unusual, it is possible that these problems could lead to a heart attack, stroke or even death. Therefore, prior evaluation and written clearance with a signature from your personal physician is strongly encouraged for you to participate in this study. You also understand that it is possible that these risks will not be eliminated completely, even with a medical evaluation prior to participation in the study. However, the investigators believe the risk of harm from study participation is relatively small and that the benefits of the study will likely outweigh any potential risks. Additionally, you understand that with the testing described above, resistance training and exercise in general there is a risk of muscle soreness or other muscle injury as well as skeletal injury. Because exercise in this study does require some degree of balance, there is also a risk of falling associated with exercise. However, the investigators will take precautions in order to reduce the likelihood that these adverse events will occur.

You understand that there will also be a very low total radiation dose for the DXA scans ( $\sim 39$ millirem), which is about one-fifth the radiation dose of a standard chest X-ray and is well below the maximal annual radiation dose (5 rems) allowed for exposure in the workplace. Naturally occurring radiation (cosmic radiation, radon gas, etc.) gives each person a whole body radiation dose of about 300 millirems per year. Therefore, the total dose of radiation exposure due to DXA is considered low. The major risk from high radiation exposure is passing on damaged genes (genetic mutations) to offspring. Therefore, this risk is of primarily a concern for those who are of childbearing age.

\section{In case there is any injury to the subject:}

In the event of physical injury resulting from participation in this study, upon your consent, emergency treatment will be available at South County Hospital with the understanding that any injury that required medical attention becomes your financial responsibility. You understand that URI will not provide any medical or hospitalization insurance coverage for participants in this research study, nor will they provide compensation for any injury sustained as a result of this research study, except as required by law.

You understand that if you are injured while participating in this research project as a result of negligence of all state employees who are involved in this research project, you may be able to be compensated for your injuries in accordance with the requirements of the Federal

Initial Date Page 4 of 6
THE

UNIVERSITY

OF RHODE ISLAND

DIVISION OF RESEARC DEVELOPMENT
IRB \# HU1415-168

IRB Approval Date 06/24/2015 IRB Approval Expiration 06/17/2016 
Tort Claims Act. If you are a federal employee acting within the scope of your employment, you may be entitled to benefits in accordance with the Federal Employees Compensation Act.

\section{Confidentiality:}

All information collected in this study is confidential, and your name will not be identified and linked to any electronic study data at any time to anyone other than the principal investigators of the study. Your data will be coded with an ID number only, which will be linked back to you only by the principal investigators of the study. Your part in this study is confidential within legal limits. The researchers and the University of Rhode Island will protect your privacy, unless they are required by law to report information to city, state or federal authorities, or to give information to a court of law. Otherwise, none of the information will identify you by name. All study data, including this consent form, will be locked in a file cabinet and also stored in a study computer with a password secured in our study office (Independence Square building, Suite P, room 119).

Benefits of this study:

You understand that this study is not designed to help you personally, but may help the investigators better understand which interventions are the most effective in helping women who have sarcopenia improve their muscle mass and physical function. However, because of what is already known regarding the effects of resistance training and exercise in general, it is likely that you will notice some benefits. These potential benefits include improved strength, mobility and blood pressure.

For your participation in the study and after the study is completed, you will receive, free of charge, information about your blood pressure, blood test results, body composition, muscle strength, and physical function.

\section{Decision to quit at any time:}

You understand that is your decision and your decision alone whether or not you consent to participate in this study. You are free to ask questions about this study before you decide whether or not to consent to participate in it. Also, if you consent to participate in the study you are free to withdraw from participation at any time without penalty or coercion, or without any requirement that you provide an explanation to anyone of your decision to withdraw. You or your insurance company will not be charged for the classes or training sessions.

\section{Rights and Complaints:}

If you are not satisfied with the way this study is performed, you may discuss your complaints with the principal investigators, Drs. Matthew Delmonico at (401) 874-5440, Disa Hatfield at (401) 874-5183, Ingrid Lofgren at (401) 874-5869, or Furong Xu (401) 874-2412 (anonymously, if you choose). In addition, if this study causes you any injury or if you have questions about your rights as a research subject you may contact the office of the Vice President for the Division of Research and Economic Development, Carlotti Administration Building, 2nd Floor, 75 Lower College Road, Suite 2, University of Rhode Island, Kingston, Rhode Island; telephone: (401) 874-4576.

Alternatives to study participation: If you choose not to participate in this study, you are encouraged to discuss with your physician about exercise strategies.

Initial Date Page 5 of 6
THE

UNIVERSITY

OF RHODE ISLAND

DIVISION OF RESEARCH AND ECONOMIC
DEVELOPMENT
IRB \# HU1415-168

IRB Approval Date 06/24/2015 IRB Approval Expiration 06/17/2016 
You have read and understand the above information in the Consent Form and have been given adequate opportunity to ask the investigators any questions you have about the study. Your questions, if any, have been answered by the investigators to your satisfaction. Your signature on this form means that you understand the information and you agree to voluntarily participate in this study.

Signature of Participant

Typed/printed Name

Date
Signature of Researcher

Typed/printed name

By signing again below you give permission for the investigators to store and use your blood samples for future research only related to the study objectives.

$\overline{\text { Signature of Participant }} \quad \overline{\text { Signature of Researcher }}$

Typed/printed Name

Typed/printed name

Date

Date

Please sign both consent forms, keeping one for you.

Initial Date Page 6 of 6
THE

UNIVERSITY IRB \# HU1415-168

OF RHODE ISLAND IRB Approval Date 06/24/2015

DIVISION OF RESEARCH IRB Approval Expiration 06/17/2016 


\section{Appendix D: Pre-participation Medical Clearance}

\author{
THE \\ UNIVERSITY \\ OF RHODE ISLAND \\ COLLEGE OF \\ HUMAN SCIENCE \\ AND SFRVICFS
}

\author{
Medical Clearance to Participate in \\ Exercise Research Project
}

THINK BIG WE DO

has volunteered to participate in an exercise study entitled "URI Resistance

Exercise Study to Reclaim Lean Muscle and Strength (URI RESTORE ME Project)" It is strongly recommended that volunteers have the clearance of her physician to participate in this study.

The aim of this study is to evaluate the impact of a 12-week resistance training exercise vs. a light physical activity program on muscle mass and physical functioning in older women aged 65-84 years who need improvements their muscle mass and physical functioning.

Exclusionary criteria for eligibility (Please check any that apply):

Significant or suspected cognitive impairment

Significant cardiovascular disease

Severe hearing loss, speech disorder, language barrier or visual impairment

Progressive, degenerative neurologic disease

Severe pulmonary/cardiovascular disease, uncontrolled diabetes, blood pressure, or anemia

Inability to safely engage in mild to moderate exercise with muscular exertion

Not within age range for study (65-84 years)

Medications not taken for $>3$ weeks, lipid lowering medications for $>6$ months

Major joint, vascular, abdominal, or thoracic surgery within six months

Although we are unaware of any cardiac complications that have resulted from resistance training, strength or physical functioning testing, there is only a limited amount of data available in older adults.

Please check one of the following:

Clearance granted

Clearance not granted

Please send me the following information about the study:

Volunteers will either participate (at the URI campus) in 1) a full-body 12-week resistance exercise training program or 2) a light physical activity (e.g. stretching, Tai Chi, walking, light calisthenics, etc.) group. Both groups will be under the supervision of exercise specialists trained specifically for this study under the direction of the Principal Investigators, Matthew J. Delmonico, PhD, MPH, Ph: (401) 874-5440, Disa Hatfield, PhD, Ph: (401) 874-5183; Furong Xu, PhD, Ph: (401) 874-2412 - Department of Kinesiology, University of Rhode Island; Ingrid E. Lofgren, PhD, MPH, RD, Department of Nutrition and Food Sciences, University of Rhode Island, Ph: (401) 874-5706

Physician's name:

Physician's signature:

Date 


\section{Appendix E: Medical History Questionnaire}

\section{Q. Physical fitNess ACTIVITY 2.2}

\section{Medical/Health Questionnaire}

According to the American College of Sports Medicine, a medical examination and clinical exercise test is recommended prior to (1) moderate or vigorous exercise training for those at high risk for disease, and (2) vigorous exercise training for moderaterisk individuals. The ACSM recommends that the pretest medical history be thorough and include 11 components: medical diagnoses, previous physical examination findings, history of symptoms, recent illness, hospitalization or surgical procedures, orthopedic problems, medication use and drug allergies, lifestyle habits, exercise history, work history, and family history of disease. The following medical and health questionnaire meets these criteria and can be used to gain a useful history on clients at fitness-testing facilities located in worksites, hospitals, and universities. In this activity, select a faculty member or member of the community that you feel would benefit from this process. Have the person answer the questions in the medical questionnaire, and then summarize important findings in the following blanks.

1. Symptoms or signs of disease:

2. Chronic disease risk factors:

3. Personal and family medical history:

4. Medications:

5. Summary of lifestyle habits: 


\section{Medical/Health Questionnaire}

\section{Personal Information}

\begin{tabular}{|c|c|c|c|c|c|c|c|c|}
\hline Coday's date. & & & & & & & & \\
\hline How old are you? & & yea & & & & & bex & \\
\hline Please circle tl & st gr & & scho & ol & & . & pplet & \\
\hline Elementary school & 1 & 2 & 3 & 4 & 5 & 6 & 7 & 8 \\
\hline High school & 9 & 10 & 11 & 12 & & & & \\
\hline College/Postgrad & 13 & 14 & 15 & 16 & 17 & 18 & 19 & $20+$ \\
\hline
\end{tabular}

What is your marital status? $\square$ Single; $\square$ Married; $\square$ Widowed; $\square$ Divorced/Separated Race or ethnic background:

$\begin{array}{lll}\square \text { White, not of Hispanic origin } & \square \text { American Indian/Alaskan native } & \square \text { Asian } \\ \square \text { Black, not of Hispanic origin } & \square \text { Pacific Islander } & \square \text { Hispanic }\end{array}$

What is your job or occupation? Check the one that applies to the greatest percentage of your time.

$\begin{array}{lll}\square \text { Health professional } & \square \text { Disabled, unable to work } & \square \text { Service } \\ \square \text { Manager, educator, professional } & \square \text { Operator, fabricator, laborer } & \square \text { Unemployed } \\ \square \text { Skilled crafts } & \square \text { Homemaker } & \square \text { Student } \\ \square \text { Technical, sales, support } & \square \text { Retired } & \square \text { Other }\end{array}$

Symptoms or Signs Suggestive of Disease

Place a check in the box if your answer is "yes."

1. Have you experienced unusual pain or discomfort in your chest, neck, jaw, arms, or other areas that may be due to heart problems?

$\square$ 2. Have you experienced unusual fatigue or shortness of breath at rest, during usual activities, or during mild-to-moderate exercise (e.g., climbing stairs carrying groceries, brisk walking, cycling)?

3. Have you had any problems with dizziness or fainting?

4. When you stand up, or sometimes during the right while you are sleeping, do you have difficulty breathing?

\section{Chronic Disease Risk Factors}

Place a check in the box if your answer is "yes."

$\square$ 9. Are you a male over age 45 years, or a female over age 55 years, or a female who has experienced premature menopause and is not on estrogen replacement therapy?

a 10. Has your father or brother had a heart attack or died suddenly of heart disease before age 55 years has your mother or sister experienced these heart problems before age 65 years?

D 11. Are you a current cigarette smoker?

口 12. Has a doctor told you that you have high blood pressure (more than $140 / 90 \mathrm{~mm} \mathrm{Hg}$ ), or are you on medication to control your blood pressure?

D 5. Do you suffer from swelling of the ankles (ankle edema)?

6. Have you experienced an unusual and rapid throbbing or fluttering of the heart?

$\square$ 7. Have you experienced severe pain in your leg muscles during walking?

a 8. Has a doctor told you that you have a heart murmur?

$\square$ 14. Do you have diabetes mellitus?

15. Are you physically inactive and sedentary (little physical activity on the job or during leisure time)?

$\square$ 16. During the past year, would you say that you experienced enough stress, strain, and pressure to have a significant effect on your health?

17. Do you eat foods nearly every day that are high in fat and cholesterol such as fatty meats, cheese, fried foods, butter, whole milk, or eggs?

$\square$ 18. Do you tend to avoid foods that are high in fiber such as whole-grain breads and cereals, fresh fruits, or vegetables?

19. Do you weigh 30 or more pounds more than you should?

13. Is your total serum cholesterol greater than $240 \mathrm{mg} / \mathrm{dl}$, or has a doctor told you that your cholesterol is at a high-risk level?

口 20. Do you average more than two alcoholic drinks each day? 


\section{Medical History}

21. Please check which of the following conditions you have had or now have. Also check medical conditions in your family (father, mother, brother $[\mathrm{s}]$, or sister[s]). Check as many as apply.

\begin{tabular}{|c|c|c|}
\hline Personal & Family & Medical Condition \\
\hline$\square$ & 口 & Coronary heart disease, heart attack, coronary artery surgery \\
\hline 0 & $\square$ & Angina \\
\hline$\square$ & $\square$ & High blood pressure \\
\hline$\square$ & $\square$ & Peripheral vascular disease \\
\hline$\square$ & $\square$ & Phlebitis or emboli \\
\hline ப & $\square$ & Other heart problems (specify: \\
\hline$\square$ & $\square$ & Lung cancer \\
\hline$\square$ & $\square$ & Breast cancer \\
\hline$\square$ & $\square$ & Prostate cancer \\
\hline$\square$ & $\square$ & Colorectal cancer (bowel cancer) \\
\hline$\square$ & $\square$ & Skin cancer \\
\hline$\square$ & $\square$ & Other cancer (specify: _ \\
\hline$\square$ & $\square$ & Stroke \\
\hline$\square$ & $\square$ & Chronic obstructive pulmonary disease (emphysema) \\
\hline$\square$ & $\square$ & Pneumonia \\
\hline 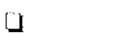 & $\square$ & Asthma \\
\hline$\square$ & $\square$ & Bronchitis \\
\hline ل & $\square$ & Diabetes mellitus \\
\hline$\square$ & $\square$ & Thyroid problems \\
\hline[ & $\square$ & Kidney disease \\
\hline 0 & $\square$ & Liver disease (cirrhosis of the liver) \\
\hline$\square$ & $\square$ & Hepatitis \\
\hline$\square$ & $\square$ & Gallstones/gallbladder disease \\
\hline$\square$ & $\square$ & Osteoporosis \\
\hline$\square$ & $\square$ & Arthritis \\
\hline$\square$ & $\square$ & Gout \\
\hline$\square$ & $\square$ & Anemia (low iron) \\
\hline$\square$ & $\square$ & Bone fracture \\
\hline 口 & $\square$ & Major injury to foot, leg, knee, hip, or shoulder \\
\hline$\square$ & $\square$ & Major injury to back or neck \\
\hline$\square$ & $\square$ & Stomach/duodenal ulcer \\
\hline$\square$ & $\square$ & Rectal growth or bleeding \\
\hline$\square$ & $\square$ & Cataracts \\
\hline$\square$ & $\square$ & Glaucoma \\
\hline$\square$ & $\square$ & Hearing loss \\
\hline$\square$ & $\square$ & Depression \\
\hline$\square$ & $\square$ & High anxiety, phobias \\
\hline ב & $\square$ & Substance abuse problems (alcohol, other drugs, etc.) \\
\hline$\square$ & $\square$ & Eating disorders (anorexia, bulimia) \\
\hline$\square$ & $\square$ & Problems with menstruation \\
\hline
\end{tabular}




\begin{tabular}{|c|c|c|}
\hline$\square$ & $\square$ & Hysterectomy \\
\hline 口 & ل & Sleeping problems \\
\hline$\square$ & $\square$ & Allergies \\
\hline Q & $\square$ & $\begin{array}{l}\text { Any other health problems (please specify, and include } \\
\text { information on any recent illnesses, hospitalizations, or } \\
\text { surgical procedures): }\end{array}$ \\
\hline
\end{tabular}

22. Please check any of the following medications you currently take regularly. Also give the name of the medication.

\section{Medication}

[] Heart medicine

ㄱood pressure medicine

- Blood cholesterol medicine

a Hormones

Birth control pills

घ Medicine for breathing/lungs

ป Insulin

$\square \quad$ Other medicine for diabetes

口 Arthritis medicine

$\checkmark$ Medicine for depression

a Medicine for anxiety

口 Thyroid medicine

- Medicine for ulcers

口 Painkiller medicine

Allergy medicine

$\square$ Other (please specify)

\section{Name of Medication}

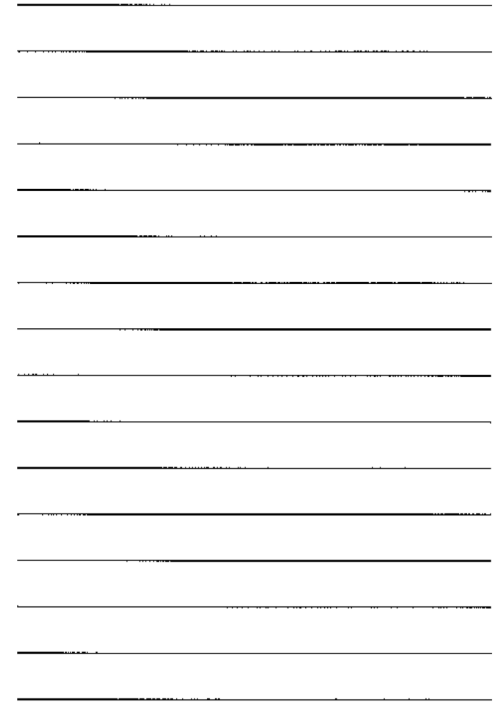

Physical Fitness, Physical Activity/Exercise

23. In general, compared to other persons your age, rate how physically fit you are:

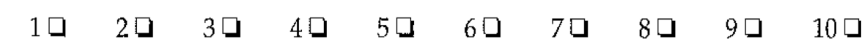

Not at all

physically fit

Somewhat

Extremely

physically fit

physically fit

24. Outside of your normal work or daily responsibilities, how often do you engage in exercise that at least moderately increases your breathing and heart rate and makes you sweat, for at least 20 minutes (such as brisk walking, cycling, swimming, jogging, aerobic dance, stair climbing, rowing, basketball, racquetball, vigorous yard work).

$\square 5$ or more times per week $\quad \square 3-4$ times per week $\quad \square 1-2$ times per week

$\square$ Less than 1 time per week $\square$ Seldom or never

25. How much hard physical work is required on your job?
$\square$ A great deal
$\square$ A moderate amount
$\square$ A little
$\square$ None

26. How long have you exercised or played sports regularly?
$\square$ I do not exercise regularly
$\square$ Less than 1 year
$\square 1-2$ years
$\square$ 2-5 years
$\square$ 5-10 years
$\square$ More than 10 years 
Diet

27. On average, how many servings of fruit do you eat per day? (One serving $=1$ medium apple, banana, orange, etc.; $1 \frac{12}{2}$ cup of chopped, cooked, or canned fruit; $3 / 4$ cup of fruit juice.)
$\square$ None
$\square 1$
$\square 2$
$\square 3$
$\square 4$ or more

28. On average, how many servings of vegetables do you eat per day? (One serving = $1 / 2$ cup cooked or chopped raw, 1 cup raw leafy, $3 / 4$ cup of vegetable juice.)
$\square$ None
口1-2
$\square 3$
$\square 4$
5 or more

29. On average, how many servings of bread, cereal, rice, or pasta do you eat per day? (One serving $=1$ slice of bread, 1 ounce of ready-to-eat cereal, $1 / 2$ cup of cooked cereal, rice, or pasta.)
$\square$ None
$\square$ 1-3
$\square 4-6$
$\square 7-9$
$\square 10$ or more

30. When you use grain and cereal products, do you emphasize:

$\square$ Whole grain, high fiber $\square$ Mixture of whole grain and refined $\square$ Refined, low fiber

31. On average, how many servings of red meat (not lean) do you eat per day? (One serving $=2-3$ ounces of steak, roast beef, lamb, pork chops, ham, burgers, etc.)
$\square$ None
$\square 1$
$\square 2$
$\square 3$
$\square 4$ or more

32. On average, how many servings of fish, poultry, lean meat, cooked dry beans, peanut butter, or nuts do you eat per day? (One serving $=2-3$ ounces of meat, $1 / 2$ cup of cooked dry beans, 2 tablespoons of peanut butter, or $1 / 3$ cup of nuts.)
$\square$ None
$\square 1$
$\square 2$
$\square 3$
$\square 4$ or more

33. On average, how many servings of dairy products do you eat per day? (One serving $=1$ cup of milk or yogurt, 1.5 ounces of natural cheese, 2 ounces of processed cheese.)
$\square$ None $\square 1$
$\square 2$
$\square 3$
$\square 4$ or more

34. When you use dairy products, do you emphasize
$\square$ Regular
$\square$ Low fat
$\square$ Nonfat

35. How would you characterize your intake of fats and oils (e.g., regular salad dressings, butter or margarine, mayonnaise, vegetable oils)?
$\square$ High
$\square$ Moderate
$\square$ Low

Body Weight

36. How tall are you (without shoes)? feet inches

37. How much do you weigh (minimal clothing and without shoes)? pounds

38. What is the most you have ever weighed? pounds

39. Are you now trying to

$\square$ Lose weight $\square$ Gain weight $\square$ Stay about the same $\square$ Not trying to do anything

\section{Psychological Health}

40. How have you been feeling in general during the past month?

In excellent spirits $\square$ In very good spirits

In good spirits mostly

$\square I^{\prime}$ ve been up and down in spirits a lot

$\square$ In low spirits mostly

$\square$ In very low spirits

41. During the past month, would you say that you experienced stress?

$\square$ A lot of $\square$ Moderate $\square$ Relatively little

$\square$ Almost no

42. In the past year, how much effect has stress had on your health?
$\square$ A lot
$\square$ Some
$\square$ Hardly any or none

43. On average, how many hours of sleep do you get in a 24-hour period?
$\square$ Less than 5
$\square$ 5-6.9
$\square 7-9$
$\square$ More than 9 


\section{Substance Use}

44. Have you smoked at least 100 cigarettes in your entire life?

$\square$ Yes

$\square$ No

45. How would you describe your cigarette smoking habits?

$\square$ Never smoked

$\square$ Used to smoke

How many years has it been since you smoked? years

\section{Still smoke}

How many cigarettes a day do you smoke on average? cigarettes/day

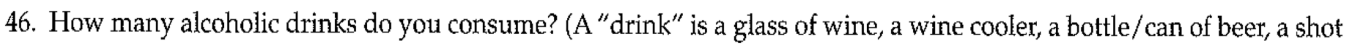
glass of liquor, or a mixed drink.)

$\square$ Never use alcohol $\quad \square$ Less than 1 per week

$\square 1-6$ per week

$\square 1$ per day

$\square$ 2-3 per day

$\square$ More than 3 per day

Occupational Health

47. Please describe your main job duties.

$+2$

48. After a day's work, do you often have pain or

All of

Most of

the time

Some of

Rarely

the time

$\square$

the time

or never stiffness that lasts for more than 3 hours?

49. How often does your work entail repetitive pushing $\quad \square$ and pulling movements or lifting while bending or twisting, leading to back pain?

$\square$

$\square$

$\square$

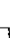

$\square$ 
Appendix F: Baseline Data Collection Sheet

THE

UNIVERSITY

OF RHODE ISLAND

COLLEGE OF

HUMAN SCIENCE

AND SERVICES

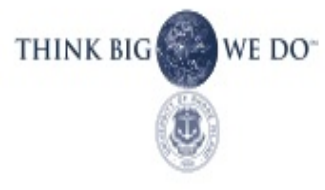

\section{URI RESTORE ME Study Data Sheet}

\section{BaselineTesting Day 1}

Participant ID \#:

Date:

\begin{tabular}{|l|l|l|}
\hline Measurements & Baseline Testing Day 1 & Initial \\
\hline Resting Heart Rate 1 (bpm) & & \\
\hline Resting Heart Rate 2 (bpm) & & \\
\hline Resting Blood Pressure 1 & & \\
\hline Resting Blood Pressure 2 & & \\
& & \\
\end{tabular}

\begin{tabular}{|l|l|l|}
\hline \multicolumn{2}{|l|}{ Grip Strength (kilograms) } & \multicolumn{2}{l|}{} \\
\hline \multicolumn{2}{|l|}{ Dynamometer Setting: } & Best Grip Trial: \\
\hline Grip R1: $\quad$ Grip R2: & Grip L1: & Grip L2: \\
\hline
\end{tabular}




\section{Baseline Testing Day 1 Participant ID\#:}

Date:

SPPB

A. Side-by-side-stand

\section{BALANCE SCORING:}

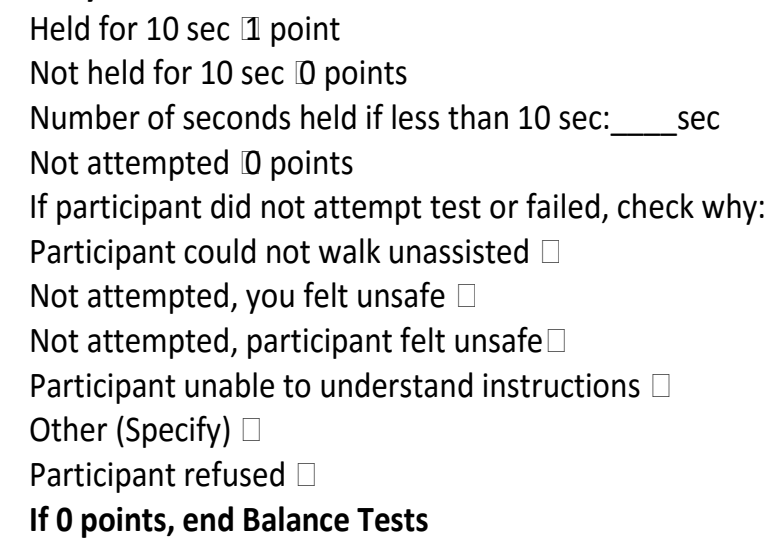

\section{B. Semi-Tandem Stand}

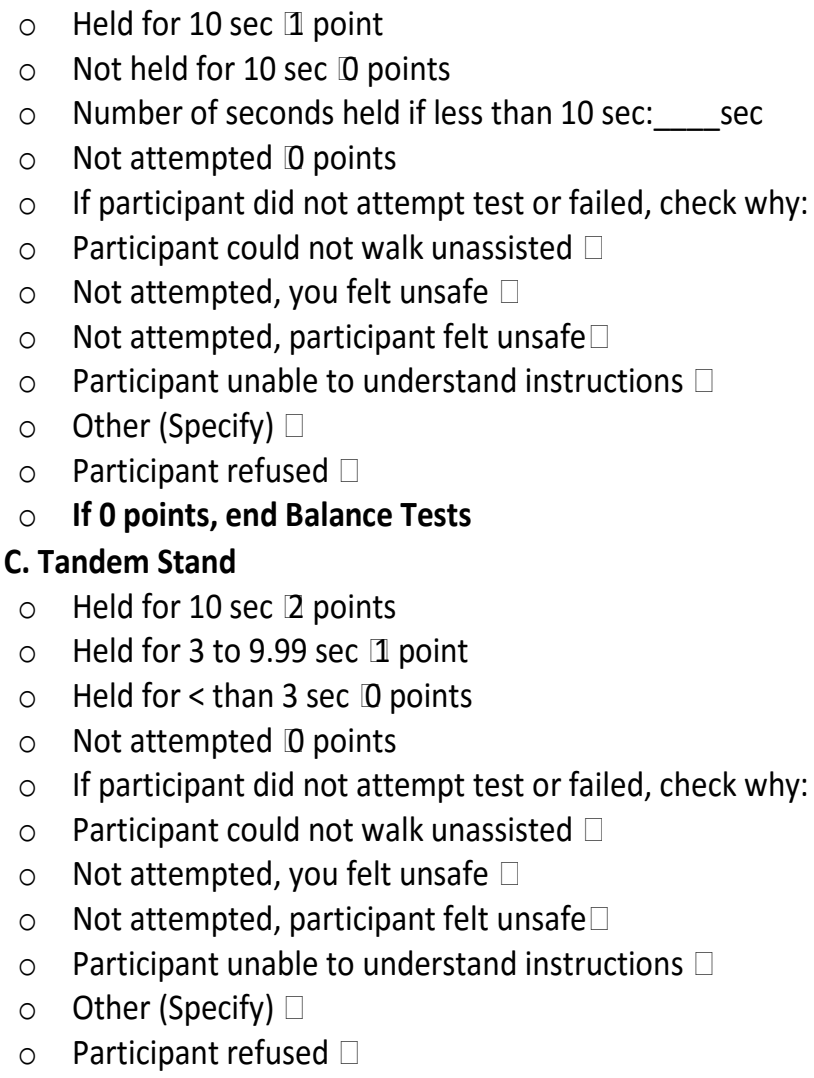

D. Total Balance Tests score (sum points)

\section{For 4-Meter Walk:}

o If time is more than 8.70 sec: 1 point 
- If time is 6.21 to 8.70 sec: 2 points

- If time is 4.82 to 6.20 sec: 3 points

0 If time is less than $4.82 \mathrm{sec}: 4$ points

\section{Single Chair Stand Test:}

\section{CHAIR SCORING:}

- Safe to stand without help YES $\square$ NO

- Participant stood without using arms YES $\mathbb{N O} \rightarrow$ If yes go to repeated stand

- Participant used arms to stand YES NO $\rightarrow$ If yes end test; score as 0 points

- Test not completed $\rightarrow$ End test; score as 0 points

- If participant did not attempt test or failed, check why:

- Tried but unable

- Participant could not walk unassisted

- Not attempted, you felt unsafe

- Not attempted, participant felt unsafe $\square$

- Participant unable to understand instructions $\square$

- Other (Specify)

- Participant refused $\square$

\section{Repeated Chair Stand Test}

- Safe to stand five times Yes $\square$ No $\rightarrow$ If five stands completed record time

- Time to complete five stands __ sec

- If participant did not attempt test or failed, circle why:

- Tried but unable $\square$

- Participant could not walk unassisted $\square$

- Not attempted, you felt unsafe

- Not attempted, participant felt unsafe

- Participant unable to understand instructions $\square$

- Other (Specify)

- Participant refused $\square$

\section{Scoring the Repeated Chair Test}

- Participant unable to complete 5 chair stands or completes stands in $>60 \mathrm{sec}$ : 0 points

- If chair stand time is $16.70 \mathrm{sec}$ or more: 1 points

- If chair stand time is 13.70 to $16.69 \mathrm{sec}: 2$ points

- If chair stand time is 11.20 to $13.69 \mathrm{sec}: 3$ points

- If chair stand time is 11.19 sec or less: $\sqsubset 4$ points

\section{Scoring for Complete Short Physical Performance Battery}

Total Balance Test score points

Gait Speed Test score points

Chair Stand Test score points

Total Score points (sum of points above) 


\begin{tabular}{|c|c|c|c|}
\hline Test & Result & Date Completed & Initial \\
\hline \multicolumn{4}{|l|}{$\begin{array}{c}400 \mathrm{~m} \text { walk } \\
\text { (sec) }\end{array}$} \\
\hline SPPB & points scored & & \\
\hline \multicolumn{4}{|l|}{$\begin{array}{c}\text { Single Leg } \\
\text { Stand, } 10 \mathrm{sec}\end{array}$} \\
\hline \multicolumn{4}{|l|}{$\begin{array}{l}\text { Sit and Reach } \\
\qquad(+/-\mathrm{cm})\end{array}$} \\
\hline \multicolumn{4}{|l|}{$\begin{array}{c}\text { Timed Up } \\
\text { and Go } 1 \\
\text { (sec) }\end{array}$} \\
\hline $\begin{array}{c}\text { Timed Up } \\
\text { and Go } 2 \\
\text { (sec) }\end{array}$ & & & \\
\hline
\end{tabular}




\section{Baseline Testing}

Participant ID \#:

\section{Date:}

\begin{tabular}{|c|l|l|}
\hline Measurements & Date & Initial \\
\hline Resting Heart Rate 1 (bpm) & & \\
\hline Resting Heart Rate 2 (bpm) & & \\
\hline Resting Blood Pressure 1 & & \\
\hline Resting Blood Pressure 2 & & \\
\hline Blood Draw 1 & & \\
\hline
\end{tabular}

\begin{tabular}{|c|c|c|c|c|}
\hline Anthropometrics & $\begin{array}{c}\text { Measurement } \\
1\end{array}$ & $\begin{array}{c}\text { Measurement } \\
2\end{array}$ & Average & Initial \\
\hline \multicolumn{5}{|l|}{ Height (inches) } \\
\hline \multicolumn{5}{|l|}{ Weight (Ibs) } \\
\hline \multicolumn{5}{|l|}{$\begin{array}{c}\text { Waist } \\
\text { Circumference } \\
\text { (inches) }\end{array}$} \\
\hline \multicolumn{5}{|l|}{$\begin{array}{c}\text { Hip } \\
\text { Circumference } \\
\text { (inches) }\end{array}$} \\
\hline BMI (kg/m²) & & $\begin{array}{l}\text { Waist to Hip } \\
\text { Ratio }\end{array}$ & & \\
\hline
\end{tabular}

\section{Notes:}


Baseline Testing

Participant ID\#:

Date:

\begin{tabular}{|c|c|c|c|}
\hline Measurements & \multicolumn{2}{|c|}{ Baseline Testing Day 1} & Initial \\
\hline \multicolumn{4}{|c|}{$\begin{array}{l}\text { Resting Heart Rate } 1 \\
\text { (bpm) }\end{array}$} \\
\hline \multicolumn{4}{|c|}{$\begin{array}{c}\text { Resting Heart Rate } 2 \\
\text { (bpm) }\end{array}$} \\
\hline \multicolumn{4}{|c|}{$\begin{array}{c}\text { Resting Blood Pressure } \\
1\end{array}$} \\
\hline \multicolumn{4}{|c|}{$\begin{array}{c}\text { Resting Blood Pressure } \\
2\end{array}$} \\
\hline \multicolumn{4}{|l|}{ Blood Draw 2} \\
\hline & Results collected & Date & Initial \\
\hline DEXA & & & \\
\hline
\end{tabular}

\begin{tabular}{|l|l|l|l|}
\hline \multicolumn{2}{|l|}{ In-Body: BIA } & Date: \\
\hline \multicolumn{2}{|l|}{ Voided Bladder } & \multicolumn{1}{|c|}{ Yes } & No \\
\hline Height: & Weight: & BMI: & L Leg LM: \\
\hline R Arm LM: & L Arm LM: & R Leg LM: & \\
\hline & & Total ALM: & \\
\hline
\end{tabular}




\section{Appendix G: One Repetition Max Testing Sheet}

RESTORE ME 1RM Testing Data Sheet (Baseline)

Date:

Subject ID:

Tester:
Resting BP

Resting HR

Dynamic Warm-up Completed

\begin{tabular}{|c|c|}
\hline Leg Press & \\
\hline Max Weight & Irization \\
\hline Warm-Ups: 1. & lbs $(5-10$ reps $@ 50 \%)$ \\
\hline 2 . & lbs (2-5 reps@75\%) \\
\hline 3. & lbs (1 rep@85-90\%) \\
\hline
\end{tabular}

Blood Pressure (after 2-3 mins rest)

Notes:
Seat Position

\section{CR-10}

Attempts: 1 lbs

2.

lbs

2.

3.

4.

5.

lbs

lbs

bs bs

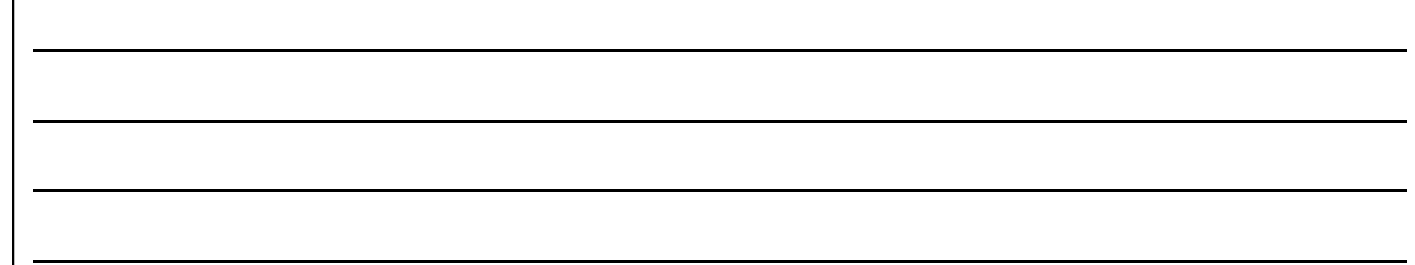

\section{Chest Press}

Max Weight Lifted During Familiarization

Seat Position

CR-10

Warm-Ups: 1. lbs (5-10 reps@50\%)

Attempts: 1. lbs

2. lbs (2-5 reps@75\%)

3. lbs (1 rep@85-90\%)

Blood Pressure (after 2-3 mins rest)

Notes:

2.

3.

4.

5.

lbs 


\section{Appendix H: Borg CR-10 Scale and Instructions}

\section{Borg CR-10 Scale of Perceived Exertion}

\begin{tabular}{|lll|}
\hline \multicolumn{1}{c|}{ Borg CR-10 Scale of Perceived Exertion } \\
0 & Nothing at all & \\
0.3 & & \\
0.5 & Extremely weak & Just noticeable \\
0.7 & & \\
1 & Very weak & \\
1.5 & \\
2 & Weak \\
2.5 & \\
3 & Moderate & \\
4 & & \\
5 & Strong \\
6 & & \\
7 & Very strong & \\
8 & & \\
9 & & \\
11 & & \\
& & \\
\hline
\end{tabular}




\section{Instructions:}

While exercising we want you to rate your perception of exertion, i.e., how heavy and strenuous the exercise feels to you. The perception of exertion depends mainly on the strain and fatigue in you muscles and on your feeling of breathlessness or aches in the chest.

Look at this rating scale; we want you to use this scale from 1 to 10 , where 1 means "no exertion at all" and 10 means "maximal or very, very strong exertion."

For most people this is the most strenuous resistance exercise they have ever experienced.

Try to appraise your feeling of exertion as honestly as possible, without thinking about what the actual physical load is. Don't underestimate it, but don't overestimate it either. It's your own feeling of effort and exertion that's important, not how it compares to other people's. What other people think is not important either. In addition, this scale has no anchor. That is, if after giving a "10" on a previous rating, you decide that the current exercise is more strenuous, you may give a higher number (i.e. "11"0. Look at the scale and the expressions and then give a number.

Any questions? 


\section{Appendix I: Dietary Screening Tool}

\section{Dietary Screening Tool}

DIRECTIONS: Please check one response to each question that best describes how you eat.

How often do you usually eat fruit as a snack?

Never

Less than once a week

1 or 2 times a week

3 or more times a week

How often do you usually eat whole grain breads?

Never or less than once a week

1 or 2 times a week

3 or more times a week

How often do you usually eat whole grain cereals?

Never or less than once a week

1 or 2 times a week

3 or more times a week

How often do you usually eat candy or chocolate?

Never

Less than once a week

1 or 2 times a week

3 or more times a week

How often do you eat crackers, pretzels, chips, or popcorn?

Never

Less than once a week

1 or 2 times a week

3 or more times a week

How often do you eat cakes or pies?

Never

Less than once a week

1 or 2 times a week

3 or more times a week 
How often do you eat cookies?

Never

Less than once a week

1 or 2 times a week

3 or more times a week

How often do you eat ice cream?

Never

Less than once a week

1 or 2 times a week

3 or more times a week

How often do you eat cold cuts, hot dogs, lunchmeats or deli meats?

Never or less than once a week

1 or 2 times a week

3 or more times a week

How often do you eat bacon or sausage?

Never or less than once a week

1 or 2 times a week

3 or more times a week

How often do you eat carrots, sweet potatoes, broccoli, or spinach? Never

Less than once a week

1 or 2 times a week

3 or more times a week

How often do you eat fruit (not including juice)? Please include fresh, canned or frozen fruit.

Never or Less than once a week

1 or 2 times a week

3 to 5 times a week

Every day or almost every day

How often do you eat hot or cold breakfast cereal?

Never

Less than once a week

1 or 2 times a week

3 to 5 times a week

Every day or almost every day 
How often do you drink some kind of juice at breakfast?

Never or Less than once a week

1 or 2 times a week

3 to 5 times a week

Every day or almost every day

How often do you eat chicken or turkey?

Never or less than once a week

1 or 2 times a week

More than 3 times a week

How often do you drink a glass of milk?

Never or Less than once a week

1 or 2 times a week

3 to 5 times a week

Every day or almost every day

More than once every day

Do you usually add butter or margarine to foods like bread, rolls, or biscuits?

Yes

No

Do you usually add fat (butter, margarine or oil) to potatoes and other vegetables?

- Yes

- No

Do you use gravy (when available) at meals?
Yes
No

Do you usually add sugar or honey to sweeten your coffee or tea? Yes

No

Do you usually drink wine, beer or other alcoholic beverages?

$$
\text { Yes }
$$

No 
How often do you eat fish or seafood that IS NOT fried?

Never

Less than once a week

Once a week

More than once a week

How many servings of milk, cheese, or yogurt do you usually have each DAY?

None

One

__ Two or more

How many different vegetable servings do you usually have at your main meal of the day?

None

One

Two

Three or more

Which of the following best describes your nutritional supplement use.

I don't use supplements

I use supplements other than vitamins and mineral

I use a multivitamin/mineral preparation (e.g. Centrum) 


\section{Appendix J: One-Week Training Program for Daily Undulating Periodization Group}

\begin{tabular}{|c|c|c|c|c|c|}
\hline \multirow{3}{*}{ Day 1} & DATE & & & & \\
\hline & Week 3 & 12 reps & $90 \mathrm{~s}$. rest & \multirow{8}{*}{ Notes: } & \\
\hline & set 1 & set 2 & set 3 & & \\
\hline Standing lunge & 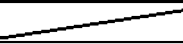 & 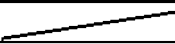 & 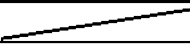 & & \\
\hline Leg press w/ calf & 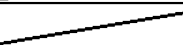 & + & 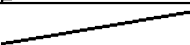 & & \\
\hline Chest press & $\longrightarrow$ & $\longrightarrow$ & $\longrightarrow$ & & \\
\hline Machine row & 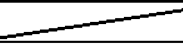 & 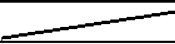 & 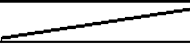 & & \\
\hline Shoulder press & - & - & - & & \multirow[b]{2}{*}{ PS: } \\
\hline Ab exercise & T & 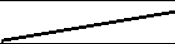 & - & & \\
\hline
\end{tabular}

\begin{tabular}{|c|c|c|c|}
\hline \multirow{3}{*}{ Day 2} & \multicolumn{3}{|l|}{ DATE } \\
\hline & Week 3 & 8-10 reps & $120 \mathrm{~s}$. rest \\
\hline & set 1 & set 2 & set 3 \\
\hline DB Squat & . & . & 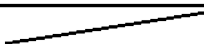 \\
\hline Swiss ball squat & . & . & 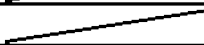 \\
\hline Bench press & $=$ & 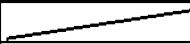 & 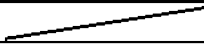 \\
\hline Upright row & 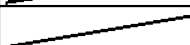 & 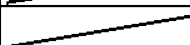 & 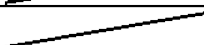 \\
\hline Lat pulldown & - & - & 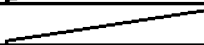 \\
\hline Back ext & & & \\
\hline
\end{tabular}

Notes:

CR-10: $\quad$ CR-10: $\quad$ CR-10

\begin{tabular}{|c|c|c|c|}
\cline { 2 - 4 } \multicolumn{1}{c|}{ Day 3 } & DATE & & \\
& Week 3 & 6-8 reps & 120 s. rest \\
\cline { 2 - 4 } & set 1 & set 2 & set 3 \\
\hline Trap bar DL & & & \\
\hline 1-legged leg & & & \\
\hline Incline DB press & & & \\
\hline Machine row & & & \\
\hline Incline push-up & & & \\
\hline Bent row & & & \\
\hline Tricep ext & & & \\
\hline Bicep curl & & & \\
\hline
\end{tabular}

CR-10: $\quad$ CR-10: $\quad$ CR-10:

